FIRMS AND LABOR IN TIMES OF VIOLENCE:

EVIDENCE FROM THE MEXICAN DRUG WAR

Hâle Utar

\title{
LATIN AMERICAN AND THE CARIBBEAN ECONOMIC ASSOCIATION
}

December 2020

The views expressed herein are those of the authors and do not necessarily reflect the views of the Latin American and the Caribbean Economic Association. Research published in this series may include views on policy, but LACEA takes no institutional policy positions.

LACEA working papers are circulated for discussion and comment purposes. Citation of such a paper should account for its provisional character. A revised version may be available directly from the author.

(C) 2020 by Hâle Utar. All rights reserved. Short sections of text, not to exceed two paragraphs, may be quoted without explicit permission provided that full credit, including (C) notice, is given to the source. 
LACEA WORKING PAPER SERIES No. 0040 December 2020

Firms and Labor in Times of Violence: Evidence from the Mexican Drug War

Hâle Utar

Grinnell College and CESifo

utarhale@grinnell.edu

\section{ABSTRACT}

I study how industrial development and employment in an emerging economy are affected by urban violence due to drug trafficking. Employing rich longitudinal plant-level data covering all of Mexico from 2005-2010 and exploiting plausibly exogenous spatiotemporal variation in homicide rates during the outbreak of drug-trade related violence in Mexico, commonly referred to as the Mexican Drug War, I show that a violent environment has a significant negative impact on manufacturing plants' output, product scope, employment, and capacity utilization. The impact is very heterogeneous among plants. Studying within and cross-plant heterogeneity points to two underlying channels through which the Drug War affects firms: violence induced reduction in local demand and violence induced drop in labor supply participation. The output sensitivity of plants to a violent conflict increases in less diversified, locally selling and sourcing plants. The employment sensitivity increases with lower wages and a higher share of unskilled female workers. The results show both channels co-exist, and by reallocating resources from smaller, local, and female-intensive plants toward bigger and more diversified ones, the rise of drug violence has significant distortive effects on domestic industrial development in Mexico.

JEL Classification: L25; L60; O12; O14; O18; R11; O54; F14.

Keywords: Drug War, Mexico, Firms, Violence, Organized Crime, Manufacturing, Labor, Technology, Productivity, Reallocation, Trade, Gender.

\section{ACKNOWLEDGEMENTS AND FINANCIAL DISCLOSURE}

I thank Luis B. Torres Ruiz and Gabriel Arturo Romero Velasco for help with the micro data; David Shirk, Octavio Rodriguez Ferreira, and Laura Calderon from Justice in Mexico and Juan Camilo Castillo for sharing their data; Rafael Dix-Carneiro, Kerem $\mathrm{Cos}_{s}$ ar, Thomas Dohmen, David Dorn, Christian Dustmann, Jonathan Eaton, Marcela Eslava, Ana Cecilia Fieler, Teresa Fort, Beata Javorcik, Ruixue Jia, Wolfgang Keller, Jann Lay, Sebastian Sotelo, John McLaren, Josef Zweimuller, and audiences at the CESIfo Global Economy, CESIfo Labor and Social Policies, CBRT Policy Evaluation Workshop, Aarhus-Kiel Workshop, TIGN-Bogota, CAED-Ann Arbor, Gottingen, Hamburg-GIGA, IZA (Bonn), CReAM at University College London, the World Bank, Johns Hopkins SAIS, the University of Virginia, SHUFE (Shanghai), CUHK (Hong Kong), and UNSW (Sydney) for helpful comments. Victor Eduardo Zapata Garcia and Elainia Gupta provided valuable research assistance. 


\section{Introduction}

Cities are the driving force for economic development. They host more than half of the human population and generate more than $80 \%$ of global GDP (World Bank). At the same time, many cities in developing countries suffer from urban violence, and drug trafficking often plays a central role. Organized crime and violence can serve as barriers to economic development, either by slowing down or preventing efficient reallocation of resources or by distorting incentive mechanisms and affecting participation decisions of economic agents, and can thus contribute to large income disparities between and within countries (Caselli, 2005; Acemoğlu and Dell, 2010). The quality and quantity of production factors are not the only determinants of regional output, but also the environment in which production takes place. For example, in the Mexican city Ciudad Juárez, 283 homicides were reported per 100,000 inhabitants in 2010. In neighboring El Paso, Texas, the number was just 0.8 homicides per 100,000 . The distance between the two cities is only a few miles, but the levels of violence are orders of magnitude apart. Aside from the direct consequences of violence on the people involved, how does a violent and conflict-afflicted environment matter for firms, workers, and the way business is conducted?

This paper studies the impacts of violent conflict on manufacturing firms, utilizing the recent period of escalation of drug-related violence in Mexico, commonly referred to as the Mexican Drug War, in a natural experimental set-up. Since 2007, there has been a drastic increase in drug-related violence in Mexico. The number of intentional homicides increased almost 200\% from 2007 to 2010 (see Figure 1), an increase attributed to unexpected and unintended consequences of a change in the government's drug enforcement policy and further fueled by a plausibly exogenous increase in cocaine prices during the period (Dell, 2015; Castillo, Mejia, and Restrepo, 2020). ${ }^{1}$ By 2010, Mexico had more than three times as many killings as war-torn Iraq and Afghanistan combined. ${ }^{2,3}$

\footnotetext{
${ }^{1}$ Angrist and Kugler (2008) emphasize the importance of demand channels in causing violence and show that plausibly exogenous increase in cocaine prices trigger violence in Colombia.

${ }^{2}$ There were 26,000 homicides in Mexico in 2010; Iraq Body Counts reports 4,167 civilian deaths from violence in 2010, and Williams (2012) reports violent deaths of 2,777 civilians and 711 soldiers in Afghanistan in the same year.

${ }^{3}$ Drug trafficking is one of the central factors driving increases in violence in Latin America. Drug trafficking regions in these countries had homicide rates twice as high as in locales with low drug trafficking (World Bank, 2011).
} 
And civilians in Juárez ran a greater risk of being killed than civilians in Baghdad, Iraq (Mora, 2009). As an emerging country, long-benefiting from an international fragmentation of production yet longsuffering from organized crime and drug trafficking, Mexico provides a unique setting to study the impact of heightened violence on manufacturing firms.

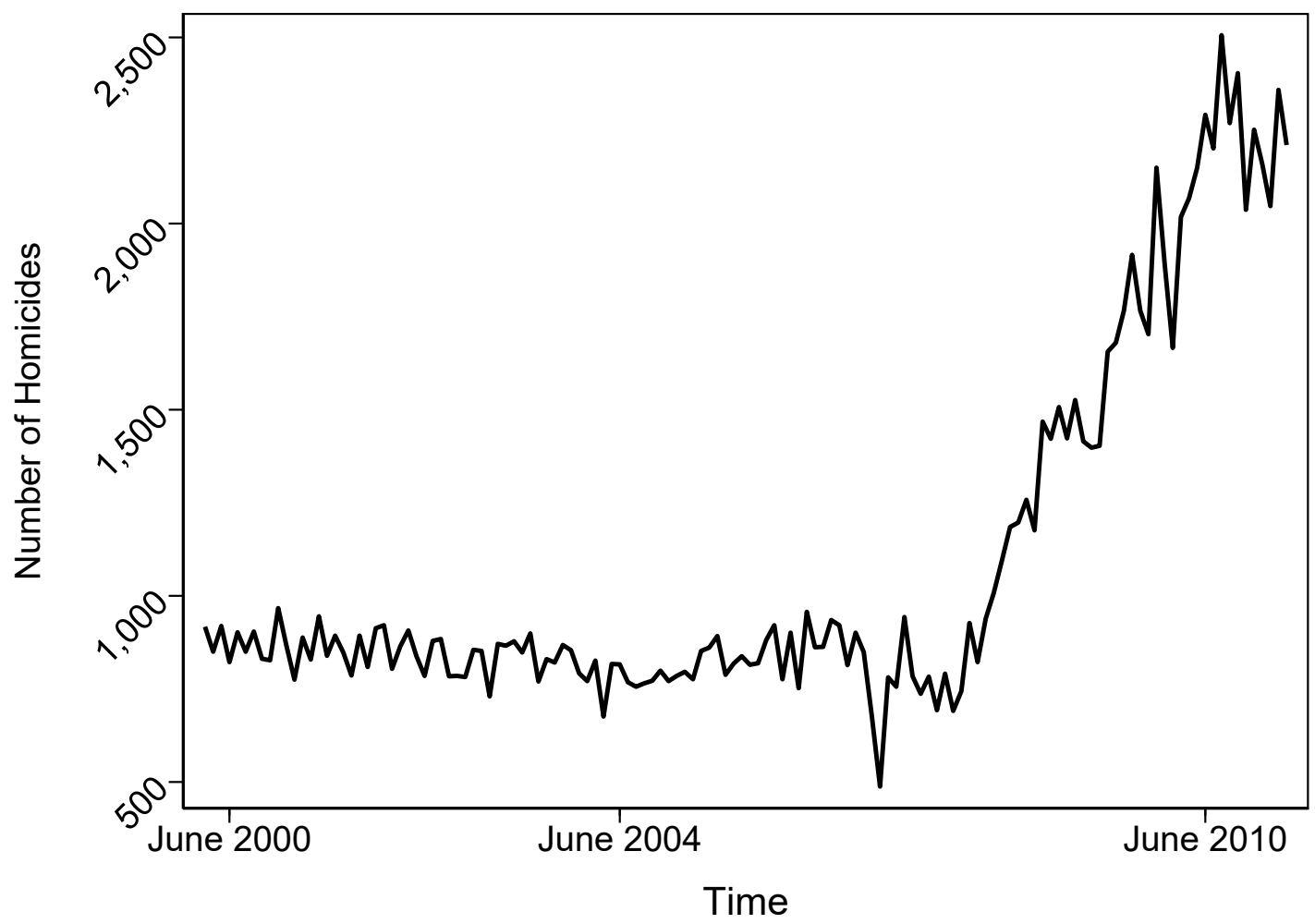

Figure 1: Surge in Violence in Mexico

This figure shows the monthly number of homicides. Source: National Institute of Statistics and Geography of Mexico, INEGI.

To derive causal effects of a violent and conflict-afflicted local environment on industrial development and employment, I employ longitudinal plant-level data covering all of Mexico for the period 2005-2010 and utilize the outbreak of violence due to the Mexican Drug War. The period of analysis is characterized by substantial variation in violence over time and among metropolitan areas across the country (see Figure 2-3).

The empirical strategy exploits within-establishment variation over time and across space (metropoli- 
tan areas) in Mexico. An important challenge in identifying causal impacts of a violent environment on industrial outcomes is that cities experiencing increased violence may have special characteristics, as the location of drug trafficking organizations (DTOs) are not random (Dell, 2015). These locations may attract particular types of firms, perhaps with technology more resilient to outbreaks of violence. Longitudinal data allow me to control for such observable and unobservable differences between firms and cities that may confound the estimates using plant fixed effects. To rule out the possible confounding effects of the Great Recession and other industry-specific shocks, the analysis controls for detailed industry-specific aggregate shocks and the findings are robust to using product by year fixed effects.

Violence, measured by the homicide rate, may also be influenced by factors other than the plausibly exogenous driver that is the Mexican Drug War, such as local income or labor market shocks, which could convolute the results. ${ }^{4,5}$ To address this concern, I develop an instrumental variable strategy utilizing the widely agreed triggers of the increased drug violence, namely the policy change by the government regarding the deployment of the military against drug cartels and the increased drug-enforcement in Colombia resulting in the decline in the cocaine supply in Colombia.

The results show that a surge of violence in a metropolitan area leads to a significant decline in plant-level output, employment, and capacity utilization. A doubling of the homicide rate in a metropolitan area causes an $8 \%$ decline in plant-level output, an impact that is neither temporary nor short term, as the violence of the drug war has dynamic implications: plants' product scopes decrease significantly, as does their chance of survival. The estimates show that the Mexican Drug

\footnotetext{
${ }^{4}$ In a Beckerian model of rational utility, changes in labor market opportunities affect the participation rate in crime, especially property crime. Raphael and Winter-Ebmer (2001) provide an evidence. In a review article, Draca and Machin (2015) conclude that relative labor market opportunities are less likely to be a significant determinant of violent crime or intentional homicide. On the other hand, Dix-Carneiro, Soares, and Ulyssea (2018) and Dell, Feigenberg, and Teshima (2018) have recently shown that trade-induced labor market conditions also affect violence. The results in this paper are robust to explicit controlling of trade exposure of local labor markets.

${ }^{5}$ Dube and Vargas (2013) examine the impact of income shocks on armed conflict in Colombia and show that increased rent opportunities due to a positive oil price shock leads to an increased likelihood of conflict in oil extraction areas, and an increase in local income due to an increase in coffee prices leads to a decline in conflict in areas where coffee production is concentrated. Such income shocks may lead to correlated plant-level outcomes and conflict intensity, and may bias the results downward or upward, depending on the source of income shocks. The empirical strategy in this paper focuses on the plausibly exogenous increase in violence due to the Mexican Drug War and controls for the size of crop production, precious metal extraction, and size of oil production at the local labor market level.
} 
War accounts for about a quarter of all plant exits over the sample period.

Interestingly, my results show that blue-collar workers are more vulnerable to increased violence than more skilled, non-production employees, as a violent environment creates a negative labor supply shock. I find that the average wages of blue-collar workers increase as result, while average wages of white-collar workers decrease, and non-production workers are used more intensively. The reduction in blue-collar employment is also concentrated on workers on payroll who are costlier to fire than contractual production workers, providing additional evidence on the labor supply channel of the Drug War. This labor market channel is particularly strong in plants with lower-wage, labor-intensive but particularly female-intensive workforces, suggesting that unskilled women living in poorer neighborhoods drop out of the labor force as the risk of exposure to violence outweighs the benefit of working.

The Mexican Drug War not only affects firms through the local labor market but also favors international trade over domestic by causing a decline in domestic transactions. I find that exportand import-intensive plants are resistant to violence-induced output decline, leading to market share reallocation from establishments focused on the local market toward export- and import-intensive establishments.

The literature that relates conflict and crime to economic outcomes largely focuses on aggregate outcomes such as regional income or stock market returns (Abadie and Gardeazabal, 2003; Guidolin and La Ferrara, 2007; Pinotti, 2015). ${ }^{6}$ Understanding how an economy reacts to violence and organized crime, and how permanent the effect will be, requires identifying channels through which organized crime and violence impact an economy. Micro-level empirical studies can zoom in on the way firms' and workers' behaviors interact with violence and potentially shed light on these channels. Among them, Ksoll, Macchiavello, and Morjaria (2016) use the increased ethnic violence following

\footnotetext{
${ }^{6}$ Abadie and Gardeazabal (2003) show that economic outcomes and stock market returns in the Basque Country were negatively affected by the outbreak of terrorist events. Similarly, Pinotti (2015), using synthetic control methods, finds lower GDP per capita in southern Italian regions exposed to organized crime. On the other hand, Guidolin and La Ferrara (2007) emphasize that violence is not necessarily perceived as negative by investors by showing that Angolan diamond firm returns were actually hurt by the end of civil war.
} 
the disputed 2007 presidential election in Kenya and study the effect on about 100 flower firms there. They quantify a significant negative effect on the export volumes, and the analysis points to worker absence as a main channel through which violence affects firms. Rozo (2018) uses micro data from Colombia and shows that the reduction in violence following President Uribe's election led to market expansion, and Klapper, Richmond, and Tran (2013) focus on civil unrest in Cote d'Ivoire following the coup d'etat in 1999 and find that the conflict led to a drop in firm productivity. Amodio and Di Maio (2018) study Palestinian firms during the Second Intifada and show that firms were affected by the conflict indirectly via border closure and their use of imported materials decreased as a result. This literature tells us that firms' operations are likely to be significantly affected by a violent environment. In this paper, moving the focus to an emerging country with relatively developed institutions and extensive data allow me to dig for a thorough and general insight into how violence affects the evolution of industries and regions, and I show that a violent environment has very heterogeneous effects on firms, and therefore it significantly distorts the resource reallocation between firms. To my knowledge, this is the first paper revealing strongly heterogeneous effects of violence across firms. Further unpacking these heterogeneous effects, I identify two important channels through which the violent environment affects firms. Firms are affected via violence-induced 1) local labor supply shocks and 2) reduction in local demand. Since the impact is disproportionately borne on smaller, locally selling, and locally sourcing manufacturing establishments, it affects the long-run development of domestic industrial capability in affected areas.

Laws and institutions of an economy shape the environment and the incentive structure that may facilitate or impede productive activity in a society. A growing literature investigates the economic consequences of weak local state institutions, lawlessness, and more recently the role of organized crime (Acemoğlu, De Feo, and De Luca, 2020; Alesina, Piccolo, Pinotti, 2018). Throughout the world, organized crime is centered on illegal drug trade and goes hand in hand with violence. I contribute to this literature by showing how a violent environment due to organized crime affects manufacturing activities, and how it can distort incentives differently for male vs. female workers and for blue-collar vs. white-collar workers, thus affecting (in)equality. 
My results on the asymmetric impact of violence on domestic versus international trade may imply a limited role of international trade in acting as a deterrent to violence and also speak into a recent nascent literature studying the linkages between globalization and civil war (McLaren, 2008; Martin, Thoenig and Mayer, 2008).

This paper also contributes to the recent literature focusing on different aspects of the Mexican Drug War. By focusing on the firm-level impact of the violence due to the Mexican Drug War, this study complements Dell (2015), who examines the impact of the change in the Mexican government's drug enforcement policy on violence and drug trafficking. She establishes a causal relationship between drug crackdowns and increased violence and finds that drug crackdowns were not effective in decreasing the drug trafficking activities. Although Dell (2015) does not focus on the economic impact of the Drug War, in her brief analysis using the labor force survey and confidential data on drug trafficking routes, she shows that female labor force participation, not male, was negatively affected by the Drug War. ${ }^{7}$ My results at the plant level corroborate and further these findings. Studies also show a negative association of the Mexican Drug War with regional inequality (Enamorado et al., 2016), housing prices (Ajzenman et al. 2015), and the percentage of working people (Robles et al., 2013). ${ }^{8}$ I contribute to this literature by showing causally how the Mexican Drug War affects firms, thus establishing the micro-foundations of regional aggregate affects. The Mexican Drug War leads to reallocation from more toward less manual labor intensive plants, from less toward more unionized plants, and from plants selling locally toward more geographically diversified firms. My estimates suggest that the Mexican Drug War accounted for the majority of the aggregate employment decline in manufacturing between 2007 and 2010 .

The remainder of the paper is as follows. The next section lays out the framework of the empirical analyses with background information on the history of organized crime in Mexico and the Drug War, describes the data, and presents a number of facts on Drug War locations and firms located in these areas. The empirical strategy is explained in Section 3. I present and discuss my results on the

\footnotetext{
${ }^{7}$ A similar conclusion is also drawn in Velásquez (2020) in her work with the Mexican Family Life Survey.

${ }^{8}$ Ashby and Ramos (2013) find no association between manufacturing foreign direct investment (FDI) and the Mexican Drug War.
} 
impact of the violence shock on firms in Section 4; this section documents a negative effect of the Drug War on firms' output, capacity utilization, employment, and product scope as well as studies violence-induced compositional changes within firms. Section 5 delves into channels through which drug violence affects firms and documents a strong heterogeneous response at both the intensive and extensive margin. A number of robustness analyses are discussed in Section 6 , followed by concluding remarks in Section 7. Supplemental analyses and a detailed description of the data sets are relegated to the Appendix.

\section{Violent Conflict and Firms: Sources of Variation and Measure-}

\section{ment}

\subsection{Organized Crime in Mexico-A Brief History}

Organized crime in Mexico is centered on the transit of illegal drugs into the United States (US). Due to its 1,969-mile-long border with the US, Mexico has been an ideal location for drug trafficking. The US is the largest cocaine market in the world, with an approximate value of 38 billion USD in 2008 (World Drug Report, 2010). ${ }^{9}$ Starting in the 1970s, the popularity of cocaine grew in the US, and criminal organizations began to gain more power and influence on a national level in Mexico. Two major trafficking routes to the US were used in the 1970s: the Caribbean and Mexico. The US gained control over the Caribbean route in the 1980s, increasing the power of Mexican DTOs. Mexico has been the major cocaine transit route to the US ever since. ${ }^{10}$

Mexico is not a source country for cocaine. Coca cultivation largely happens in the Andean region, and particularly Colombian cocaine, trafficked through Mexico, dominates the US cocaine market. ${ }^{11}$ Cocaine (including crack) has long constituted the largest market share among all illicit

\footnotetext{
${ }^{9}$ In 2008, an estimated 500 metric tons of pure cocaine was in the market, with 480 metric tons consumed that year. The US consumed 165 metric tons of pure cocaine that year, and all together, the North American market consumed 196 metric tons. The second largest market is the Western European market (EU and EFTA), which, all together consumed 124 metric tons (World Drug Report, 2010).

${ }^{10}$ According to the US State Department's 2013 International Narcotics Control Strategy Report (INCSR), more than $90 \%$ of the cocaine seized in the US has transited the Central America/Mexico corridor.

${ }^{11}$ In 2000, 73\% of the net coca cultivation was performed in Colombia (National Drug Control Agency, 2015). Other
} 
drugs in the US and has been the primary focus of virtually all DTOs in Mexico. ${ }^{12}$ The major competitive assets of Mexican organized crime groups are, in essence, rapid and low-friction transit routes in Mexico, complemented by links to cocaine suppliers in Central America and to consumers in the US. In addition to controlling most of the cocaine market in the US, Mexican DTOs also control the majority of marijuana, heroin, and methamphetamine supply. Their activities in the US are almost exclusively related to drug trafficking and they have little involvement in other types of illicit business (Finckenauer, Fuentes, and Ward, 2001).

Throughout the 20th century, a single political party, the Institutional Revolutionary Party (Partido Revolucionario Institucional, PRI), dominated the political atmosphere in Mexico. It has been believed that local and national authorities controlled by PRI had been in implicit agreement with the DTOs in exchange for peace and order in their regions (Chabat, 2010). This situation changed radically with the election of Calderón in 2006. In the next section I expand on this change and provide information on the shift of government policy and the subsequent surge of violence.

\subsection{Change in the Drug Enforcement Policy and Subsequent Surge of Violence-}

\section{Identifying Variation}

Until the mid-2000s, anti-drug operations in Mexico mainly focused on destroying marijuana and opium crops in mountainous regions. After the election of president Calderón in December 2006, the Mexican government, with the purpose of decreasing organized crime in the country, changed the focus of the battle against the powerful drug cartels, going from ineffective crop eradication programs to actively seeking to capture cartel leadership through an approach known as the 'kingpin strategy'. The kingpin strategy was developed by the US Drug Enforcement Administration (DEA) in 1992 to target and to eliminate, by death or capture, commanders, controllers, and key leaders of major

source countries are Bolivia and Peru.

${ }^{12}$ Cocaine itself constituted $40 \%$ of the total illicit drug market share. Other major drugs are heroin, marijuana, and methamphetamine (Kilmer et al., 2014). 
DTOs. ${ }^{13,14}$ The Calderón administration deployed military forces on a large scale and was successful in removing key leaders from major criminal organizations through arrests or by death in arrest efforts. $^{15}$

Paradoxically, despite the success of the new strategy in weakening the major cartels, it also had the unfortunate and unanticipated consequence of increased violence. Killing and capturing DTO leaders triggered fights for powerful and profitable leadership positions within the same organizations among different factions. As the organized crime groups fragmented and the balance of power changed among the cartels, fighting ensued for control over the drug routes of now weaker competitors. ${ }^{16}$ Table A-4 in the Appendix shows the fragmentation of major DTOs over the sample period. In just a few years, DTOs increased substantially in number, as factions of some of the DTOs formed new criminal organizations.

An additional factor that potentially fueled the flare of violence after 2008 is the decline in the cocaine supply in the market. Castillo, Mejía, and Restrepo (2020) show that intensified government seizures in Colombia, Mexico's major cocaine supplier, played an important role in the decline of cocaine supply. This led to increased cocaine prices in the US and increased drug-related violence, especially in areas around the strategic drug trafficking routes to the US market. ${ }^{17}$

Thus, after decades of stable rates of violent crime in Mexico, nation-wide homicide rates almost tripled from 2007 to 2010 (Figure 1). However, not every part of Mexico was affected by the sudden surge of violence.

My spatial unit of analysis is a metropolitan area, which consists of an employment core and the surrounding areas that have strong commuting ties to the core. ${ }^{18}$ This allows me to focus on

\footnotetext{
${ }^{13}$ See also Cockburn (2015).

${ }^{14}$ Despite the fact that DTOs are not cartels in the sense that they do not control prices by colluding, the term "drug cartel" is used colloquially to refer to DTOs. Drug cartels and DTOs are used interchangeably in this paper.

${ }^{15}$ The average annual number of troops assigned for battling drug trafficking increased $133 \%$ to 45,000 during the Calderón administration compared to the preceding Fox administration (Grayson, 2013).

${ }^{16}$ Lindo and Padilla-Romo (2018) show that the kingpin strategy led to an increase in the homicide rate by about $60 \%$.

${ }^{17}$ Cocaine production in Colombia decreased $43 \%$ from a potential 510 pure metric tons in 2006 to 290 pure metric tons in 2009, according to a US Justice Department report published in 2011 (National Drug Assessment Report).

${ }^{18}$ The INEGI constructed 59 such local labor markets in collaboration with the National Population Council (CONAPA)
} 
well-defined local labor markets rather than administrative units. Focusing on metropolitan areas also prevents the differences in urban and rural areas from confounding the results. Figure 2 and 3 show the homicide rates in selected local labor markets (metropolitan areas). The spatial variation in homicide rates is mainly due to the presence of the DTOs and the selective federal army operations that triggered the war. This outbreak of violent conflict, plausibly exogenous to local market conditions, allows me to study the causal relationships between an increase in violence in the local environment and detailed establishment-level outcomes.

and the Ministry of Social Development (SEDESOL). 

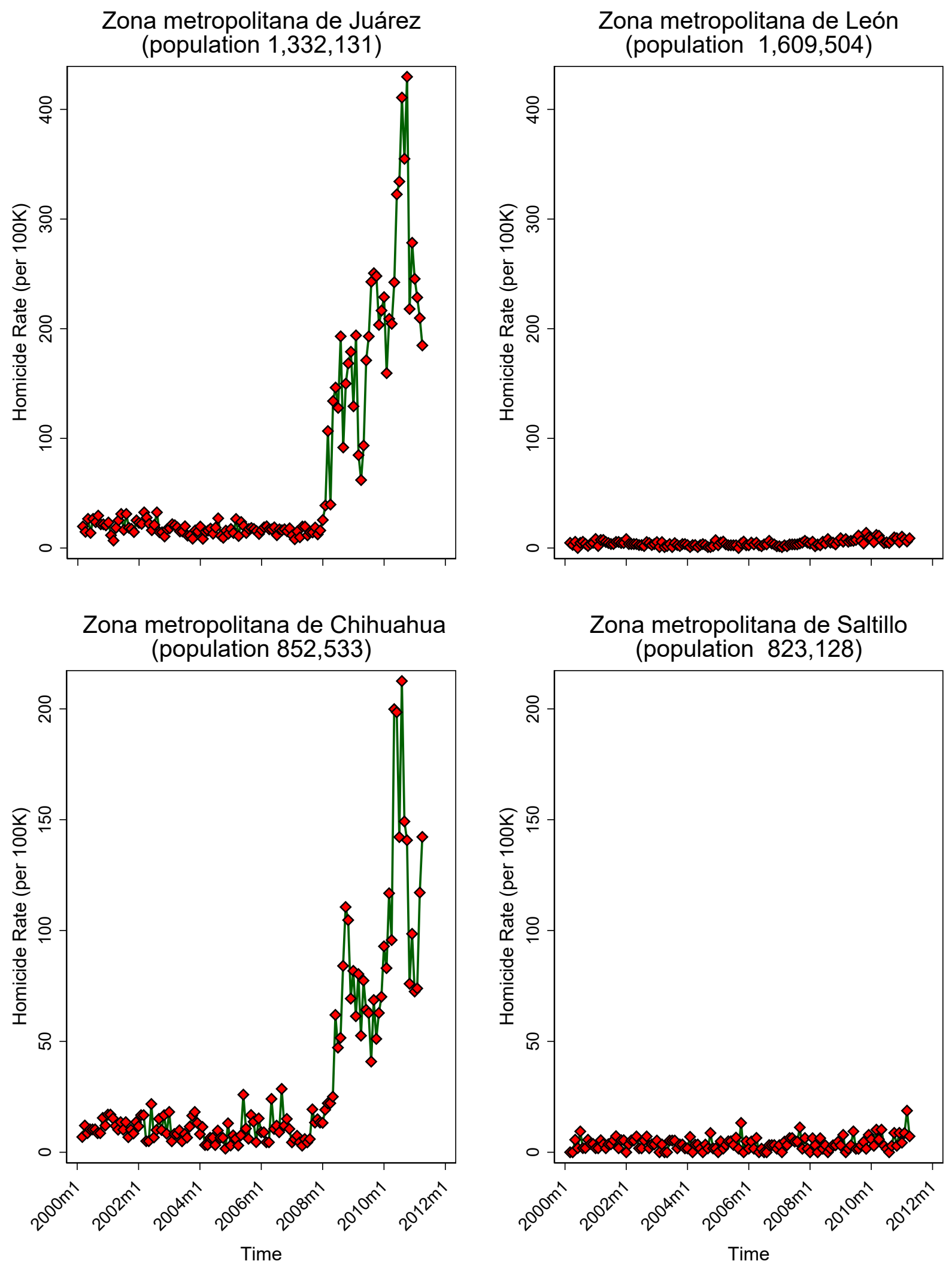

Figure 2: Homicide Rates across Selected Metropolitan Areas I

The number of homicide occurrences and population information are from the National Institute of Statistic and Geography (INEGI). Populations in the figure titles are year 2010 numbers. Homicide rates are calculated using annual population figures and are annualized monthly rates of homicides. X-axis scale and labels of the top graphs follow the $\mathrm{x}$-axis labels of the bottom graphs. 

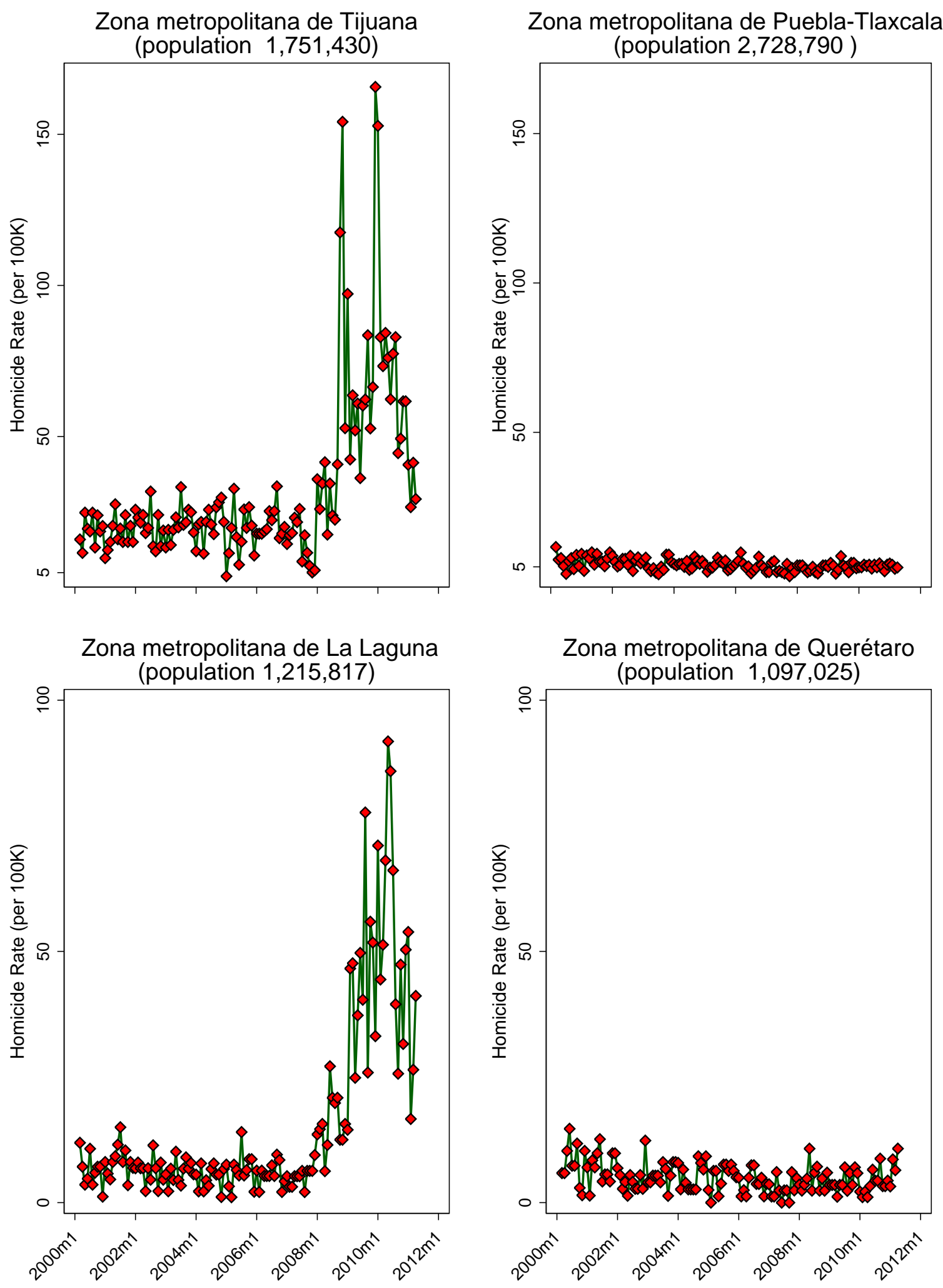

Figure 3: Homicide Rates across Selected Metropolitan Areas II

The number of homicide occurrences and population information are from the National Institute of Statistic and Geography (INEGI). Populations in the figure titles are year 2010 numbers. Homicide rates are calculated using annual population figures and are annualized monthly rates of homicides. X-axis scale and labels of the top graphs follow the $\mathrm{x}$-axis labels of the bottom graphs. 


\subsection{Drug Violence As a Local Disamenity Shock}

Much of the urban violence in Mexico has been due to fights between and within drug cartels, and many of the victims were drug cartel associates. However, urban violence also led to widespread, random violence, especially in poorer neighborhoods of affected metropolitan areas. ${ }^{19}$ A possible factor in this may be drug cartels' use of violence to terrorize the public in an attempt to force the government to back down. Additionally, drug cartels may have relied more on criminal activities like kidnappings, extortions and thefts that directly affect the civil population in order to fund their fight with rival cartels and the military.

From news reports, we can identify at least two different ways that workers' life risk may be directly affected by the Drug War. One way is through direct assaults or by being directly involved with drug businesses. The annual profit estimates of the drug cartels in the US ranges from 18 to 39 billion USD (Mexico Drug War Fast Facts_CNN Library). With the large amount of money involved, poor workers' involvement in logistics, transportation, and other drug-related businesses may not be that surprising. A second way workers' survival may be affected is by being an indirect target by either DTOs or military/police forces. For example, news reports show that workers living in poor neighborhoods may be victims of either drug gangs or government forces by being in the wrong place at the wrong time (see, e.g., Cardona, 2010). ${ }^{20}$

Figure 4 shows the evolution of intentional homicides victims and the probability of being killed across a selected set of occupations. Production workers are especially susceptible to violence; the number of homicide victims who are production workers increased 160\% between 2007 and 2010 . Since there will be more unskilled production workers than, say, professionals and technicians or

\footnotetext{
${ }^{19}$ Let's return to Juárez for an example of DTOs' use of violence. In October 2010, a group of gunmen stormed into a party in search of a specific person. The person they were looking for was not among the party, but that did not prevent them from killing 13 people aged 13 to 32, including 6 women and girls, and wounding others, which included a 9-year-old boy (Williams, 2012). The following month, in the same city, another group of armed men attacked three buses belonging to an auto parts manufacturer as the buses took third-shift workers home in the early morning, killing and wounding many. The gang members were apparently looking for one worker, whom they took away from the scene (La Botz, 2011). In August of 2010 in San Fernando, the Mexican army found the bodies of 72 South American migrants, men and women, killed and buried in a mass grave. It later appeared that they were killed when resisting recruitment by the Zeta cartel.

${ }^{20}$ Melnikov, Schmidt-Padilla and Sviatschi (2019) find that gangs increases costs of mobility and restricts labor choices for people who live in neighborhoods controlled by gangs in El Salvador.
} 

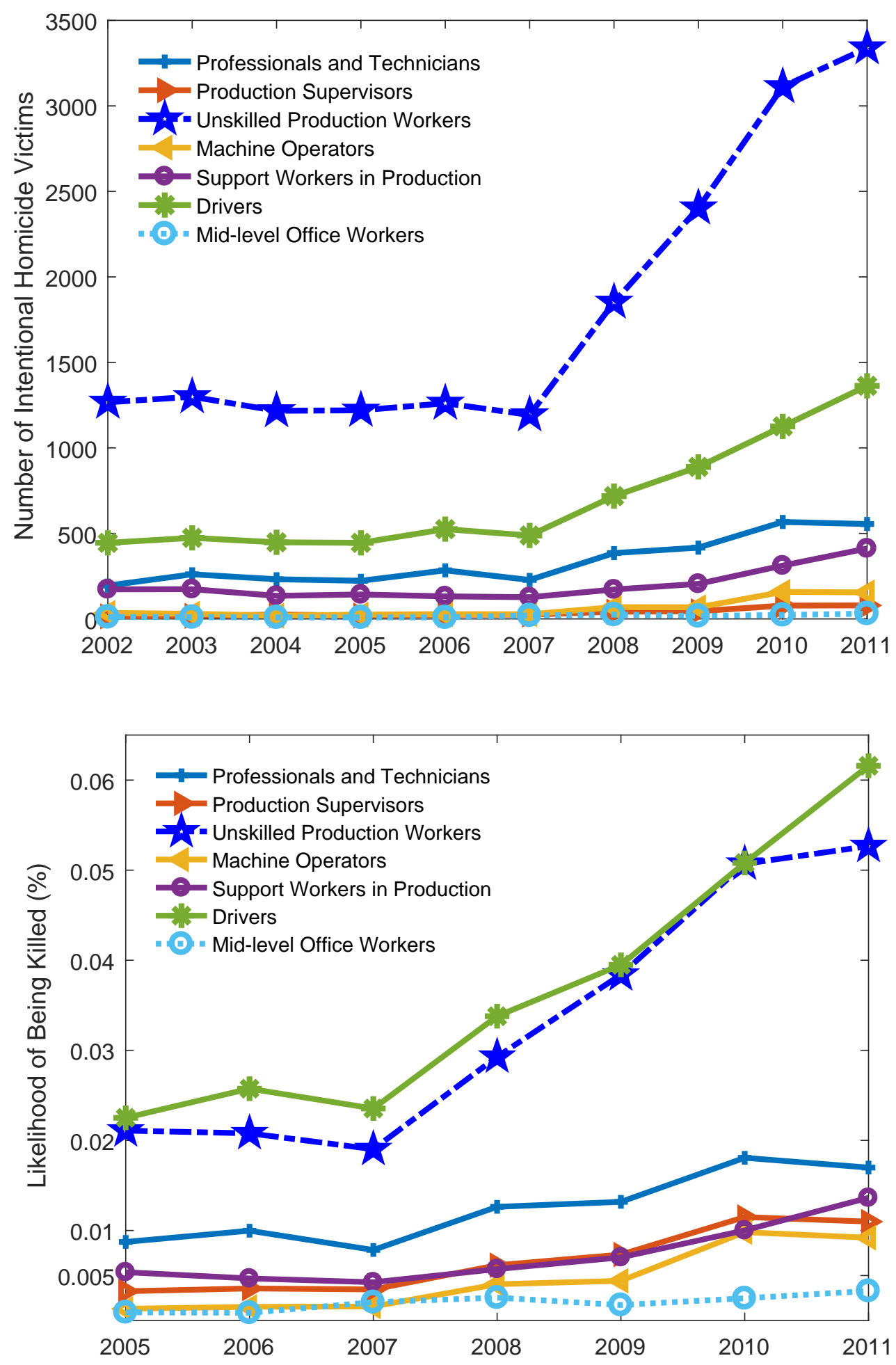

Figure 4: Occupations and Risk to Life

This figure shows the annual number of nationwide homicides depending on victims' occupations (top) and the number of homicides over the total number of people employed in that occupation (bottom). A selected set of occupations is shown here. Source: National Institute of Statistic and Geography (INEGI), Estadísticas de mortalidad, and Encuesta Nacional de Ocupación y Empleo. 
machine operators, a difference in the level of homicide between these groups is expected. But the rate of increase in the killings of production workers is striking. The bottom graph of the figure shows the likelihood of being a homicide victim, taking the total number of workers in these occupations into account. It is clear that risk to life increases substantially for production workers to almost the level of drivers, who are more likely to be direct targets of the drug gangs, as they may also be involved in drug trafficking. ${ }^{21}$ The figure makes it clear that unskilled production workers are far more likely to be victimized during the Drug War compared to other typical occupations within manufacturing.

While Figure 4 shows the direct effect of drug violence on workers' death, being a homicide victim is not the only way that workers are affected. The likelihood of witnessing violence and unsafe commuting are likely to be important factors affecting the broader population of workers' decision to participate in the labor market. Blue collar workers may be particularly prone to commuting risks as they are likely to reside in relatively unsafe locations as also suggested by Figure $4 .^{22}$ And women's labor market participation may be especially sensitive to increased commuting risks as they tend to have more elastic labor supply participation. Additionally, intense criminal activities in a neighborhood may also affect children's safety in schools. Jarillo, Magaloni, Franco and Robles (2016) show the significant role of the drug war in increasing the student absenteeism, especially in poorer neighborhoods in Mexico. If schools become unsafe for children, this may have an indirect impact on parents' labor market participation. Figure A-6 in the Appendix shows the evolution of the manufacturing employment across the metropolitan areas shown in Figures 2-3. The aggregate manufacturing employment either declined or stayed constant between 2005 and 2010 in all of the highly exposed metropolitan areas, whereas all four of the similarly sized non-exposed metropolitan areas experienced a net increase in manufacturing employment over the same period. In the next section, I introduce the longitudinal plant-level data sets employed in the analysis.

\footnotetext{
${ }^{21}$ The occupation classification is economy-wide, so while unskilled production workers or machine operators are largely manufacturing occupations, professionals and technicians, for example, include professionals such as journalists, lawyers, or bankers who are likely to be employed in non-manufacturing sectors and can also be direct targets of DTO violence.

${ }^{22}$ Commuting risks also increases with the length of commuting, and in a model linking worker skills with physical space of cities, Brueckner, Thisse, and Zenou (2002) show lower skill workers tend to locate further from their employers.
} 


\subsection{Data and Preliminary Evidence}

The main data set used in this study is Encuesta Industrial Mensual Ampliada (EIMA) 2005-2010, a monthly survey of plants collected by the INEGI that covers $90 \%$ of the nationwide manufacturing value added. Its main purpose is to monitor short-term trends in employment and output; therefore the information collected focuses especially on employment and output changes of manufacturing plants. An important feature of this dataset is that it contains quantities and values separately for each product variety that a plant produces, which makes it possible to construct plant-level unit prices. EIMA 2005-2010 covers plants for each of the 32 states, and the level of coverage in 28 of the 32 states is higher than $70 \%$. All plants in Mexico that have more than 300 employees are included in the survey. Smaller plants are included according to the following criteria: for each detailed manufacturing activity, clase, plants are ranked according to their production capacity as of Economic Census 2004, and they are surveyed from the top until at least $80 \%$ of all production within each detailed product category is covered. ${ }^{23}$ Because of this survey design, there is a bias in favor of bigger plants. I show below that a violent environment especially affects the operation of smaller plants; therefore, the estimates presented here can be seen as a lower bound of the real impact.

For the purpose of this study, I focus on plants located in metropolitan areas. Table C-1 in the appendix presents summary statistics for this sample. The average plant employs 239 workers and produces 3 product varieties. ${ }^{24}$ On average for every two blue-collar workers, firms employ one non-production (white-collar) employee. Figure A-1 in the appendix shows the distribution of plants in year 2005 across the three-digit industries. The sample covers a wide variety of plants, and the distribution of plants across industries reflect the overall pattern of Mexican manufacturing with a relatively high share of food manufacturing as well as plastics, chemicals, non-metallic mineral products, and automotive (transportation equipment) sectors.

I match EIMA with the annual survey of manufacturing plants, Encuesta Industrial Anual (EIA),

\footnotetext{
${ }^{23}$ Activities within the manufacturing sector are classified into 230 economic activities, or clases. Each clase is denoted by a unique six-digit number. For example, 311320 refers to "Preparation of chocolate and chocolate products from cacao," and 311330 refers to "Preparation of chocolate products from chocolate."

${ }^{24}$ Throughout the paper, a product variety refers to 9-digit SCIAN products, e.g. "chocolate covered raisins produced from purchased chocolate", (SCIAN 311330025).
} 
which provides detailed balance sheet information of the same manufacturing plants before the Drug War period of 2003-2007. As both EIA and EIMA are based on the same survey design and are run in parallel, 90\% of the plants surveyed in EIMA can be matched with EIA. ${ }^{25}$ Maquiladoras, which are export-processing plants mainly owned by foreign companies and supplying into the US market, are not part of either EIMA or EIA. ${ }^{26}$ Exit is observed in the data at a monthly frequency as the exiting plants drop from the sample; however, the survey design is fixed so that possible entries of new plants are not observed.

For detailed technological and organizational pre-shock characteristics, I also utilize Encuesta Nacional de Empleo, Salarios, Tecnología y Capacitación en el Sector Manufacturero (ENESTyC) 2005, which is a representative establishment-level survey on technological and organizational capabilities of plants. Detailed technological and employee characteristics obtained from this nationally representative survey is mapped at the four-digit industry level to EIMA, the main data set used in the analysis. ${ }^{27}$ Plants in the ENESTyC report geographic distribution of their annual sales as well as their use of imports from across the world. I use this information to construct entropy measures of sales and input diversification and study heterogeneity of the output elasticity of violence with respect to firm diversification.

I begin by documenting the broad patterns of the data to obtain an insight into the relationship between metropolitan areas that are susceptible to heightened violence and firm characteristics. As a first step I compute the mean values of homicide rates and homicide numbers before and after the Drug War for each metropolitan area across the 2005-2006 and 2008-2010 periods. I classify metropolitan areas as High-Intensity Drug War zones if the differences between the pre- and post-period rate and number of homicides are larger than the mean differences. Doing that identifies six metropolitan areas as high-intensity drug war zones: Acapulco, Chihuahua, Juárez, La Laguna, Monterrey, and Tijuana.

\footnotetext{
${ }^{25}$ Unfortunately EIA was replaced with a new survey based on a new sampling in 2008, therefore I rely on EIA for initial, pre-Drug War, characteristics of the plants.

${ }^{26}$ Due to the different legal framework that maquiladoras were subject to, INEGI has carried out a separate survey for them (see Utar and Ruiz, 2013 for more details).

${ }^{27}$ In principle, plants surveyed within ENESTyC can also be matched with the plants in EIMA. However, the resulting data set is relatively small and significantly biased toward big plants, hence the choice of utilizing this data set at the industry level.
} 
Notice that in the empirical application, I rely on a continuous measure of exposure to the Drug War, namely the homicide rate. However, this discrete scheme helps to understand the potential systematic differences between plants located in the drug-violence-exposed areas and others. I first focus on the pre-Drug War characteristics.

Table 1 reports the plant-level characteristics across the two areas as of 2005. The average sizes of plants are very similar in areas that will subsequently be exposed to rising violence and other areas, whether measured by value of output or employment. Plants also have no significant difference in labor productivity or the number of varieties produced per plant. Violence-exposed areas are, on average, closer to the US border, and as a result significantly more plants export in areas that will be exposed to heightened violence after president Calderón's launch of the war on drug cartels. On the other hand, the likelihood of importing among plants across the two locations are just the same. Table 1 also shows that plants in metropolitan areas that will be heavily exposed to the Drug War violence are more capital-intensive with a higher utilization rate than plants in other metropolitan areas, which is possibly associated with a higher share of exporters in the former areas. Finally, Table 1 reports that the average homicide rate was higher across the exposed areas in 2005 , but not significantly so. 
Table 1: Pre-Shock (2005) Plant Characteristics

\begin{tabular}{lccccccc}
\hline & \multicolumn{2}{c}{ High-intensity } & \multicolumn{2}{c}{ Other metropolitan } & & \\
& drug war metros & \multicolumn{2}{c}{ areas } & & \\
Plant-level variables & Mean & SD & Mean & SD & Diff. & t-stat \\
\hline Log Output & 11.31 & 1.99 & 11.22 & 1.95 & 0.09 & 1.28 \\
Log N of employees & 4.57 & 1.33 & 4.56 & 1.31 & 0.01 & 0.26 \\
Log capital per worker & 5.00 & 1.41 & 4.84 & 1.42 & $0.16^{*}$ & 2.91 \\
Log labor productivity & -1.09 & 1.12 & -1.14 & 1.15 & 0.04 & 1.05 \\
Capacity Utilization Rate & 74.00 & 18.78 & 70.63 & 20.12 & $3.37 *$ & 4.53 \\
N of varieties & 3.05 & 2.85 & 3.21 & 3.12 & -0.16 & -1.42 \\
Export dummy & 0.42 & 0.49 & 0.34 & 0.47 & $0.08^{*}$ & 4.49 \\
Import dummy & 0.48 & 0.50 & 0.48 & 0.50 & 0.00 & -0.08 \\
Share of Payroll Workforce & 0.88 & 0.31 & 0.89 & 0.30 & -0.01 & -0.93 \\
Homicide rate & 12.16 & 6.52 & 7.35 & 6.35 & 4.82 & 1.75 \\
\hline
\end{tabular}

Note: Values are measured in 2010 thousand Mexican pesos. Labor productivity is measured as the value of production per hour unit of labor. There are 908 plants in the six metropolitan areas defined as "High-intensity drug war zones" and 4,575 in "Other locations". Data on import and capital per worker are from Encuesta Industrial Anual (EIA); other data are from Encuesta Industrial Mensual Ampliada (EIMA). ${ }^{*}$ indicates significance at the $5 \%$ level or below.

Exposed areas are important locations for manufacturing activities. The total manufacturing employment in the highly exposed six metropolitan areas is $21 \%$ of the total manufacturing employment in the other metropolitan areas. ${ }^{28}$ Figure A-2 shows the distribution of plants in 2005 across threedigit industries, separately in the highly exposed six metropolitan areas and in the other metropolitan areas. Food manufacturing constitutes the largest manufacturing sector in both areas (as in overall Mexico), and there is no substantial difference in the industry specialization patterns across the two areas.

Since the plant-level analysis only covers areas where manufacturing takes place, I also use municipality-level data covering the whole of Mexico to elucidate broad correlation patterns of violence with the geographic, economic, and socioeconomic characteristics of local areas. Table A-2 in

\footnotetext{
${ }^{28}$ Author's calculation using EIMA.
} 
the Appendix presents the pairwise correlation coefficients of the average post-Drug War homicide rates with various pre-Drug War municipality characteristics. In general, Drug War violence is not negatively correlated with pre-Drug War economic activities; indeed, if anything it is positively associated with the output per capita. This may be driven by the fact that areas closer to the US are important locations for DTO activities as well as for FDI and exporting. The overall pattern in Table A-2 shows that the outbreak of violence was largely exogenous to local economic and socioeconomic factors. Regardless, the empirical strategy described below will control for any differences in the pre-shock characteristics of firms and metropolitan areas.

\section{Empirical Strategy}

This section describes the empirical strategy employed to identify the effect of increased violence on plant-level outcomes. Drawing from a longitudinal plant-level survey allows me to focus on within-plant variation and eliminates the possibility that unobservable characteristics of plants and their locations affect the results. I start with the following estimation equation at the plant-year level:

$$
\ln Y_{i k j t}=\alpha_{0}+\alpha_{1} \text { Violence }_{j t-1 / 2}+X_{j t}+\tau_{k t}+\eta_{i}+\varepsilon_{i k j t},
$$

where $Y_{i k j t}$ is plant $i$ 's outcome in industry $k$ located in metropolitan area $j$ and year $t$. Violence $e_{j t-1 / 2}$ is the logarithm of the number of intentional homicides that occurred between June $t-1$ and June $t$ per thousand people in the area. ${ }^{29}$ That is, the homicide rate is lagged by six months as the annual plant-level outcomes are the averages across the months of a calendar year. $X_{t j}$ is a vector of timevarying metropolitan area characteristics. $\tau_{k t}$ denotes industry by year fixed effects, and $\eta_{i}$ denotes plant fixed effects that can be correlated with plant or metropolitan area characteristics.

By making comparisons within a plant over time, observable and unobservable time-invariant characteristics, such as productivity and technology differences across firms, or metropolitan area characteristics that make the local area less or more attractive to legal and illegal businesses (e.g.

\footnotetext{
${ }^{29}$ Throughout the estimation analysis, the homicide rate refers to the number of homicides per thousand inhabitants instead of the convention per hundred thousand inhabitants.
} 
infrastructure, ports, and economic development), are controlled for. Further, as I focus on plants in metropolitan areas in the analysis, potential correlation between rural versus urban characteristics of locations with the homicide rate would not affect the results. I leave out the metropolitan area that was affected by the Tabasco flood. ${ }^{30}$ Table A-3 reports the distribution of plants across 57 metropolitan areas in the sample. ${ }^{31}$

Inclusion of industry by time fixed effects account for aggregate changes affecting manufacturing firms similarly, but also industry-specific time trends that may affect certain regions disproportionately, perhaps due to a potential geographic concentration of industries. It is especially important to take into account for industry-specific business trends due to the possible differential impact of the Great Recession. ${ }^{32}$ For this reason, the default specification controls for trends for each five-digit manufacturing industry (168 of them in the data). These industries are narrowly defined and can be considered product lines. ${ }^{33}$

Moreover, standard errors are allowed to have arbitrary patterns of correlation within each metropolitan area, and also separately within each four-digit industry, and are two-way clustered for each metropolitan area and industry.

Dube and Vargas (2013) study how different types of commodity shocks affect civil war outcomes and show that a sharp fall in coffee prices during the 1990s in Colombia led to an increase in violence differentially in municipalities cultivating more coffee. This is the opportunity cost effect of conflict, and the presence of such shocks may lead to an overestimation of the negative impact of violence. To address this, the vector $X_{j t}$ includes metropolitan-level employment shares of crop

\footnotetext{
${ }^{30}$ In late 2007, there was a major flood in the state of Tabasco, affecting over one million residents. The state capital went bankrupt as a result, and thousands of businesses were affected. Since this event is likely to affect the opportunity cost of crime, I do not include plants in the flood area in the analysis.

${ }^{31}$ There are total 59 designated metropolitan areas of Mexico as of 2010. Plants in EIMA were operating across 58 metro areas. Puerto Vallarta which is the only metro area not in the EIMA is a beach resort area where tourism is the main economic activity.

${ }^{32}$ Nonetheless, studies tend to find that the geographic heterogeneity of the crime rate in Mexico did not correspond to the differential regional magnitude of the Great Recession (e.g., Ajzenman et al., 2015).

${ }^{33}$ Some examples of five-digit industries are the following: "Manufacture of cement for construction", "Concrete manufacturing", "Manufacture of cement and concrete pipes and blocks", "Manufacture of prestressed products", "Preparation of breakfast cereals", "Manufacture of chocolate and chocolate products from cocoa", "Manufacture of chocolate products from chocolate".
} 
production. Dube and Vargas (2013) also find that a positive income shock due to a rise in oil prices intensifies attacks in oil-producing regions. The increase in oil price increases the contestable income, thereby increasing the conflict intensity. Such shocks are likely to lead to an underestimation of the violence effect on plant-level outcomes. To prevent a possible convolution of the results, the vector $X_{j t}$ also includes metropolitan-level employment shares of metal mining including gold, silver, copper, and uranium; and oil and natural gas extraction.

Additionally, $X_{j t}$ includes the pre-trends in the homicide rate per metropolitan areas. To control for pre-trends, the year dummies are interacted with the year 2002 level of homicide rates of the metropolitan areas. $\alpha_{1}$ measures the variation in within-plant outcomes specific to local markets that experience a heightened violence over 2005-2010.

\subsection{Instrumental Variable Strategy}

Although the spatiotemporal variation in the homicide rate during the sample period is mainly driven by the Drug War, it is still possible that the variation in homicide rates, particularly in nonconflict areas, may be influenced by other factors that may be correlated with plant-level performance. For example, increased productive capacity in an area may attract unskilled migrants, potentially driving socioeconomic inequality, that in turn contributes to an increase in local crime. To rule out the possibility that the homicide rate is correlated with the error term, and to make sure the results are driven by the plausibly exogenous escalation of violent conflict due to the unexpected consequences of a policy turn in Mexico, I employ an instrumental variable (IV) strategy and construct an instrument that is based on the triggers of the Mexican Drug War.

When the Calderón government decided to use military power on the drug cartels in 2007, Mexican states were offered to engage in joint military operations with the federal forces against the criminal organizations (Operativos Conjuntos Militares). Some states opted in with the federal military operations, while others opted out. Figure A-4 in the Appendix show the states that collaborated with the federal government's operations. ${ }^{34}$ I utilize the federal army entrance in states as a measure of the

\footnotetext{
${ }^{34}$ Michoacán, Guerrero, and Baja California participated in 2007. Nuevo León, Tamaulipas, Chihuahua, Sinaloa and Durango participated in 2008. Other states were not involved.
} 
implementation of the kingpin strategy, and thus of the unintended violence shock, as the military is the main actor in implementing the kingpin strategy. Let $M O_{s t}$ be an indicator for state $s$ whether it collaborates with the federal government's military operations,kingpin strategy. That is,

$$
\begin{aligned}
& M O_{s t}=1 \quad \text { if state } s \text { agrees to participate in the joint military operations from 2007, and } \\
& M O_{s t}=0 \quad \text { otherwise. }
\end{aligned}
$$

Note that $M O_{s t}=0$ before 2007. Federal army operations resulted in captures or killings of drug cartels leaders, and that in turn triggered fights between cartels (Dell, 2015; Lindo and Padillo-Romo, 2018). Figure A-5 in the Appendix shows the homicide rate increased dramatically after 2007 in states with federal military operations as opposed to other states and the increase in homicide rate was driven by drug-related homicides.

The decline in cocaine supply from Colombia and the resulting change in cocaine prices intensified drug violence by increasing rent opportunities (Castillo, Mejia, and Restrepo, 2020; Angrist and Kugler, 2008). To capture the time variation in the strength of Colombian drug enforcement, I use the cocaine seizures in Colombia normalized with the annual cocaine cultivated land in Colombia. Interacting this time-varying variable with the susceptible locations in Mexico due to the government's Kingpin strategy, I obtained my instrument.

$$
I 1_{j t} \equiv M O_{s t} * D E C_{t-1 / 2}^{c o k e}
$$

Here, $D E C_{t-1 / 2}^{c o k e}$ measures the annual amount of cocaine seized by Colombian forces. It is normalized by the annual amount of cocaine cultivated land in Colombia. Just like the homicide rate, it is lagged by six months, and measures the seizures from June $t-1$ toward June $t$. By construction $D E C_{t-1 / 2}^{c o k e}$ captures the time variation in the strength of the Colombian drug enforcement agencies.

Assuming a strong correlation between the homicide rate and the instrument which is based on the Mexican and Colombian policy triggers of the Drug War, the exclusion restriction is valid as long as the Colombian drug enforcement and the Mexican Kingpin policy affect the Mexican manufacturing plants via their effects on heightened violence conditional on the pre-trends, industry by time, and plant fixed effects (i.e., $E\left[\varepsilon_{i k j t} I_{j t} \mid X_{j t}, \tau_{k t}, \eta_{i}\right]=0$ ). 
In order to make sure that the exclusion restriction is not violated, due to, for example, possible impact of increased security expenses on manufacturing plants, I additionally control for the growth in security expenses with robust findings (see Table B-10).

\section{Decline in Industrial Activities and Violent Conflict}

This section shows that when the Drug War brings a surge of violence to a metropolitan area, manufacturing enterprises experience a severe decline. Plants' rate of capacity utilization, output, employment, and labor productivity fall in response to violence. The Drug War also affects the composition of employment and alters wages within establishments.

\subsection{Decline in Plant-level Output and Employment Due to Violence}

Table 2 presents the results from estimation of Equation 1 by ordinary least squares (OLS). Violence is measured as the number of homicides per thousand inhabitants. In column (1), the dependent variable is the logarithm of the value of output produced in a plant. The estimate shows a negative and significant relationship between plant-level output and the metropolitan area level homicide rate. In column (2), the dependent variable is the logarithm of employment, and the estimate shows a negative and significant effect of violence. Quantitatively, the coefficients in columns (1) and (2) mean that an increase from zero to one homicide per thousand people is associated with a $10 \%$ reduction in plantlevel output and $8 \%$ reduction in plant-level employment. In column (3), the dependent variable is the logarithm of the capacity utilization, indicating the rate at which manufacturing plants utilize their fixed assets. The results show a significant reduction in the capacity utilization rate with increased violence. And finally in column (4), the dependent variable is the logarithm of the number of distinct product varieties that a plant produces. Heightened violence due to the Drug War as measured by the homicide rate not only reduces sales but also the product scope of manufacturing plants in Mexico. 
Table 2: OLS Results-Violence and Plant-Level Output and Employment

\begin{tabular}{|c|c|c|c|c|}
\hline & (1) & (2) & (3) & (4) \\
\hline Specification: & OLS & OLS & OLS & OLS \\
\hline \multirow[t]{2}{*}{ Dep. var. (in log): } & Output & Employment & Capacity & Product \\
\hline & & & Utilization & Scope \\
\hline \multirow[t]{2}{*}{ Homicide Rate } & $-0.103 * * *$ & $-0.076 * * *$ & $-0.164 * * *$ & $-0.051 * *$ \\
\hline & $(0.025)$ & $(0.019)$ & $(0.045)$ & $(0.021)$ \\
\hline Plant FEs & $\checkmark$ & $\checkmark$ & $\checkmark$ & $\checkmark$ \\
\hline 3-dig. Industry $\mathbf{x}$ Year FEs & $\checkmark$ & $\checkmark$ & $\checkmark$ & $\checkmark$ \\
\hline 2002 Homicide Rate $\mathbf{x}$ Year FEs & $\checkmark$ & $\checkmark$ & $\checkmark$ & $\checkmark$ \\
\hline Time-varying Local Market Characs & $\checkmark$ & $\checkmark$ & $\checkmark$ & $\checkmark$ \\
\hline No. of Observations & 30,605 & 30,605 & 29,735 & 30,605 \\
\hline No. of Local Markets (clusters) & 57 & 57 & 57 & 57 \\
\hline
\end{tabular}

Note: All dependent variables are in logarithm. They are the value of output, the number of employees, the capacity utilization rate and the number of product varieties produced in a plant respectively from columns 1 to 4 . "Homicide rate" is measured as the number of homicides per thousand inhabitant of each metropolitan area. "Time-varying local market characteristics" include metropolitan area-level employment shares of crop production; metal mining including gold, silver, copper, and uranium; and the metropolitan area-level employment share of oil and natural gas extraction. Robust standard errors, reported in parentheses, are two-way clustered by local market (metropolitan area) and four-digit industry level. ${ }^{*},{ }^{* *}$, and ${ }^{* * *}$ indicate significance at the $10 \%$, $5 \%$, and $1 \%$ levels, respectively.

While the Drug War produces a quasi-natural variation in the homicide rate in Mexico, the homicide rates, especially in non-affected regions, are expected to be correlated with inter-temporarily changing characteristics of the local economy or local labor markets. ${ }^{35}$ In order to establish a causal relation between the drug war violence and the firm-level outcomes, I employ an instrumental strategy that is based on the policy triggers of the Drug War. These results follow next, starting with the employment elasticity of drug-violence.

\footnotetext{
${ }^{35}$ Raphael and Winter-Ebmer (2001) find a positive impact of unemployment on crime. Exposure to trade shocks can also influence, in general, crime via changes in labor market conditions or provision of public goods (Feler and Senses, 2016). Recently Dell, Feigenberg, and Teshima (2018) show that a trade-induced decline in male employment may fuel violence. Dix-Carneiro, Soares, and Ulyssea (2018) find that trade-induced labor market changes in Brazil increase crime.
} 


\subsubsection{Job Losses in Manufacturing}

Table 3 presents the IV estimates of the employment elasticity with respect to drug violence. Column (1), first, shows the OLS estimate of the employment elasticity. In column (2), the logarithm of the homicide rate is instrumented with $M O_{s t} * D E C_{t-1 / 2}^{\text {coke }}$. The coefficient of interest is larger in magnitude and more precisely estimated. This shows that potential confounding factors, such as a positive oil price shock boosting the local economy with oil production and causing increased criminal activities by increasing the contestable income, or other intertemporal shocks affecting the homicide rate that are not related to drug trafficking lead to an underestimation of the impact of drug-violence in OLS. First-stage results show that the instrument is indeed strongly correlated with the homicide rate. Instrumentation is strong, as indicated by the first-stage $F$-statistics (Kleibergen-Paap $F$-statistic) at the bottom of the table. The coefficient estimate in column 2 tells us that doubling the homicide rate leads to a $4.5 \%$ drop in plant-level employment.

In order to address the concerns noted in Dube and Vargas (2013), metropolitan-level employment of crop production, precious metal mining (gold, silver, copper, and uranium), and oil and natural gas extraction are included in column (3). Once the homicide rate is instrumented, including time-varying local market characteristics does not affect the impact of violence on plant-level employment. ${ }^{36}$ This is reassuring, as it indicates that the instrument rightly captures the identifying variation in the homicide rate over 2005-2010 that is driven by the outbreak of the Mexican Drug War.

\footnotetext{
${ }^{36}$ Since including time-varying metropolitan controls on crop, oil, gas, and metal mining may add into endogeneity concerns, and the IV strategy focuses on the triggers of the drug war, the default specification with two-stage least squares (2SLS) estimation does not include the employment shares of strategic sectors. They are only included when OLS is used. However, including them does not change the results, as it is also clear from Table 3.
} 
Table 3: Drug Violence Decreases Manufacturing Employment

\begin{tabular}{lccccc}
\hline & $(1)$ & $(2)$ & $(3)$ & $(4)$ & $(5)$ \\
Specification & OLS & 2SLS & 2SLS & 2 SLS & 2SLS \\
\hline & & & & & \\
Dep. var.: Log employment & & & & & \\
\hline & $-0.024^{* *}$ & $-0.064^{* * *}$ & $-0.065^{* * * *}$ & $-0.069^{* * * *}$ & $-0.070^{* * * *}$ \\
Log Homicide Rate & $(0.011)$ & $(0.022)$ & $(0.022)$ & $(0.022)$ & $(0.023)$ \\
& $\checkmark$ & $\checkmark$ & $\checkmark$ & $\checkmark$ & $\checkmark$ \\
Plant FEs & $\checkmark$ & $\checkmark$ & $\checkmark$ & $\checkmark$ & $\checkmark$ \\
2002 Homicide Rate $\mathbf{x}$ Year FEs & - & - & $\checkmark$ & - & - \\
Time-varying Local Market Characs. & $\checkmark$ & $\checkmark$ & $\checkmark$ & - & - \\
3-dig. Industry $\mathbf{x}$ Year FEs & - & - & - & $\checkmark$ & - \\
5-dig. Industry $\mathbf{x}$ Year FEs & - & - & - & - & $\checkmark$ \\
Product $\mathbf{x}$ Year FEs & 30,605 & 30,605 & 30,605 & 30,605 & 30,605 \\
No. of Observations & 57 & 57 & 57 & 57 & 57 \\
No. of Clusters (LM) & & & & & \\
\hline First stage & & $0.390^{* * * *}$ & $0.391 * * *$ & $0.395 * * *$ & $0.394 * * *$ \\
Instrument $\left(M O_{s t} * D E C_{t-1 / 2}^{c o k e}\right)$ & & $(0.093)$ & $(0.094)$ & $(0.086)$ & $(0.085)$ \\
Kleibergen-Paap $F$-excluded instrument & & 17.55 & 17.40 & 21.15 & 21.72 \\
\hline
\end{tabular}

Note: The dependent variable is the logarithm of the number of employees. "Log homicide rate" is the logarithm of the number of homicides per thousand inhabitant of each metropolitan area. "Timevarying local market characteristics" include metropolitan area-level employment shares of crop production; metal mining including gold, silver, copper, and uranium; and the metropolitan area-level employment share of oil and natural gas extraction. Robust standard errors, reported in parentheses, are two-way clustered by local market (metropolitan area) and four-digit industry level. ${ }^{*},{ }^{* *}$, and ${ }^{* * *}$ indicate significance at the $10 \%, 5 \%$ and $1 \%$ levels, respectively.

So far I use three-digit industry by year fixed effects to control for the potentially disproportionate impact of the Great Recession across local labor markets in Mexico, but there could also be finer industry-specific shocks that are felt differently across local markets. Next, I shut off all variation across very detailed five-digit industry by time. The impact of violence is more precisely estimated, and it gets larger in magnitude. This shows that the drug violence leads to a significant decline in plant-level employment, independent from any type of shocks, whether common across industries or specific to very narrow industries. And, to remove any suspicion regarding confounding factors 
such as trade competition or the Great Recession, I include product by year fixed effects in addition to plant fixed effects and pre-trends in the homicide rate. The 2SLS estimate in column (5) shows that drug violence causes significant decline in plant-level employment. More specifically, doubling the homicide rate in a metropolitan area leads to a 5\% decline in plant-level employment (column 5). Since the nationwide homicide rate tripled between 2007 and 2010, and the aggregate manufacturing employment declined by $7 \%$ over the same period, this estimate implies a substantial impact of the Mexican Drug War on the aggregate employment decline. In a back of the envelope calculation with the total number of manufacturing establishments and their average size from the 2004 Census, ${ }^{37}$ this is a reduction in jobs of about 300,000. This means that, at the intensive margin alone, the Drug War accounts for about $68 \%$ of the decline in manufacturing employment. ${ }^{38}$

The decline in employment may be due to reduced local demand, labor market effects of violence or some combination of both.

Next, I focus on two-stage least squares estimation of the output elasticity with respect to a violent environment, and other within-plant changes to shed more light on how a violent environment affects the plant-level outcomes. For the rest of the analysis, I employ five digit industry by year fixed effects to make sure the estimates are free from possibly confounding effects of non-drug war factors.

\subsubsection{Violence and Plants' Output, Product Scope, Utilization, and Productivity}

The OLS estimates in Table 2 have shown that the homicide rate is associated with a significant reduction in manufacturing product volume and scope at the plant-level. Now, Table 4 presents twostage least squares results when the Mexican and the Colombian drug enforcement policy triggers are used to instrument the metropolitan area level violence in Mexico. In column (1) the dependent variable is the logarithm of the plant-level output. The estimate shows that the drug war violence causes a significant reduction in manufacturing output. The estimate -0.112 indicates that doubling the homicide rate decreases plant-level output by close to $8 \%$.

\footnotetext{
${ }^{37}$ The 2004 Census reports 328,671 industrial establishment with an average employment 13.

${ }^{38}$ In Mexico, the aggregate manufacturing employment declined 7\% over 2007-2010. The total number of manufacturing employees decreased by 442,128 from 6,205,468. The decline in the number employees is driven by the decline in workers on payroll; the total number of payroll workers in manufacturing decreased by $9 \%$ during the same period. In the next section I will show that the Drug War-induced reduction in employment is also concentrated on payroll workers.
} 
Output demand may decline due to business closures, emigration, or a decrease in conspicuous consumption (Mejia and Restrepo, 2016b). The negative demand shocks may lead to a decline in prices (assuming some market power). Violence-induced labor supply changes, and other factors, such as increased security expenses, tend to increase marginal costs of operating (or reduce productivity) and to increase firms' price. ${ }^{39}$ In situations where violence leads to both a negative labor supply shock and a decrease in output demand, the impact on prices will be biased toward zero, as these effects will be running in opposite directions. In column (2) of Table 4, I present the impact of violence on firm-level price. The estimate of elasticity of firm-level price with respect to violent conflict is positive but imprecisely estimated. The positive price effect implies a possible cost shifter effect of violence, e.g. a labor supply shock.

Column (3) of Table 4 presents the effect on the product portfolio of plants. The results show that the reduction in output due to the Drug War is accompanied with a significant drop in the number of varieties produced. This is important because the significant drop in the product scope of firms suggests that the decline in production has long term implications. The estimate in column (3) shows a drop in the number of varieties by approximately $3 \%$ in response to doubling the homicide rate in the metropolitan area.

Does the fixed productive assets of firms respond to drug violence? Firms do not directly report capital in EIMA, but they report capacity utilization. This variable shows the percentage of fixed assets utilized in the plant. ${ }^{40}$ If the productive fixed assets of the establishments decrease proportionately with employment, capacity utilization would not be affected by downsizing. The results, presented in column (4) of Table 4, show that violence significantly reduces capacity utilization. The coefficient -4.1 implies an average 11 percentage point drop between 2005 and 2010 in the utilization rate of plants in Juárez. ${ }^{41,42}$ The stronger impact on output in comparison to labor, together with a significant

\footnotetext{
${ }^{39}$ The change in average plant-level price can also be affected if firms disproportionately drop products along one end of the price distribution.

${ }^{40}$ The utilization rate shows the relationship between the volume of production that is currently being obtained and the volume of production that could potentially be generated given the conditions of infrastructure, machinery, equipment, technical and organizational procedures that are currently used in the establishment.

${ }^{41}$ The homicide rate, lagged by six months, increases from 15 to 228 between 2005 and 2010 in Juárez.

${ }^{42}$ For the purpose of comparison with the elasticity estimates, the capacity utilization rate is also used in logarithm as a
} 
decline in the utilization rate, imply a drop in plant efficiency. This is confirmed in column (5) of Table

4. Thus, violence causes reduced productivity as measured by the output per hour worked.

\section{Table 4: Mexican Drug War and Decline in Manufacturing Plants}

\begin{tabular}{lccccccc}
\hline & $(1)$ & $(2)$ & $(3)$ & $(4)$ & $(5)$ & $(6)$ & (7) \\
Specification & 2SLS & 2SLS & 2SLS & 2SLS & 2SLS & 2SLS & 2SLS \\
& Output & Output & Product & Capacity & Labor & Export & Export \\
& (in log) & Price & Scope & Utilization & Productivity & & Intensity \\
& & (in log) & (in log) & Rate & (in log) & & \\
& $-0.112^{* * *}$ & 0.037 & $-0.045^{* *}$ & $-4.131 * * *$ & $-0.062 *$ & -0.018 & -0.009 \\
Violence & $(0.033)$ & $(0.022)$ & $(0.020)$ & $(1.071)$ & $(0.035)$ & $(0.023)$ & $(0.010)$ \\
& $\checkmark$ & $\checkmark$ & $\checkmark$ & $\checkmark$ & $\checkmark$ & $\checkmark$ & $\checkmark$ \\
Plant FEs & $\checkmark$ & $\checkmark$ & $\checkmark$ & $\checkmark$ & $\checkmark$ & $\checkmark$ & $\checkmark$ \\
Pre-trends in Homicide Rate & $\checkmark$ & $\checkmark$ & $\checkmark$ & $\checkmark$ & $\checkmark$ & $\checkmark$ & $\checkmark$ \\
5-dig. industry x Year FEs & $\checkmark, 605$ & 28,589 & 30,605 & 29,926 & 30,605 & 30,605 & 30,605 \\
No. of observations & 57 & 57 & 57 & 57 & 57 & 57 & 57 \\
No. of clusters (LM) & 21.15 & 20.86 & 21.15 & 20.32 & 21.15 & 21.15 & 21.15 \\
K-P F-excluded instrument & & & & & & &
\end{tabular}

Note: "Violence" is the logarithm of the number of homicides per thousand inhabitants of a metropolitan area. "Capacity utilization" is the percentage rate of utilization of the fixed assets of the plant. All dependent variables, except "Capacity utilization", "Export indicator," and "Export intensity" are in logarithm. Output is the total value of production. Output price is the average unit price of a plant's product varieties. Labor productivity is the value of output per hour worked. Export is an indicator variable that takes 1 if a plant exports in year $t$. Export Intensity is the share of export revenues over the total sales. Pre-trends in Homicide Rate is the interaction of year dummies with the year 2002 homicide rate for each metropolitan area. Robust standard errors, reported in parentheses, are two-way clustered by metropolitan area and four-digit industry level. ${ }^{*},{ }^{* *}$, and ${ }^{* * *}$ indicate significance at the $10 \%, 5 \%$, and $1 \%$ levels, respectively.

Foreign demand is not likely to be influenced by the Drug War shock. However, possible disruptions on highways and other international routes may deter Mexican firms' international trade activities. Martin, Mayer, and Thoenig (2010) show that international trade may serve as insurance if international trade substitutes internal trade during civil wars. In column (6) of Table 4, the outcome variable is an indicator variable for exporting. The results show that the likelihood that firms export dependent variable. The corresponding estimate is -0.07 , which is similar to the employment elasticity estimate. 
is not affected significantly by the Drug War. The impact on foreign sales' share is also not found to be significant (column 7). Further results on exported products (see column (5) of Table B-1 in the Appendix) also reveal that the domestic market drives the decline in the number of products. These results show that violence leads to a decline in domestic demand.

The following section focuses on the compositional changes in the plant-level workforce and further elucidates the sources of decline in employment.

\subsection{Violence-induced Labor Supply Shock and Employment Composition of Firms}

I have shown above that drug war violence reduces both plant-level output and employment. While the drug war-induced drop in demand may be strong and permanent enough to lead to a decline in plant-level employment, drug violence can also directly affect employment via its effect on the local labor supply. In this section, I study the impact on employment composition and wages at the plant level to illustrate this labor supply channel as a driver for the employment effect of violence.

Figure 5 shows the plot of the results from estimating equation 1 by two-stage least squares while the full results are presented in Table 7. As before, in addition to plant fixed effects and pretrends, very detailed five-digit industry by year fixed effects are controlled for in these regressions. Figure 5a shows the employment elasticity estimates separately for the total production (blue-collar) workers and for the total non-production (white-collar) workers. The dependent variables include both employees on payroll and contractual employees that are not on the firm's payroll. The left hand side of Figure 5a focuses on the number of white-collar and blue-collar workers and the right hand side focuses on the same variables measured in total hours worked.

The first observation is that there is only a large drop among blue-collar workers in response to the Drug War; the impact among non-production workers is even positive, though not significantly so. The 2SLS estimate in $5 \mathrm{a}$ is -0.10 , larger than the estimate on total employment, which is -0.07 in the corresponding specification (Table 3, column 4) and statistically significant at the $1 \%$ level. It shows that doubling the homicide rate in a metropolitan area causes a 7\% decline in the number of 
blue-collar employees. Although the increase in white-collar employment is not precisely estimated, it can surely be concluded that the level of non-production employment is not negatively affected by the heightened violence of the drug war.

The second observation is that the impacts on employee count and hours worked are very similar. Suppose firms downsize because of a violence-induced negative demand shock. In that case, one expects to see a stronger impact on hours as it is less costly to reduce hours than to lay off workers altogether. Adjustment costs are also higher for payroll workers in comparison to less permanent, contractual workers. In Mexico, firms can employ workers directly, as payroll employees, or indirectly, as contractual employees via an external company. For workers on the payroll, firms are required to pay social security contributions and severance payments at the termination of a contract. On the other hand, firms are not responsible for social security contributions and severance payments in contractual employment.

In the presence of labor market frictions, such as severance payments, if the violence shock is felt purely as a demand shock, one expects 1) a stronger decline in hours worked than in the number of employees for hourly paid workers and 2) a stronger response in indirect employment than in payroll employment. This is so because it is cheaper to decrease workers' hours worked than to lay them off, and it is cheaper to start cutting labor among contractual employees first, as firms have no or imperfect knowledge of how severe or permanent the shock will be (Bloom, 2009).

In Figure 5b, the dependent variables are the blue-collar and white-collar employees on payroll. As before, the left hand side of the figure plots the elasticity of employment across the two groups as measured in employee counts, and the right hand side of the figure plots the employment elasticity estimates as measured in hours worked. The results show that firms experience a stronger decline in employment of blue-collar workers on payroll than the overall blue-collar employment decline. That is, the violence shock does not cause a stronger reduction in temporary blue-collar workers (not on payroll). The violence shock does just the opposite: a reduction in blue-collar employees is concentrated among the payroll, permanent, employees. Further, we see that the extent of reduction both in blue-collar hours worked on payroll and the number of blue-collar employees on payroll is 
similar, indeed the number of employees is more sensitive to the heightened violence of the Drug War than the hours worked (-0.12 versus -0.11). These are significant indications that a violence-induced reduction in local demand is not the main driver of the decline in blue-collar employment.

Why, then, are blue-collar workers more affected by the war than more skilled and higher-paid white-collar employees? If kidnapping risk and risk to life due to being in the wrong place at the wrong time increases for all workers, it would lead to an increased reservation wage for workers, a wage below which these risks outweigh the benefits of working. As blue-collar workers are the lowest paid workers, the increase in reservation wage will be binding for their participation decision. Additionally, production workers are more likely to be prone to risk to life (see Figure 4), as they travel during nights and early mornings according to production shifts.

Further, Ajzenman et al. (2015) as well as news reports as discussed in Section 2.3, emphasize that especially poorer workers and poor neighborhoods within metropolitan areas are impacted by the drug war, making lower-paid workers more susceptible to witnessing brutality. If increased reservation wages due to increased risk leads to a drop in the labor market participation of workers, one may expect the impact to be stronger on female workers. Women tend to be paid less and are less likely to be primary breadwinners, and hence will have a more elastic labor supply participation compared to male workers. Alternatively, or additionally, possible expansion of the illegal sector and increased demand for brutal male force may lead workers, especially male, to leave the legal sector for the illegal one.

Figure $5 \mathrm{c}$ plots the impact of the shock on plant-level wages. The average wages do not react to the heightened drug war violence but this is due to a significant increase in blue-collar wages and a corresponding significant decline in white-collar wages. Blue-collar wage elasticity is estimated to be 0.11 and significant at the five percent level. It implies that doubling the drug war violence in a metropolitan area leads to a $7.7 \%$ increase in the average wages paid to blue-collar workers at a manufacturing plant. The coefficient estimate for the wages of non-production workers is -0.08 . It implies that doubling the drug war violence in a metropolitan area leads to a $5.6 \%$ decrease in the average wages paid to white-collar workers at a manufacturing plant. 

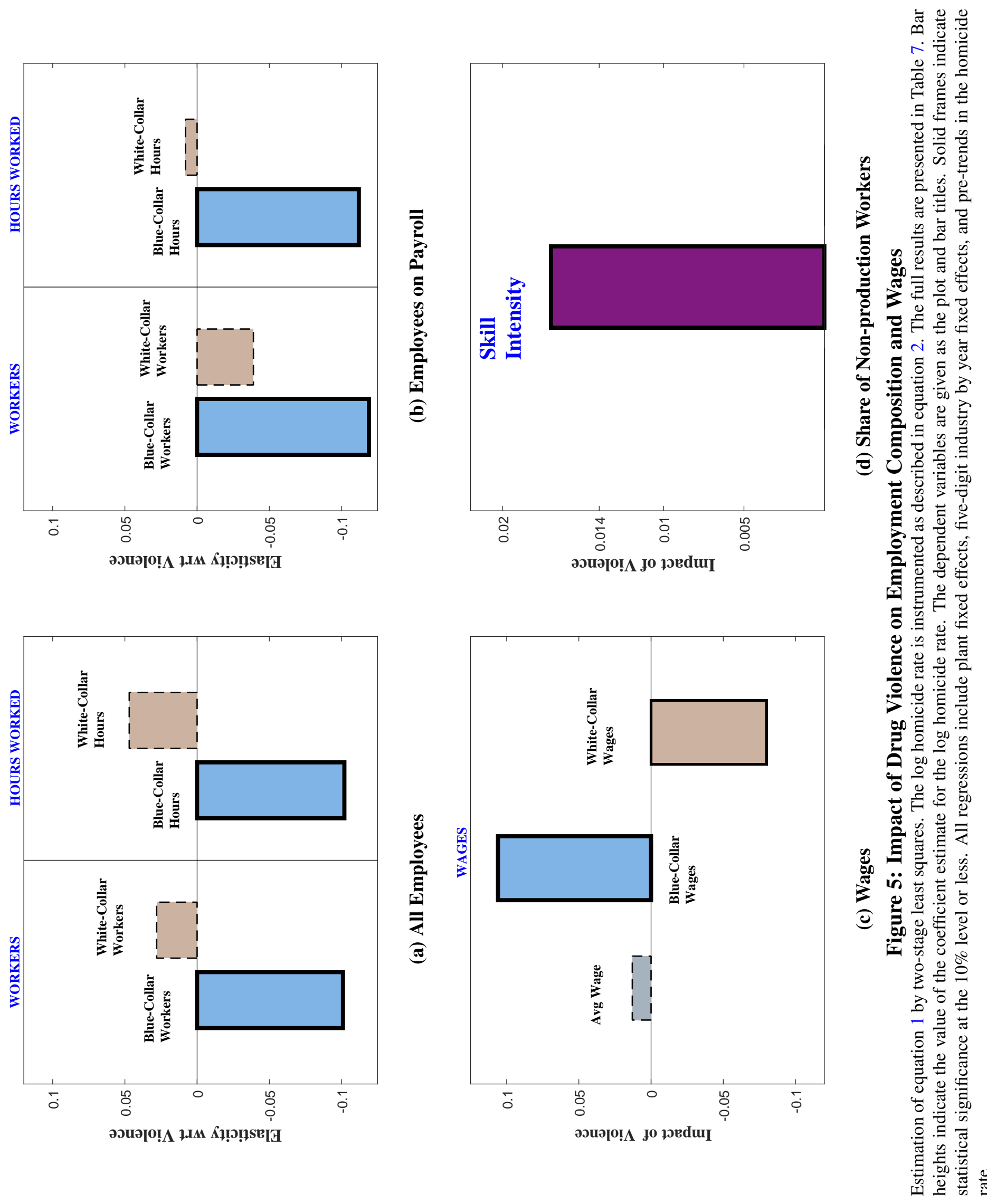
The increase in blue-collar workers' wages does not have to correspond to an actual worker-level increase in the wages of blue-collar workers. If it is the lower-wage individuals among blue-collar workers who leave the workforce, the increase in blue-collar workers' wages may be driven by selection. But given that the violence also causes a decline in white-collar wages, violence indisputably increases the relative wages of blue-collar, production workers (i.e., it decreases the skill premium.) ${ }^{43}$

Figure $5 \mathrm{~d}$ shows that drug violence increases the share of white-collar or non-production employees in total employment. That is, increased violence due to the drug war works as a negative labor supply shock on blue-collar workers. As blue-collar workers become relatively scarce in the local labor market, blue-collar employment decreases with a significant increase in the relative wages of blue-collar workers. These results show that a violent environment has the ability to influence the technology of firms - the way production is organized. Firms use production technologies that are more intensive in the use of the relatively more abundant labor type, white-collar workers, in response to violence-induced local labor supply shocks. ${ }^{44}$

\section{Anatomy of $\operatorname{Mis}(\mathrm{Re})$-allocation Induced by Drug Violence}

The results so far point to two crucial channels through which firms are affected by the Mexican Drug War: 1) via violence-induced local labor supply shocks, primarily affecting blue-collar workers; and 2) via a reduction in local demand induced by the Drug War. Some firms are likely to be more or less prone to the demand effect of violence or the labor supply effect of violence. For example, exporters' output demand is less likely to be affected by local violence, and high-wage plants are less likely to be affected by local labor supply shocks. This section uses the additional information on plants obtained from the annual survey (EIA) and the technology survey (ENESTyC) to study the potentially heterogeneous impact of violence to pinpoint the channels through which firms are affected and to document the extent of reallocation induced by violence.

\footnotetext{
${ }^{43}$ Both white-collar and blue-collar wages in columns 3-4 in Panel C of Table 7 are average wages across workers on payroll.

${ }^{44}$ Note that all adjustment to a local labor supply shock could also take place between firms or between industries by inducing a decrease in scale of those production units that are intensive in the use of the now relatively scarce labor input (Rybczynski Theorem). Dustmann and Glitz (2015) emphasize the importance of within-firm adjustment in response to changes in local labor supply.
} 


\subsection{Local Labor Market Channel}

Employing the rich information on plants' characteristics provided by the annual survey (EIA) and the technology survey (ENESTyC), my approach is to partition the estimation sample depending on plants' initial year-2005 characteristics and estimate equation 1 by two-stage least squares separately for the resulting subsamples.

Compositional changes within firms are in line with the idea that drug violence leads to a negative labor supply shock on blue-collar workers. The descriptive analysis points to a higher risk of life, especially for unskilled production workers, who also earn lower wages. As a local disamenity that especially affects poorer neighborhoods, violence is likely to increase the reservation wages of workers (below which the discomfort and risks outweigh the benefit of working). As mentioned above, this mechanism is likely to be stronger for women, despite their not being the immediate target of violence, simply because of their more elastic labor supply -especially on the participation margin -as they are less likely to be their family's primary breadwinner and their labor is less well paid. 45 We would expect that a violence-induced decline in labor force participation of women affects female-intensive manufacturing plants more strongly. ${ }^{46}$ On the other hand, if the drug war expands the illegal sector and pushes up blue-collar wages in the legal sector, we would still observe stronger employment reduction on lower-wage plants, but on male-intensive rather than female-intensive ones.

To distinguish among alternative explanations of labor supply changes, I partition the sample depending on median level of plants' initial characteristics and conduct the analysis separately for the resulting subsamples. Figure presents the sensitivity of the employment response to drug violence across plants with different susceptibility to violence-induced labor supply shocks. Table 8 present the full results.

\footnotetext{
${ }^{45}$ There is a broad consensus among labor economists that labor supply elasticities are large for married women. See Keane (2011) for a survey of the literature.

${ }^{46}$ Note that migration out of exposed areas is likely to affect both genders similarly. Table A-5 in the Appendix shows a modest migration response. Table A-5 shows that people living in exposed states are more likely to emigrate to other countries in comparison to people in non-exposed states. However, in general, there is a strong overall declining trend in the number of international emigrants (namely emigrants to the US) over the sample period, which is likely to be due to stricter policies in the US regarding illegal immigration. Bazzi, Burns, Hanson, Roberts, and Whitley (2018) show that increased sanctions of the US Border Patrol on apprehended illegal immigrants from Mexico over 2008-2012 was effective in increasing border security.
} 
Figure 6a presents the impact of violent conflict on employment separately among low and high wage plants. I classify all plants below the sample median of average monthly wages as of year 2005 as low-wage, and plants with the average monthly wages above the median value $(9,3002010$ Mexican peso) as high-wage plants. Equation 1 is estimated for each sample by two-stage least squares, where the logarithm of the homicide rate is instrumented with the instrument described in Equation 2. Lowwage plants must be more exposed to the labor market channel because the new reservation wage will be more binding for lower-wage plants. The results confirm this, the drop in employment is concentrated among low-wage plants. The elasticity estimate is -0.12 and statistically significant at the $5 \%$ level for low-wage plants, the estimate for high-wage plants is -0.03 and statistically insignificant.

Next, I focus on the share of female workers among firm's payroll workers. Figure $6 \mathrm{~b}$ shows that plants with a female-intensive workforce experience a stronger decline in employment. The estimates suggest that doubling the homicide rate causes a $10.5 \%(=-0.15 * 70 / 100)$ decline in total employment for plants with female-intensive workforce as opposed to a $4 \%(=-0.06 * 70 / 100)$ drop for other plants. ${ }^{47}$ This is in line with the idea that by increasing the risk to life, a violent environment decreases the value of work and increases the reservation wages of workers. Due to their more elastic labor supply and lower wages, female workers are more likely to drop out of the labor force as a result of this. $^{48}$

Next I focus on women's and men's average wages in unskilled occupations across plants. I use the nation-wide representative plant-level survey, ENESTyC 2005, to derive the average annual wages of female and male workers in unskilled occupations and match the information to plants in my sample at the four-digit industry level. Figure 6c shows that employment decline is concentrated among plants in industries with lower unskilled female wages. Other plants are not susceptible to violence-induced employment reduction.

Figure 6d plots the employment elasticity estimates across low- and high-wage industries, this

\footnotetext{
${ }^{47}$ The median level of female share of workforce in 2005 is 0.20 ; therefore, female-intensive plants are plants with at least $20 \%$ female employment.

${ }^{48}$ Dell (2015), for example, shows a significant negative effect of the drug war on female labor force participation at the municipality-level, and no effect on male labor force participation.
} 


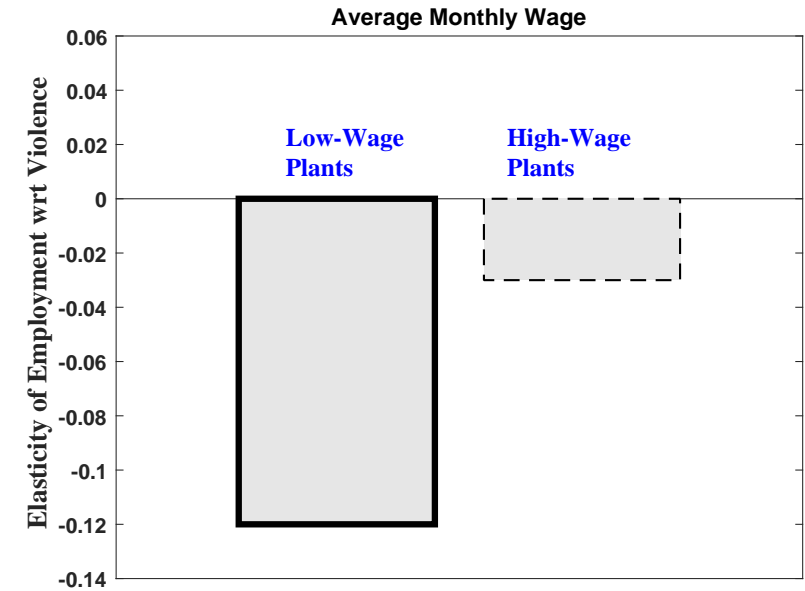

(a) Employment Response among High- and LowWage Plants

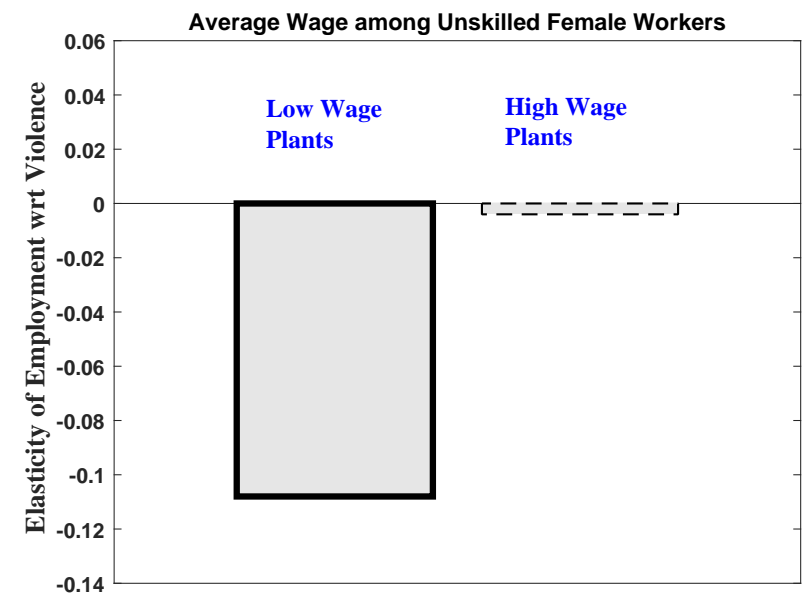

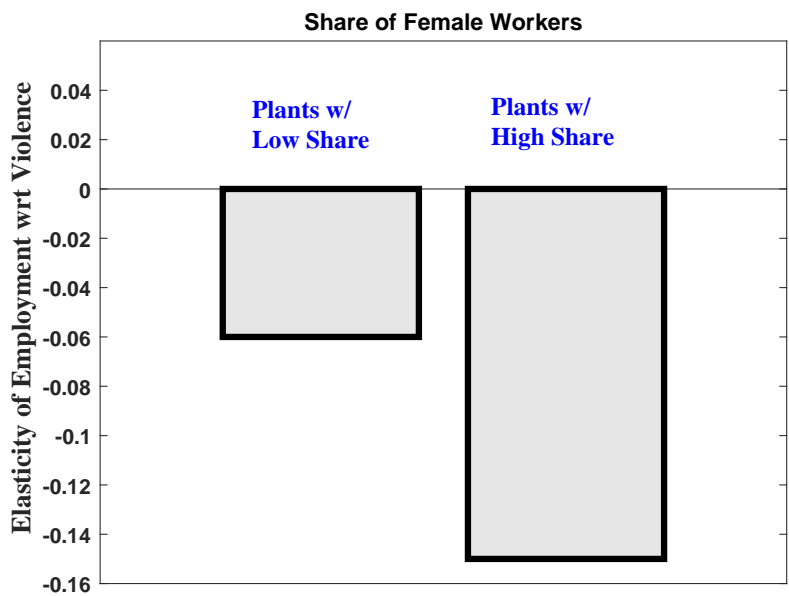

(b) Employment Response depending on the Share Female Workforce

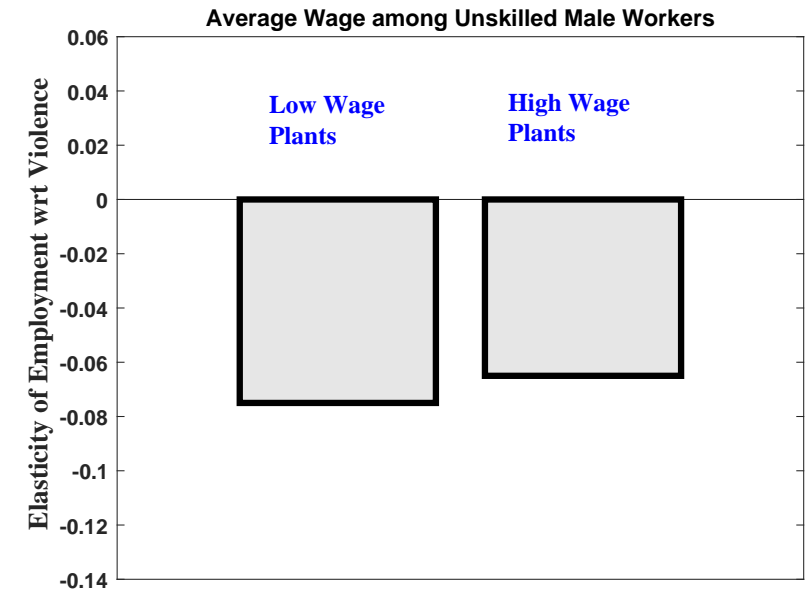

(c) Employment Response depending on Wages of Fe- (d) Employment Response depending on Wages of male Workers Male Workers

Figure 6: Heterogeneity in Employment Response to Drug War Violence

Solid bar frames indicate statistical significance at the $10 \%$ or less. For each figure, estimation is conducted separately depending on the median level of the characteristics written on the top of each figure. All characteristics are the values as of year 2005. All regressions include plant fixed effects, five-digit industry by year fixed effects, and pre-trends in the homicide rate. The log homicide rate is instrumented using equation 2. Full results are shown in Table 8.

time for unskilled male workers. The employment effect of violence is precisely estimated for both groups, and the magnitudes are similar whether plants on average have lower unskilled male wage or not. This once again confirms that the dropping of relatively lower-paid female workers from the labor force is the main driver of the labor market effect of violence on firms. 
Unionization would also be an important factor influencing workers' bargaining power, hence their compensation level and amenities, such as more secure worker transportation and a safer and better protected work environment. Such amenities could help to reduce the impact of violence on workers. Panel $\mathrm{C}$ of Table 8 shows that plants with a higher than median level of unionization rate among their production workers do not experience significant declines in total employment, while plants with a low degree of unionization experience a significant reduction in total employment. For plants with a low degree of unionization, doubling the homicide rate means a $6 \%$ reduction in total employment.

The next section turns the focus to the heterogeneity in output elasticity of violence.

\subsection{Violence-induced Local Demand Shock}

Violence is likely to reduce the size of the market, and this effect is expected to be stronger for firms selling and sourcing locally. Since the first-order effect of a violence-induced demand shock is on output, let us focus in this section on the elasticity of output with respect to a violent environment. Table 9 presents the output elasticity of violence depending on establishment characteristics as of the year 2005 and Figure 7 plots the selective results from this table.

The first panel of Table 9 presents the output elasticity of violence among firms that only sell domestically (non-exporters) and among exporters, and the top left part of Figure 7 plots these results. The output decline due to the drug war is concentrated among domestic sales intensive plants. The estimate of -0.17 implies that doubling the homicide rate decreases the value of output by $12 \%$ for non-exporting plants. The reduction of output among exporters, on the other hand, is close to zero and not statistically significant.

Next, the sample is partitioned depending on whether a plant imports its materials as of 2005 . The estimate of output elasticity is -0.20 versus -0.09 for plants that are not-importers and importers, respectively. Plants that source only domestic inputs experience a $14 \%(=-0.20 \times 70 / 100)$ drop in output due to heightened violence, while the average impact on importing plants is $6 \%$ and significant only at the $10 \%$ level (Table 9 Panel B). 
These results show that domestically selling and sourcing firms reduce their outputs disproportionately, due to the escalation of drug violence. ${ }^{49}$ These results also suggest that the drug violence did not constitute a major problem in transportation since exporters and importers rely more heavily on transporting their goods as they have to reach more distant markets. Just to confirm this, Panel C of Table 9 presents the output elasticity with respect to the local drug-violence depending on the share of freight expenses in total service expenses of plants. ${ }^{50}$ The results show a significant sensitivity of output to the drug-violence regardless of the importance of the transportation expenses. Magnitudewise the effect is larger for non-transportation intensive plants $(-0.19$ versus -0.11$)$. This is likely to be driven by the fact that plants oriented to local markets tend to have lower freight expenses. These results confirm that disruption in transportation is not a major channel through which the Drug War affects firms.

Next, I use the information on plants' sales and materials purchases across different regions in the nation-wide representative ENESTyC data set and construct entropy measures of firm diversification across four-digit industries. The sales diversification measure, which is used in the IO literature (Palepu, 1985; Rumelt, 1982), gets larger the more geographic segments a firm operates in and the less the relative importance of each of the segments in the total sales. It takes zero for non-diversified firms. Similarly, I define materials diversification measures based on the geographic distribution of firms' materials purchases. ENESTyC provides information on plants' sales and procurement of materials across eight mutually exclusive and exhaustive regions worldwide. Mexico as a whole is considered as one market, as there are no details regarding sales and purchases within the domestic market. The idea is that the more diversified a firm is worldwide, the more diversified it is likely to be domestically. Plants are classified as 'diversified' if their entropy index takes a value that is larger than the sample median.

Figure 7c shows that the output elasticity of violence is larger the smaller the geographic diversification of sales. More precisely, doubling the homicide rate leads to a $10 \%(=-0.14 \times 70 / 100)$ decline

\footnotetext{
${ }^{49}$ The analysis using the export and import intensity measures produce similar results and available.

${ }^{50}$ This information, just like the plant-level import information, is obtained from the EIA and hence the estimation sample is somewhat smaller. The EIA-EIM matched sample properties is provided in Appendix C.
} 
in value of production among plants with a lower rate of sales diversification, while the effect is not statistically significant among diversified establishments. Similar results are obtained when focusing on geographic diversification of inputs (Figure 7d or Panel E of Table 9) with less of a stark difference in this case. The output response to drug violence is larger on locally selling and sourcing plants. ${ }^{51}$

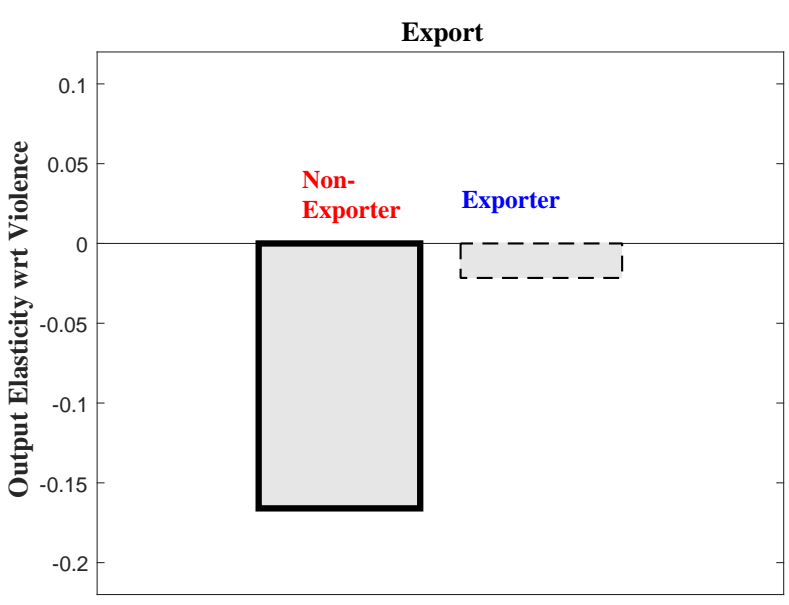

(a) Exporters vs. Non-exporters

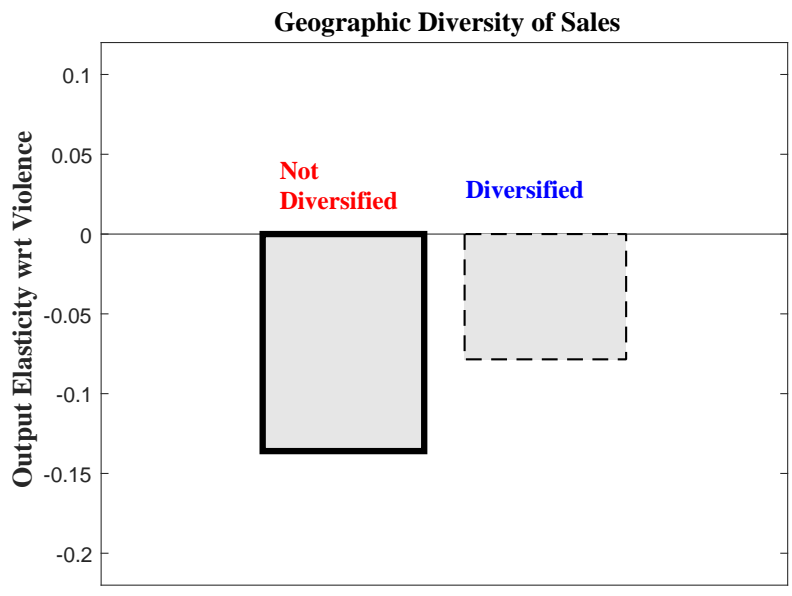

(c) Diversity in Output Markets

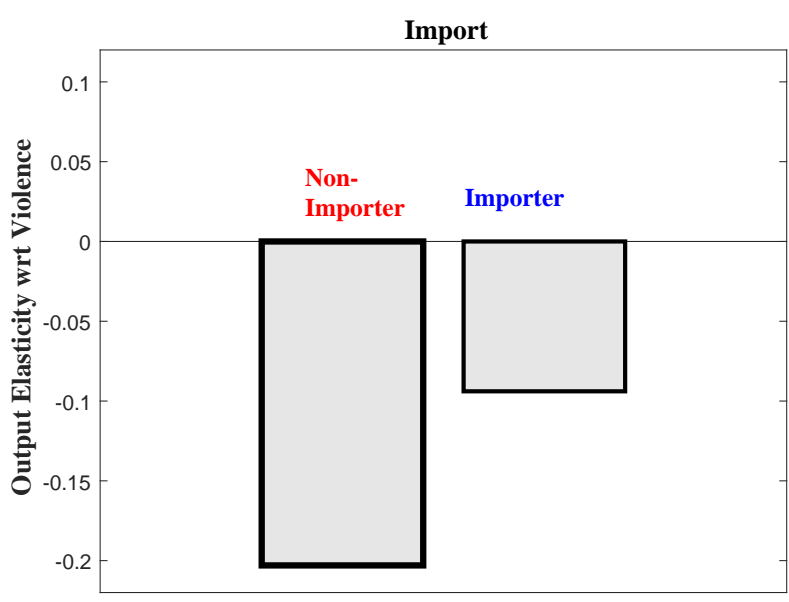

(b) Importers vs. Non-importers

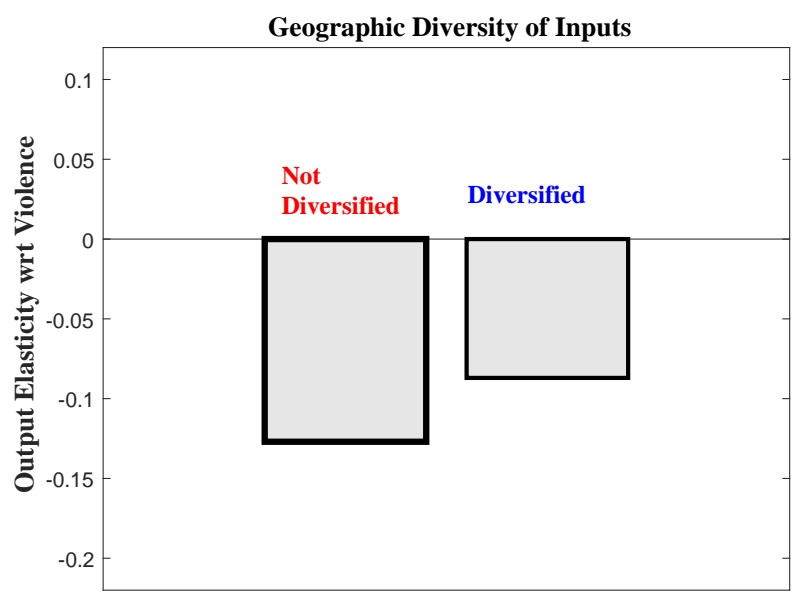

(d) Diversity in Input Markets

Figure 7: Heterogeneity in Output Response to Drug War Violence

Solid bar frames indicate statistical significance at the $10 \%$ or less. For each figure at the bottom part, a separate estimation is conducted depending on the median level of the characteristics written on the top of each figure. For export, the estimations are conducted among exporters and non-exporters, and similarly for import. All characteristics are the values as of year 2005. All regressions include plant fixed effects, five-digit industry by year fixed effects, and pre-trends in the homicide rate. The log homicide rate is instrumented as described in (2). Full results are shown in Table 9.

\footnotetext{
${ }^{51}$ Note that the sample does not include export-processing plants that may entirely supply to and source from the US market.
} 
These results imply that violence distorts the domestic, local market, but not foreign markets, which could happen, for example, by affecting the international transportation of goods. This finding matches with the all-time-high trade by surface transport between the US and Mexico within the Drug War period and provide a rationale behind the media view that despite the escalation of violence in Mexico, the business between the US and Mexico went smoothly (The Economist, June 26, 2010).

Table 9 also shows that the output sensitivity of plants differ widely depending on their technology. Panel F shows that plants with a lower level of capital per worker experienced the bulk of the output decline. Similarly, plants that rely more heavily on labor as measured by an above median level of labor cost-share (share of labor expenses over total non-capital expenses), experience a substantial reduction in output (-0.263), while other plants do not face a significant effect on output. In particular, the estimate of -0.263 implies that doubling of the violence in a metropolitan area leads to an $18 \%$ reduction in the output of labor-intensive plants.

\subsubsection{The Labor Market and Demand Channels Operate Independently}

If firms are more susceptible to the drug war's labor market channel, both their employment and output should decrease disproportionately. However, the other way around does not need to be the case. Firms that are more vulnerable to a violence-induced negative output demand shock do not necessarily have more elastic employment with respect to violence, especially if the demand shock is not perceived as permanent. Panel A of Table 5 presents the disproportionate impact on output, employment, and wages depending on plants' exporting status as of the initial year, 2005. It confirms that the output decreases disproportionately among non-exporters in response to heightened drug violence while exporting does not necessarily shield the plants from the labor supply effects of violence. Exporters and non-exporters are not significantly different from each other in violence's impact on blue-collar employment and wages.

Panel B of Table 5 presents the effect depending on the average wage of unskilled female workers within a plant's four-digit industry. Lower wage plants should experience a disproportionate decline in output too, as they are more vulnerable from the labor supply channel. The results confirm this. Additional results presented in the Appendix (Table B-2) support the conclusion that the two channels 
co-exist.

Together these results show that the Mexican Drug War affects manufacturing via 1) its effect on the local labor force and 2) its effect on local market size or demand. These two channels at the end lead to a strong reallocation within firms and between continuing firms.

Are the effects of the Mexican Drug War so strong that the same channels also operate at the extensive margin, leading to plant exits? In the following, I examine the relationship between heightened conflict due to the Mexican Drug War and the likelihood of plant exit.

\subsection{Drug Violence and Plant Closings}

In this section I study the relationship between the likelihood of exit and the number of homicides per thousand inhabitants in the metropolitan area where a plant is located. Table 6 shows these results. First, I adopt a probit specification that includes three-digit industry by year fixed effects to remove industry-specific business cycles. ${ }^{52}$ Column (1) of Table 6 shows a significant positive impact of the homicide rate on the probability of exit. In column (2) the pre-trends in the homicide rate is included and the impact, although still positive and significant, is lower in magnitude. In columns (3) and (4) initial characteristics of plants (the logarithm of capital per worker, the ratio of IT expenditure over the total expenses, the logarithm of labor productivity, export indicator, and import indicator), and metrolevel controls (employment shares of crop production, precious metal mining, oil and natural gas extraction) are included. The coefficient in column (4) implies that a marginal change in the homicide rate from the average of 0.085 increases the likelihood of plant exit by 1.8 percentage points. In column (5) the homicide rate is instrumented with the Colombian and the Mexican policy triggers of the Drug War in Mexico. The Wald test confirms the endogeneity of the homicide rate (at the ten percent level). The coefficient of interest is still positive and significant, indicating that escalation of violence due to the Drug War leads to plant closings and explains one quarter $(0.007 / 0.028)$ of the plant exits over the period.

\footnotetext{
${ }^{52}$ As exit is a relatively rare event, including five-digit industry by year fixed effects kills much of the identifying variation. As a result, for exit I use three-digit by industry fixed effects.
} 


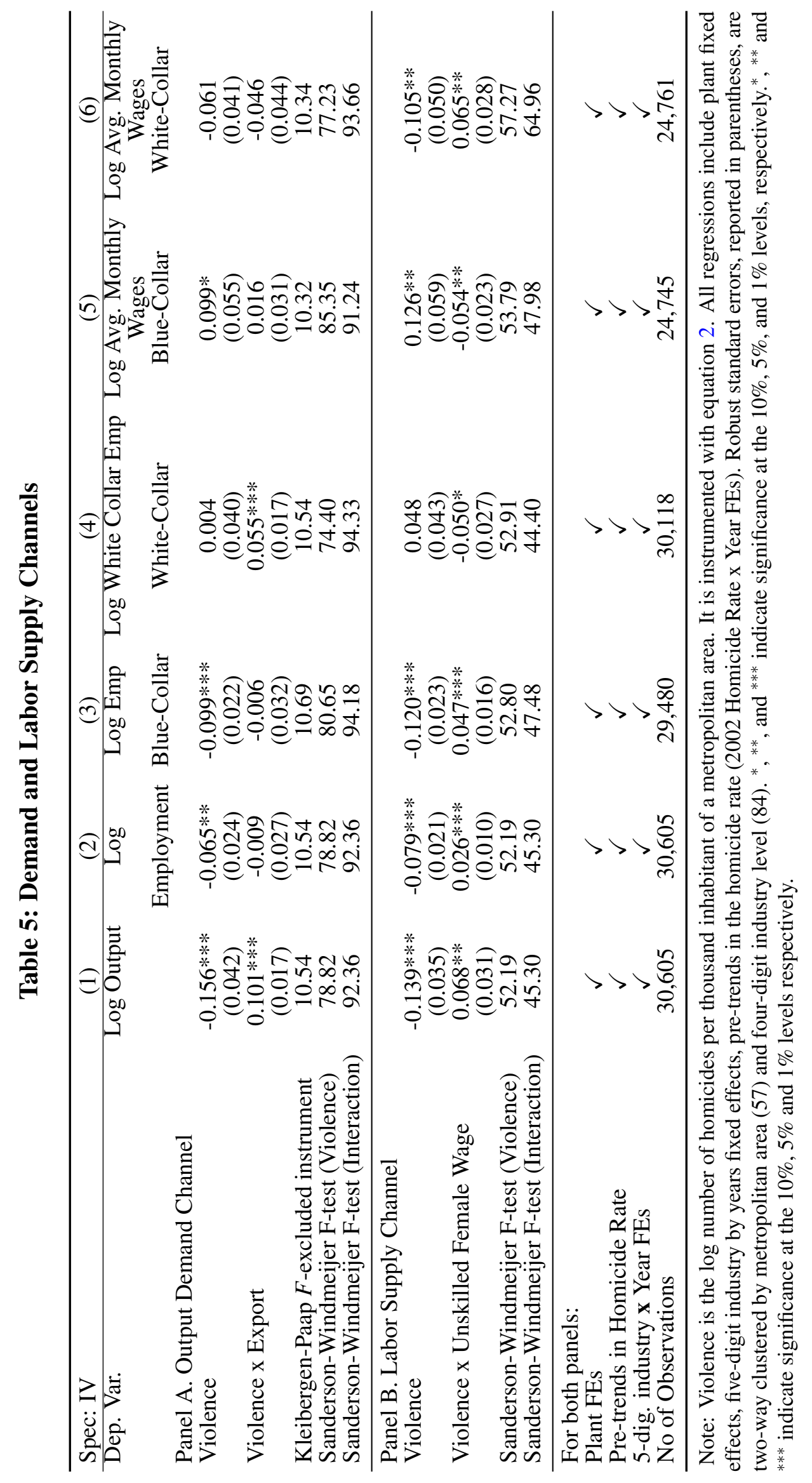


Are all plants equally affected by drug violence in terms of exit probability? The results presented in Table B-3 in the Appendix reveal a heterogeneous impact. ${ }^{53}$ Table B-3 shows that small plants (plants with up to 40 employees) are significantly more vulnerable to the drug war. Plants with a higher ratio of female employees, and low-wage plants are also significantly more likely to exit, which shows that the labor supply channel of the Drug War violence is also operative at the extensive margin. The results also show that being an exporter or importer significantly decreases the impact of the Drug War on exit probability as well as the diversification of sales and materials usage.

In sum, the Mexican Drug War leads to reallocation of resources across heterogenous plants, both at the intensive, and at the extensive margin. Locally sourcing, locally selling and female worker intensive, low-wage plants are especially and badly affected by violence. As the disproportionate impact of the Mexican Drug War was born on plants that tend to be less productive, the aggregate output implications may be limited. But at the same time firms start small and local and the most productive ones grow bigger and become international. By affecting those plants that have potential to be big and diversified, the organized crime related violence is likely to be an important obstacle in the development of domestic industrial capability.

\footnotetext{
${ }^{53}$ Since probit estimation does not allow for plant fixed effects, these results are estimated using a linear probability model.
} 
Table 6: Drug War Leads to Plant Closings

\begin{tabular}{lccccc}
\hline & $(1)$ & $(2)$ & $(3)$ & $(4)$ & $(5)$ \\
Specification: & Probit & Probit & Probit & Probit & IVProbit \\
\hline Violence (Homicide Rate) & $0.447^{* * *}$ & $0.197^{*}$ & $0.253^{* * *}$ & $0.275^{* * *}$ & $1.157^{* * *}$ \\
& $(0.152)$ & $(0.116)$ & $(0.100)$ & $(0.102)$ & $(0.573)$ \\
Marg. Eff. & 0.033 & 0.015 & 0.016 & 0.018 & 0.007 \\
Prob of Exit & 0.033 & 0.033 & 0.028 & 0.028 & 0.028 \\
Plant characteristics & no & no & $\checkmark$ & $\checkmark$ & $\checkmark$ \\
Time-varying Local Market Characs & no & no & no & $\checkmark$ & $\checkmark$ \\
Pre-trends in Violence & no & $\checkmark$ & $\checkmark$ & $\checkmark$ & $\checkmark$ \\
3-dig. industry x Year FE & $\checkmark$ & $\checkmark$ & $\checkmark$ & $\checkmark$ & $\checkmark$ \\
Pseudo $R^{2}$ & 0.067 & 0.068 & 0.065 & 0.065 & \\
Wald test of Exogeneity & & & & & 2.840 \\
p> $\chi^{2}$ & & & & & 0.092 \\
No. of observations & 25,979 & 25,979 & 22,528 & 22,528 & 22,528 \\
\hline
\end{tabular}

Note: "Violence" is measured as the number of homicides per thousand inhabitant in a metropolitan area. The dependent variable in all regressions is plant exit which is an indicator variable that takes 1 if a plant exit the next period, as a result it is not defined in year 2010. "Plant characteristics" include year 2005 values of log capital per worker, IT-intensity, labor productivity, exporter dummy, importer dummy. "Time-varying local market characteristics" include metropolitan area-level employment shares of crop production; metal mining including gold, silver, copper, and uranium; and the metropolitan area-level employment share of oil and natural gas extraction. "Pre-trends in violence" are the 2002 homicide rate interacted with year dummies. Robust standard errors, reported in parentheses, are clustered by metropolitan area $(57) .{ }^{*},{ }^{* *}$, and ${ }^{* *}$ indicate significance at the $10 \%, 5 \%$, and $1 \%$ levels, respectively.

\section{Additional and Robustness Analysis}

In this section, I go over the possible confounding effects and alternative explanations to show that the results stand and are causal. 


\subsection{Recession or Trade-Induced Labor Market Shocks}

The empirical strategy in this paper allows for differential time trends across industries, and the results are also robust to include product-specific business cycles (Table 3, column(5)). However, even within a detailed manufacturing activity, not all plants export or sell domestically. If exporters are more likely to be affected by the Great Recession, as their main market, the US, is heavily affected by the recession, this could lead to a heterogeneous impact of the Great Recession within industries. To investigate if such a channel plays a role in the results, I additionally include differential time trends for exporters, namely the interaction of the exporter dummy with year fixed effects, and estimate Equation 1 by two-stage least squares. The results are presented in Table B-4. They show that differential time trends for exporters do not affect the analysis and indicate that the Great Recession does not confound the estimated effect of violence. In order to confirm, I additionally conduct the analysis using the data from only two years, 2005 and 2010, removing the period of the recession. These results are presented in Table B-5 and they confirm the main findings of the paper.

Another related issue is a potential effect of trade competition during the sample period. If trade competition induces layoffs in a local market, it may increase local violence by lowering the opportunity cost of crime. Several studies show that the rise of China in global trade was an important shock to the US manufacturing sector (Pierce and Schott, 2016; Autor, Dorn, and Hanson, 2013), and Utar and Torres-Ruiz (2013) show that increased competition in the US with China spilled over to Mexico substantially via the US-Mexico production chain. And more recently, Dell, Feigenberg, and Teshima (2018) find that increased competition in the US with China increases drug violence in Mexico. Would such a mechanism affect my results then?

Since the results here are robust to controlling for product by year fixed effects, and my instrument focuses on the spatio-temporal variation in the plausibly exogenous outbreak of violence due to the Mexican Drug War (Dell, 2015), trade-induced labor market changes are not likely affecting my results. Additionally controlling for differential time trends for exporters also indicates that the results in this paper are free from potential confounding effect of trade competition.

To directly address this concern, I construct the trade exposure measure of Dell, Feigenberg, and 
Teshima (2018) in my sample and additionally control for the local trade exposure of metropolitan areas (see Appendix B.4 for details on the construction of trade exposure measures). The results that are presented in Table B-6 show qualitatively similar findings and, magnitude-wise, adding the trade exposure control strengthens the effect of drug-trafficking related violence on plant-level output and employment. In sum, I did not find any evidence that the results are influenced by either trade- or recession-induced employment loss.

\subsection{Firm Selection}

In section 5.3 I show that plants exposed to the violence shock are more likely to exit and the likelihood of exit is stronger if plants are more female-intensive, oriented toward the domestic market, and smaller. In section 5 I also show that conditional on staying in the market, such plants disproportionately downsize. These findings may imply that the true impact of the violence shock at the intensive margin may be underestimated due to selection. To gauge this, I rely on the "identification at infinity" idea (Chamberlain, 1986; Mulligan and Rubinstein, 2008) that the selection bias must be lower for plants with higher survival probability. I restrict the estimation sample to plants with higher survival probability and observe how the estimates change as the plants most likely to exit are dropped from the sample step-by-step. The results, shown in Table B-11 in the Appendix, confirm that the negative effect of violence on output at the intensive margin is partly underestimated due to plant exits. The results in Table B-11 indicate, otherwise, that the effect of selection due to plant exits is limited on the compositional changes within firms.

\subsection{Alternative Specifications}

Alternative instruments to capture drug-related escalation of violence resulting from the

\section{Drug War}

The main variation in the IV strategy in the paper comes from the radical shift in the Mexican government's drug-enforcement strategy. But the time variation in the instrument also comes from the cocaine seizures in Colombia, insofar as these happen after the implementation of the Mexican government's kingpin strategy. A more effective drug-enforcement policy in Colombia during the 
time period led to a shortage in cocaine supply, resulting in increased cocaine prices, fueling the violence in Mexico due to rapacity effect (Castillo, et al. 2020).

Since the decline in Colombian cocaine affects the intensity of violence as it increases the rent opportunities for the DTOs, as an alternative, I use the effect of Colombian drug enforcement developments on cocaine prices directly in my instrument. To do that, I estimated the predicted cocaine prices over the sample period by the Colombian supply developments and interact it with the locations susceptible to the policy intervention. (See Appendix B.5.1 for details.) Thus, I only use the time variation in cocaine prices that is associated with the plausibly exogenous changes in Colombia. ${ }^{54}$ The summary of results from this alternative instrument, including results from additional alternative instruments utilizing the DTO locations as well as the distance of metropolitan areas to the US border are presented in Table B-7 in the appendix. In general, the findings in the paper are robust to these alternative approaches in the empirical strategy.

A Difference-in-differences methodology using a discreet exposure variable In Section 2.4 I classify metropolitan areas as high-intensity drug war areas depending on the rate of increase in violence between 2005/06 and 2008/10. Using this classification as a discrete measure of exposure and the timing of Calderón's presidency, I also run a difference-in differences specification. The results from this exercise, presented in Table B-8, show qualitatively similar findings.

Yet another alternative method to identify causal impact would be to rely on close election results and a regression discontinuity design as in Dell (2015). Municipalities with close election results number only around 150 out of approximately 2,500 municipalities in Mexico, whereas the current analysis covers all metropolitan areas. Since many of the municipalities with close election results are not urban, industrial areas, but small, rural municipalities, limiting the analysis to them lowers the number of observations substantially. Restricting the analysis to these municipalities would also mean giving up the local labor market approach, as municipalities are administrative borders and do

\footnotetext{
${ }^{54}$ Beginning in 2000, Colombia implemented policies aimed at reducing the cultivation of coca together with policies that aimed at preventing drug shipments out of the country (Mejia and Restrepo, 2016a). The efforts were especially effective in declining the cocaine supply during the second half of 2000s. Consequently, the dealer-level price of cocaine per pure gram increased between 2005 and 2010 by $46 \%$ in the US (author's calculation from the National Drug Control Strategy data).
} 
not coincide with commuting patterns.

\section{Results using monthly data}

The main plant-level data set is collected at the monthly frequency, since addressing my question does not require a high-frequency data analysis and the supplemental data used in the analysis only available at the annual frequency, I conduct the analysis with the annual data. For robustness, I also conduct the main analysis with the monthly plant-level data. Equation 1 is estimated by two-stage least squares with the same instrument as described in (2) except now the Colombian cocaine seizures data reported at the monthly frequency are used. As before, both the homicide rate and the cocaine seizures are lagged six months. Table B-9 in the Appendix present these results. They show very similar findings.

\section{Conclusion}

To shed light on how violence and organized crime affect urban and industrial development, I study firm-level consequences of drug-trade related violence. Exploiting the sudden, unanticipated, and geographically heterogeneous surge in organized crime and violence in Mexico during the late 2000s, and employing longitudinal plant-level data from all metropolitan areas of Mexico, I show that violence causes significant decline in plant-level output, employment, product scope, and the capacity utilization of Mexican manufacturing plants.

A violent environment affects relatively unskilled, lower-paid, female production workers more, and manifests as a negative unskilled labor supply shock, pushing up the relative wages of unskilled workers and the skill intensity of manufacturing establishments. Thus, in response to the violenceinduced labor supply shock, firms adjust by using the relatively abundant type of labor more intensively. Labor-intensive establishments with workforce compositions intensive in female, lower-wage, and not unionized workers are disproportionately affected by this channel and experience a stronger decline in employment. These results suggest that there are important distributional and inequality consequences of the recent rise of violence in Mexico. At the same time, local violence reduces domestic but not international demand. As a result, plants that are intensive in export and import 
are shielded from violence-induced negative demand shocks and the resulting declines in output and product scope.

At the extensive margin, the Mexican Drug War causes plant closings; the survival likelihood of plants decreases, especially if they are smaller, female-intensive, domestically selling and sourcing plants. Overall, the results show that both at the intensive and at the extensive margin, disruptions in the local labor supply and local demand are important channels in which violence affects firms.

The Mexican Drug War significantly hinders development of domestic industrial capability by taking away resources from locally sourcing and selling plants, as well as plants with a femaleintensive workforce, and re-allocating resources toward international markets oriented, diversified, and bigger plants. While the short-run aggregate output effects of the violence may be mitigated by this reallocation, the results suggest potentially important long run effects on the development of domestic industrial capability. And the findings may explain why the violent drug war in Mexico has received relatively little international attention and has not significantly deterred foreign investment.

\section{References}

Ajzenman, N., Galiani, S., and Seira, E. 2015. "On the Distributive Costs of Drug-Related Homicides", Journal of Law and Economics, 58(4): 779-803.

Abadie, Alberto and Javier Gardeazabal 2003. "The Economic Costs of Conflict: A Case Study of the Basque Country", American Economic Review, 93(1): 113-132.

Acemoğlu, Daron, and Melissa Dell 2010. "Productivity Differences Between and Within Countries", American Economic Journal: Macroeconomics, 2(1), 169-188.

Acemoğlu, Daron, Giuseppe De Feo, and Giacomo De Luca 2020. "Weak States: Causes and Consequences of the Sicilian Mafia”, Review of Economic Studies, 87(2):537-581.

Alesina, Alberto , Salvatore Piccolo, and Paolo Pinotti 2018. "Organized Crime, Violence, and Politics", The Review of Economic Studies, rdy036.

Amodio, Francesco and Michele Di Maio 2018. "Making Do With What You Have: Conflict, Input Misallocation and Firm Performance", The Economic Journal, 128(615): 2559-2612.

Angrist, Joshua D. and Adriana D. Kugler 2008. "Rural Windfall Or A New Resource Curse? Coca, Income, and Civil Conflict in Colombia", The Review of Economics and Statistics, 90(2): 191-215.

Ashby, Nathan and Ramos, Miguel 2013. "Foreign direct investment and industry response to organized crime: The Mexican case", European Journal of Political Economy, 30(C):80-91. 
Autor, David, David Dorn, and Gordon Hanson. 2013. "The China Syndrome: Local Labor Market Effects of Import Competition in the United States", American Economic Review, 103(6): 21212168.

Bagley, Bruce M. and Rosen, Jonathan D. 2015. Drug Trafficking, Organized Crime, and Violence in the Americas Today. Gainesville: University Press of Florida.

Bazzi, Samuel, Sarah Burns, Gordon Hanson, Bryan Roberts, and John Whitley. 2018. "Deterring Illegal Entry: Migrant Sanctions and Recidivism in Border Apprehensions", NBER WP No. 25100 .

Bloom, Nicholas 2009. "The Impact of Uncertainty Shocks", Econometrica, 77: 623-685.

Brueckner, Jan K., Jacques-François Thisse, and Yves Zenou 2002. "Local Labor Markets, Job Matching, And Urban Location”, International Economic Review, 43: 155-171.

Cardona, Julian 2010. "Poor Mexicans easy scapegoats in vicious drug war", World News October 7, 2010, Reuters.

Caselli, Francesco 2005. "Accounting for Cross-Country Income Differences", Handbook of Economic Growth, in: Philippe Aghion \& Steven Durlauf (ed.), Handbook of Economic Growth, edition 1, volume 1, chapter 9, pp. 679-741 Elsevier.

Castillo, Juan Camili, Daniel Mejia, and Pacual Restrepo 2020. "Scarcity without Leviathan: The Violent Effects of Cocaine Supply Shortages in the Mexican Drug War", The Review of Economics and Statistics, 102(2): 269-286.

Chabat, Jorge 2010. "Combatting Drugs in Mexico under Calderon: The Inevitable War", Centro de Investigación y Docencia Económicas, División de Estudios Internacionales.

Chamberlain, Gary 1986. "Asymptotic efficiency in semi-parametric models with censoring", Journal of Econometrics, 32(2):189-218.

Cockburn, Andrew 2015. "The Kingpin Strategy.” Huffington Post April 28.

Dell, Melissa. 2015. "Trafficking Networks and the Mexican Drug War.", American Economic Review, 105(6): 1738-79.

Dell Melissa, Ben Feigenberg, and Kensuke Teshima 2019. “ The Violent Consequences of TradeInduced Worker Displacement in Mexico", American Economic Review: Insight, 1(1):43-58.

Dix-Carneiro, Rafael, Rodrigo Soares and Gabriel Ulyssea 2018. "Economic Shocks and Crime: Evidence from the Brazilian Trade Liberalization", American Economic Journal: Applied Economics, 10(4):158-195.

Draca, Mirko and Stephen Machin 2015. "Crime and Economic Incentives", Annual Review of Economics, 7:389-408.

Dube, Oeindrila and Juan F. Vargas 2013. "Commodity Price Shocks and Civil Conflict: Evidence from Colombia”, Review of Economic Studies 80, 1384-1421. 
Dustmann, Christian and Albrecht Glitz 2015. "How Do Industries and Firms Respond to Changes in Local Labor Supply?", Journal of Labor Economics, 33(3):711-750.

Enamorado, Ted, Luis F. López-Calva, and Carlos Rodríguez-Castelán 2014. "Crime and growth convergence: Evidence from Mexico", Economics Letters, 125(1): 9-13.

Feler, Leo and Mine Senses 2017. "Trade Shocks and the Provision of Local Public Goods", American Economic Journal: Applied Economics, 9(4):101-143.

Finckenauer, James O., Joseph, R. Fuentes, George L. Ward 2001. "Mexico and the United States: neighbors confront drug trafficking.", National Institute of Justice Publications. 2001

Grayson, George W 2013. “The Impact Of President Felipe Calderón's War On Drugs On The Armed Forces: The Prospects For Mexico's “Militarization" and Bilateral Relations", The Strategic Studies Institute, U.S. Army War College.

Guerrero-Gutiérrez, Eduardo 2011. "Security, Drugs, And Violence In Mexico: A Survey”, 7th North American Forum, Washington DC.

Guidolin, Massimo and Eliana La Ferrara 2007. "Diamonds Are Forever, Wars Are Not: Is Conflict Bad for Private Firms?” American Economic Review 97(5): 1978-1993.

Jarillo, Brenda, Beatriz Magaloni, Edgar Franco and Gustavo Robles 2016. "How the Mexican drug war affects kids and schools? Evidence on effects and mechanisms", International Journal of Educational Development, 51:135-146.

Keane, Michael P. 2011. "Labor Supply and Taxes: A Survey.", Journal of Economic Literature, 49 (4): 961-1075.

Klapper, Leora, Christine Richmond, and Trang Tran 2015. "Civil Conflict and Firm Performance: Evidence from Côte d'Ivoire", unpublished manuscript.

Kilmer, Beau, Susan S. Sohler Everingham, Jonathan P. Caulkins, Gregory Midgette, Rosalie Liccardo Pacula, Peter Reuter, Rachel M. Burns, Bing Han, and Russell Lundberg 2014. "What America's Users Spend on Illegal Drugs: 2000-2010”, Santa Monica, CA: RAND Corporation, RR534-ONDCP.

Ksoll, Christopher, Rocco Macchiavello, and Ameet Morjaria, 2016. "Guns and Roses: Flower Exports and Electoral Violence in Kenya", working paper.

La Botz, Dan 2011. “Mexico's Drug War Wreaks Havoc on Workers”, Labor Notes, January 03, 2011.

Lindo, Jason M. and María Padilla-Romo 2018. "Kingpin Approaches to Fighting Crime and Community Violence: Evidence from Mexico's Drug War", Journal of Health Economics, Elsevier, vol. 58(C):253-268.

Martin, Philippe, Mathias Thoenig, and Thierry Mayer 2008. "Civil Wars and International Trade", Journal of the European Economic Association, 6:541-550. 
Mejia, Daniel and Pascual Restrepo 2016a. "The Economics of War on Illegal Drug Production and Trafficking", Journal of Economic Behavior and Organizations, 126(PA): 255-275.

Mejia, Daniel and Pascual Restrepo 2016b. "Crime and conspicuous consumption", Journal of Public Economics, 135(C):1-14.

Melnikov, Nikita, Carlos Schmidt-Padilla and María Micaela Sviatschi 2019. "Gangs, Labor Mobility, and Development", working paper.

McLaren, John, 2008. "Globalization and Civil War”, mimeo, University of Virgnia.

Mora Edwin, 2009. Civilians ran a greater risk of being killed in Juárez last year than in Baghdad. CNS News, Mar 5.

Mulligan, Casey B. and Yona Rubinstein 2008. "Selection, Investment, and Women's Relative Wages over Time", The Quarterly Journal of Economics, 123(3):1061-1110.

National Drug Assessment Report 2011. U.S. Department of Justice, National Drug Intelligence Center.

Palepu, Krishna 1985. "Diversification Strategy, Profit Performance and the Entropy Measure", Strategic Management Journal, 6:239-255.

Pierce, Justin R. and Peter K. Schott 2016. “The Surprisingly Swift Decline of U.S. Manufacturing Employment", American Economic Review, 106(7): 1632-62.

Pinotti, Paolo 2015. "The economic costs of organised crime: Evidence from Southern Italy", The Economic Journal, 125(586):F203-F232.

Raphael and Winter-Ebmer 2001. "Identifying the Effect of Unemployment on Crime", The Journal of Law \& Economics , 44(1):259-283.

Robles, Gustavo, Gabriela Calderón, and Beatriz Magaloni "The Economic Consequences of Drug Trafficking Violence in Mexico”, mimeo, Stanford University.

Rozo, Sandra V. 2018. "Is Murder Bad for Business? Evidence from Colombia", The Review of Economics and Statistics, 100(5):769-782.

Rumelt, Richard P. 1982. "Diversification strategy and profitability", Strategic Management Journal, 3:359-369.

UNODC (United Nations Office on Drugs and Crime). 2014. Cocaine Retail Prices (Street Prices), USD Per Gram. Technical Report. New York. Accessed June 13, 2017.

Utar, Hale, and Luis B. Torres Ruiz 2013. "International Competition and Industrial Evolution: Evidence from the Impact of Chinese Competition on Mexican Maquiladoras", Journal of Development Economics, 105: 267-287.

Velasquez, Andrea 2020. “The Economic Burden of Crime: Evidence from Mexico”, The Journal of Human Resources, 55(4): 1287-1318.

Williams, Phil 2012. “The Terrorism Debate Over Mexican Drug Trafficking Violence”, Terrorism and Political Violence, 24:2, 259-278. 
World Bank (2011). Crime and Violence in Central America: A Development Challenge. Washington DC: World Bank

World Drug Report (2010). United Nations Office on Drugs and Crime (UNODC), United NationsPublication, Sales No. E.10.XI.13. 
Table 7: Violence As a Negative Supply Shock of Blue-Collar Workers

(1)

(2)

(3)

(4)

Panel A. Both payroll and indirect employees

\begin{tabular}{lcccc} 
Dependent variable & $\begin{array}{c}\text { Blue-Collar } \\
\text { workers }\end{array}$ & $\begin{array}{c}\text { White-Collar } \\
\text { workers }\end{array}$ & $\begin{array}{c}\text { Blue-Collar } \\
\text { hours }\end{array}$ & $\begin{array}{c}\text { White-Collar } \\
\text { hours }\end{array}$ \\
\hline Violence & $-0.101 * * *$ & 0.028 & $-0.102 * * *$ & 0.047 \\
& $(0.023)$ & $(0.036)$ & $(0.030)$ & $(0.047)$ \\
No. of observations & 29,480 & 30,118 & 29,658 & 25,071 \\
$F$-excluded instrument & 21.45 & 21.20 & 20.29 & 23.25 \\
\hline
\end{tabular}

Panel B. Employees on payroll

Dependent variable Blue-Collar White-Collar Blue-Collar White-Collar

\begin{tabular}{lcccc} 
& workers & workers & hours & hours \\
\hline Violence & $-0.119 * * *$ & -0.039 & $-0.112 * * *$ & 0.008 \\
& $(0.029)$ & $(0.034)$ & $(0.028)$ & $(0.036)$ \\
No. of observations & 26,186 & 25,846 & 25,595 & 21,148 \\
$F$-excluded instrument & 21.10 & 21.39 & 20.25 & 23.47 \\
\hline
\end{tabular}

Panel C. Monthly wages

Dependent variable Avg wage Avg wage Blue-Collar White-Collar

\begin{tabular}{lcccc} 
& & on payroll & avg wage & avg wage \\
\hline Violence & -0.023 & 0.013 & $0.106^{* *}$ & $-0.080^{*}$ \\
& $(0.019)$ & $(0.021)$ & $(0.052)$ & $(0.047)$ \\
No. of observations & 29,992 & 26,077 & 24,745 & 24,761 \\
F-excluded instrument & 20.74 & 20.90 & 20.66 & 20.74 \\
\hline
\end{tabular}

Panel D. Skill intensity and growth rates

Dependent variable Skill intensity Employment Blue Collar White Collar

\begin{tabular}{lcccc} 
& $\left(\frac{\text { NonProduction }}{\text { TotEmp }}\right)$ & Growth & Growth & Growth \\
\hline Violence & $0.017^{* *}$ & -0.032 & -0.062 & -0.014 \\
& $(0.007)$ & $(0.028)$ & $(0.038)$ & $(0.072)$ \\
No. of observations & 30,605 & 24,926 & 24,090 & 24,559 \\
F-excluded instrument & 33.24 & 27.17 & 26.46 & 27.48 \\
\hline
\end{tabular}

Note: All estimations are by 2SLS using the instrument as described in Section 3. "Violence" is measured as the logarithm of the number of homicides per thousand inhabitant of a metropolitan area. All dependent variables are in logarithmic form except the dependent variables in Panel D. "Skill intensity," is the ratio of total number of white-collar employees over the total employment. All regressions include plant fixed effects, five-digit industry by year fixed effects, and the pre-trends in the homicide rate per metropolitan area. Robust standard errors, reported in parentheses, are clustered two-way by metropolitan area and industry. *, ${ }^{* *}$, and ${ }^{* * *}$ indicate significance at the $10 \%, 556$ and $1 \%$ levels, respectively. 


\section{Table 8: Heterogeneity in Employment Elasticity of Violence}

\begin{tabular}{lcc} 
Dependent Variable for all regressions: Log Total Employment & & \\
Partition variable & Low & High \\
Panel A. Log monthly wage $(\mathrm{p} 50=9.14)$ & $<=p 50$ & $>p 50$ \\
\hline Violence & $-0.119^{* *}$ & -0.032 \\
& $(0.048)$ & $(0.030)$ \\
N & 14,173 & 14,220 \\
First-stage F-test & 15.50 & 25.83 \\
Panel B. Share of unionized production workers $(\mathrm{p} 50=0.35)$ & $<=p 50$ & $>p 50$ \\
\hline Violence & $-0.107 * * *$ & -0.030 \\
& $(0.030)$ & $(0.026)$ \\
N & 15,333 & 15,159 \\
First-stage F-test & 18.48 & 23.98 \\
Panel C. Female workforce share $(\mathrm{p} 50=0.20)$ & $<=p 50$ & $>p 50$ \\
\hline Violence & $-0.059 * *$ & $-0.154 * *$ \\
& $(0.026)$ & $(0.077)$ \\
N & 13,303 & 13,273 \\
First-stage F-test & 25.40 & 14.04 \\
Panel D. Unskilled female production wage $(\mathrm{p} 50=70,000$ peso $)$ & $<=p 50$ & $>p 50$ \\
\hline Violence & $-0.108^{* * *}$ & -0.004 \\
First-stage F-test & $(0.023)$ & $(0.029)$ \\
Panel E. Unskilled male production wage $(\mathrm{p} 50=613,000$ peso $)$ & $<=p 50$ & $>p 50$ \\
\hline Violence & 15,550 & 14,942 \\
N & 22.56 & 17.73 \\
\hline & $-0.075^{* * *}$ & $-0.065 * *$ \\
& $(0.023)$ & $(0.029)$ \\
& 16,639 & 13,853 \\
& 16.63 & 25.66 \\
\hline
\end{tabular}

Note: Each cell shows the 2SLS estimation of the log homicide rate on the logarithm of the total number of employees when the sample is partitioned according to the value of the variable on the left in the respective row. All characteristics are from the start of the period (2005). Each regression includes plant fixed effects, five-digit industry by year fixed effects, and the pre-trends. Unionization and unskilled wage data are from ENESTyC, female workforce information is from EIA. Robust standard errors, reported in parentheses, are clustered two-way by metropolitan area (57) and industry (84). ${ }^{*}, * *$, and ${ }^{* * *}$ indicate significance at the $10 \%, 5 \%$, and $1 \%$ levels, respectively. 
Table 9: Heterogeneity in Output Elasticity of Violence

\begin{tabular}{|c|c|c|}
\hline \multicolumn{3}{|c|}{ Dependent Variable for all regressions: Log value of output } \\
\hline \multirow[t]{2}{*}{ Partition variable } & Low & High \\
\hline & $<=p 50$ & $>p 50$ \\
\hline Panel A. Exporters versus Non-exporters & Non-Exporters & Exporters \\
\hline \multirow[t]{2}{*}{ Violence } & $-0.166 * * *$ & -0.022 \\
\hline & $(0.050)$ & $(0.039)$ \\
\hline $\mathrm{N}$ & 19,775 & 10,830 \\
\hline Panel B. Importers versus Non-importers & Non-importers & Importers \\
\hline \multirow[t]{2}{*}{ Violence } & $-0.203^{* * *}$ & $-0.094 *$ \\
\hline & $(0.071)$ & $(0.050)$ \\
\hline $\mathrm{N}$ & 13,775 & 13,145 \\
\hline Panel C. Transport-Intensive Plants & $<=p 50$ & $>p 50$ \\
\hline \multicolumn{3}{|c|}{ Share of Freight Expenses in Service Expenses (p50=0.08) } \\
\hline \multirow[t]{2}{*}{ Violence } & $-0.194 * * *$ & $-0.105^{* *}$ \\
\hline & $(0.071)$ & $(0.042)$ \\
\hline $\mathrm{N}$ & 13,387 & 13,387 \\
\hline \multicolumn{3}{|l|}{ Panel D. Geog. diversity of sales $(\mathrm{p} 50=0.14)$} \\
\hline \multirow[t]{2}{*}{ Violence } & $-0.136 * * *$ & -0.078 \\
\hline & $(0.040)$ & $(0.052)$ \\
\hline $\mathrm{N}$ & 15,426 & 15,179 \\
\hline \multicolumn{3}{|c|}{ Panel E. Geog. diversity of materials (p50=0.21) } \\
\hline \multirow[t]{2}{*}{ Violence } & $-0.127 * * *$ & $-0.087 *$ \\
\hline & $(0.045)$ & $(0.045)$ \\
\hline $\mathrm{N}$ & 15,407 & 15,198 \\
\hline \multicolumn{3}{|l|}{ Panel F. Log Capital per Worker (p50=4.86) } \\
\hline \multirow[t]{2}{*}{ Violence } & $-0.179 * * *$ & $-0.084 * *$ \\
\hline & $(0.058)$ & $(0.032)$ \\
\hline $\mathrm{N}$ & 13,282 & 13,275 \\
\hline \multicolumn{3}{|c|}{ Panel G. Labor Share in Non-Capital Expenses (p50=0.17) } \\
\hline \multirow[t]{2}{*}{ Violence } & -0.019 & $-0.263 * * *$ \\
\hline & $(0.032)$ & $(0.090)$ \\
\hline $\mathrm{N}$ & 13,401 & 13,399 \\
\hline
\end{tabular}

Note: Each panel shows the 2SLS estimations of the log homicide rate on the logarithm of the value of production when the sample is partitioned according to the value of the variable on the left in the respective row. All characteristics are from the start of the period (2005). Each regression includes plant fixed effects, five-digit industry by year fixe 58 ffects, and the pre-trends. Robust standard errors, reported in parentheses, are clustered two-way by metropolitan area (57) and industry (84). ${ }^{*},{ }^{* *}$, and *** indicate significance at the $10 \%, 5 \%$, and $1 \%$ levels, respectively. The charactersitics in Panels B, $\mathrm{C}, \mathrm{F}$, and $\mathrm{G}$ are from the EIA and the estimation is conducted among the EIA-EIM matched sample. 


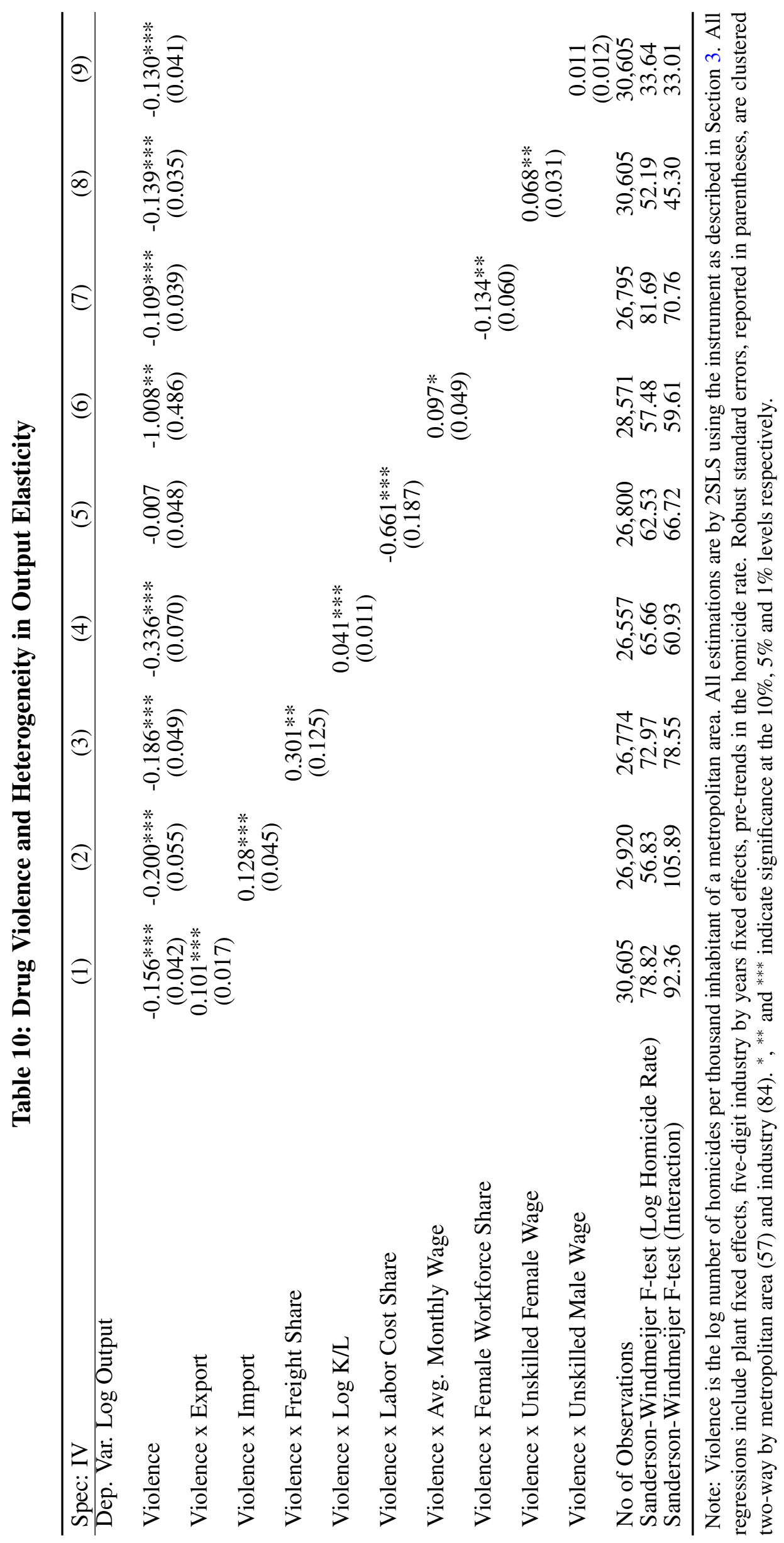




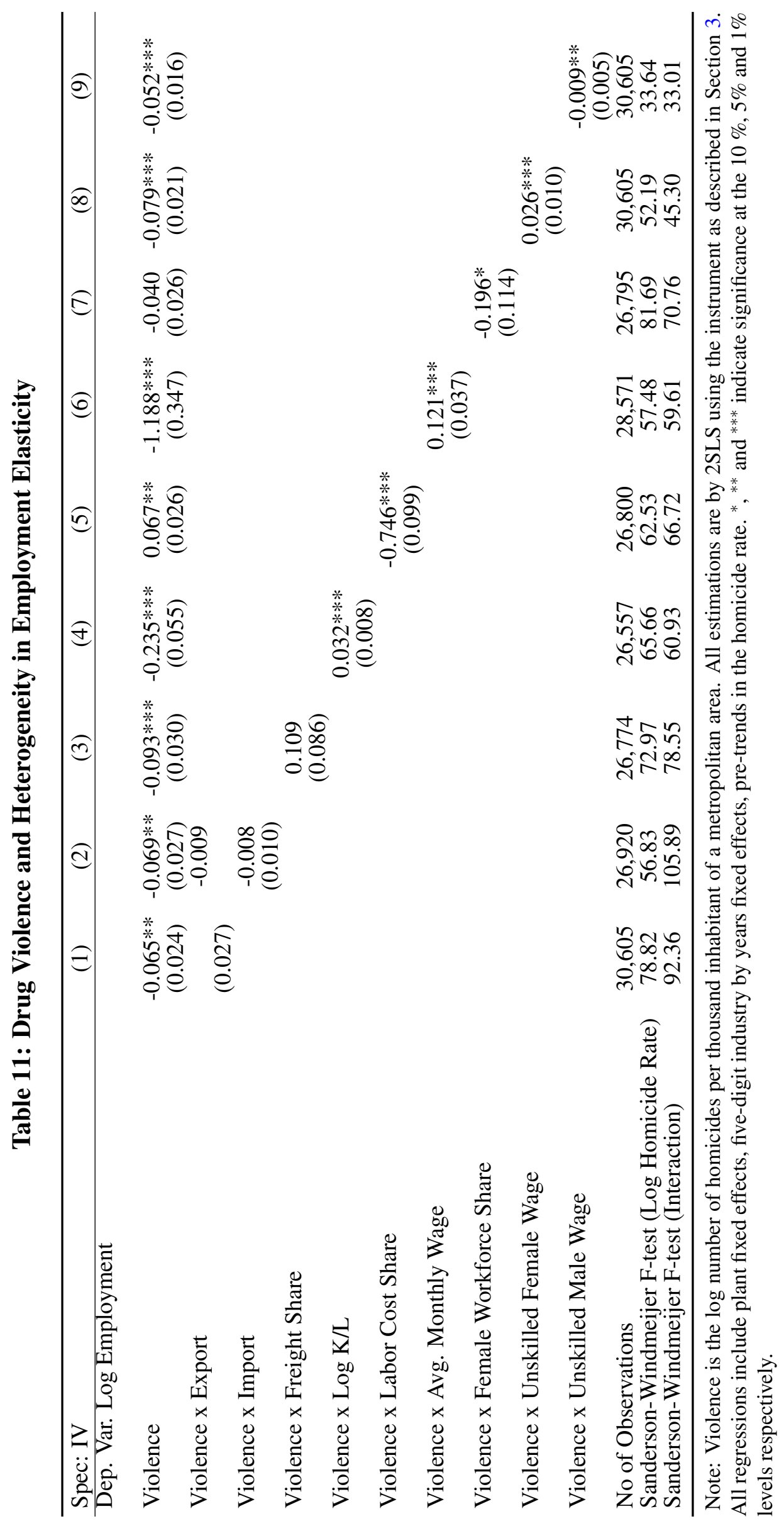




\title{
Appendix:
}

"Firms and Labor in Times of Violence"

\author{
Hale Utar
}

December 3, 2020 


\section{Contents (Appendix)}

$\begin{array}{ll}\text { A Summary Statistics and Descriptive Analysis } & 1\end{array}$

A.1 Summary Statistics . . . . . . . . . . . . . . . . . . . . 1

A.2 The Drug War in Mexico . . . . . . . . . . . . . . . . . . . 8

A.3 Military Interventions . . . . . . . . . . . . . . . . . . . . . . 9

A.4 Migration patterns . . . . . . . . . . . . . . . . . 11

A.5 Manufacturing employment across selected metropolitan areas . . . . . . . . . . 12

B Robustness and Additional Analysis $\quad 13$

B.1 Additional Results . . . . . . . . . . . . . . . . . . . . . . 13

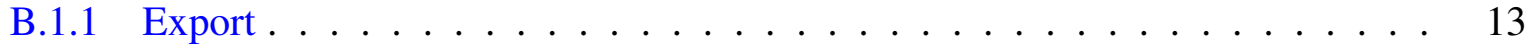

B.1.2 Heterogeneity across Firms . . . . . . . . . . . . . . . 15

B.1.3 Plant Exit . . . . . . . . . . . . . . . . 15

B.2 Differential Time Trends for Exporters . . . . . . . . . . . . . . . . 15

B.3 Analysis with only data from 2005 and $2010 \ldots \ldots$. . . . . . . . . . . 15

B.4 Violence Outbreak and Trade Shocks . . . . . . . . . . . . . . . . . . . 15

B.5 Alternative Specifications . . . . . . . . . . . . . . . . . . 19

B.5.1 Alternative Instruments . . . . . . . . . . . . . . . . . 19

B.5.2 A Difference-in-Differences Specification . . . . . . . . . . . . . . . 24

B.6 Analysis with the Monthly Data . . . . . . . . . . . . . . . 25

B.7 Metropolitan Area Level Security Expenses . . . . . . . . . . . . . . . . . . . . 27

B.8 Plant Exit and the Impact at the Intensive Margin . . . . . . . . . . . . . . . . 28

$\begin{array}{ll}\text { C Data Appendix } & 30\end{array}$

C.1 Plant-level Data . . . . . . . . . . . . . . . . . . . 30

C.2 Spatial and Regional Data . . . . . . . . . . . . . . . . 33

C.3 Time-Series data . . . . . . . . . . . . . . . . . . 35 
C.4 Construction of Variables . . . . . . . . . . . . . . . . . . . . 36 


\title{
A Summary Statistics and Descriptive Analysis
}

\section{A.1 Summary Statistics}

\author{
Table A-1: Summary Statistics
}

\begin{tabular}{lcccc}
\hline & Mean & Median & StDev & N \\
& & & & \\
\hline Number of Employees & 238.364 & 99.833 & 491.393 & 30,605 \\
Number of Blue-Collar Employees & 159.559 & 64.667 & 322.900 & 30,605 \\
Number of White-Collar Employees & 71.924 & 22.917 & 229.183 & 30,605 \\
Number of Days Worked & 280.482 & 295 & 55.582 & 30,605 \\
Capacity Utilization Rate & 70.230 & 75 & 21.110 & 29,926 \\
Number of Varieties & 3.126 & 2 & 3.023 & 30,605 \\
Log Value of Output & 11.254 & 11.272 & 2.048 & 30,605 \\
Log Value of Domestic Sales & 11.035 & 11.060 & 2.022 & 30,293 \\
Log Value of Foreign Sales & 10.236 & 10.405 & 2.570 & 10,812 \\
Share of Foreign Sales & 0.111 & 0 & 0.237 & 30,605 \\
\hline
\end{tabular}

Note: All values are expressed in 2010 thousand Mexican peso. Table shows the summary statistics of main variables in the estimation sample (metropolitan areas). Source: EIMA, INEGI. 


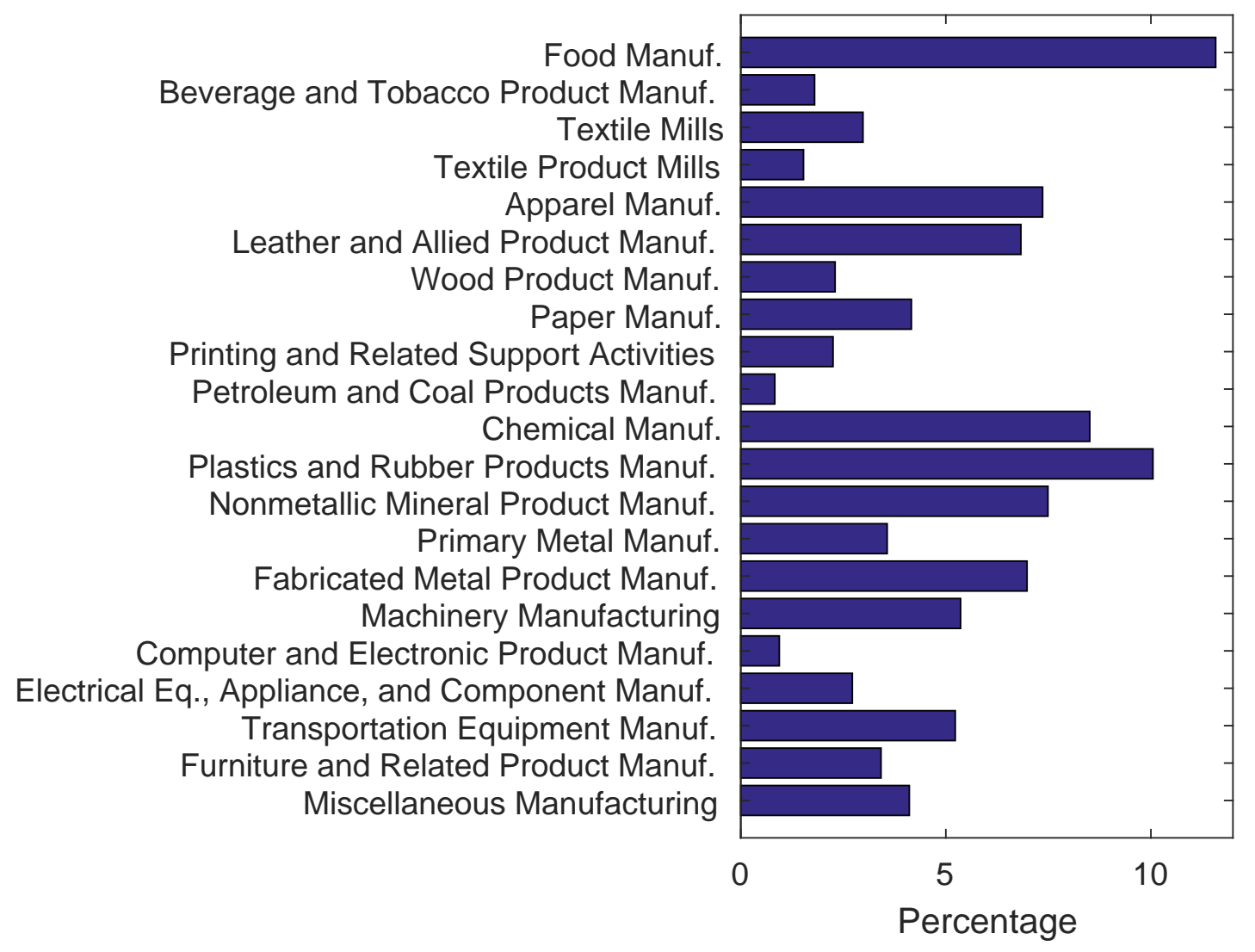

Figure A-1: Distribution of Number Plants across Three-Digit Industries

Figure shows the year 2005 distribution of plants in the estimation sample across the three-digit NAICS industries. 


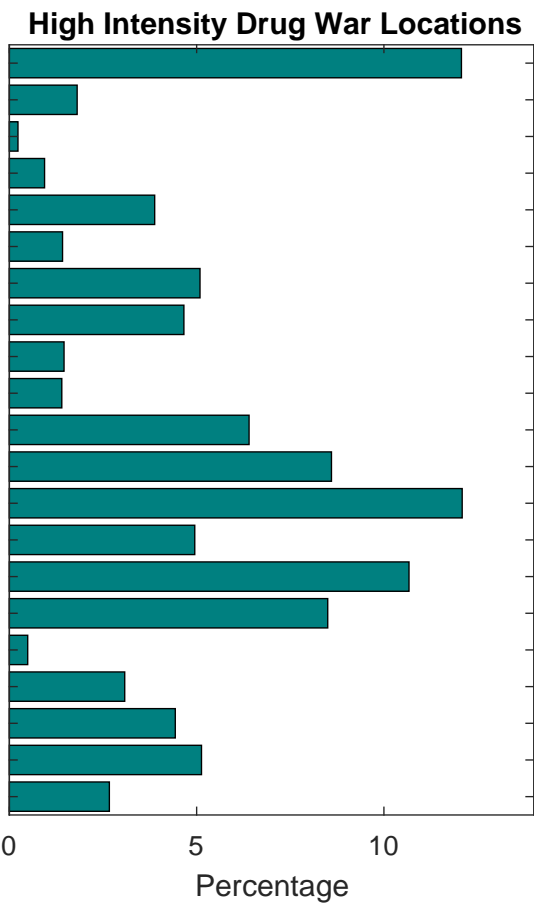

Food Manuf.

Beverage and Tobacco Product Manuf.

Textile Mills

Textile Product Mills

Apparel Manuf.

Leather and Allied Product Manuf.

Wood Product Manuf.

Paper Manuf.

Printing and Related Support Activities

Petroleum and Coal Products Manuf.

Chemical Manuf.

Plastics and Rubber Products Manuf.

Nonmetallic Mineral Product Manuf.

Primary Metal Manuf.

Fabricated Metal Product Manuf.

Machinery Manufacturing

Computer and Electronic Product Manuf.

Electrical Eq., Appliance, and Component Ma

Transportation Equipment Manuf.

Furniture and Related Product Manuf.

Miscellaneous Manufacturing

Percentage

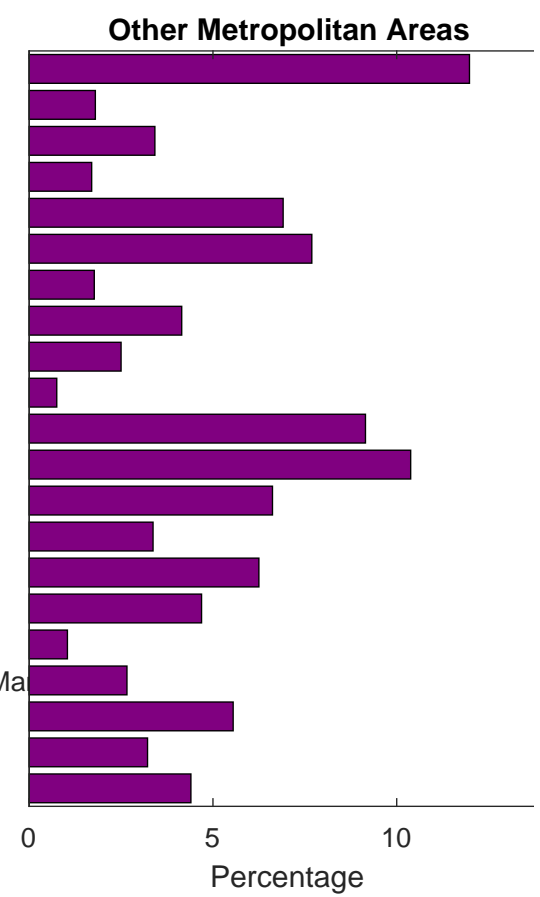

Figure A-2: Distribution of Number Plants across Three-Digit Industries by Exposure

Figure shows the year 2005 distribution of plants in the estimation sample across the three-digit NAICS industries across 'High Intensity Drug War Zones' and 'Other Metropolitan Areas'. High Intensity Drug War Zones are the following metropolitan areas: Acapulco, Chihuahua, Juárez, La Laguna, Monterrey, and Tijuana. 
Table A-2: Pairwise Correlation of Pre-War Municipality Characteristics and Post-War Violence

\begin{tabular}{lcc}
\hline Municipality Characteristics & Correlation Coefficient & Nobs \\
& & \\
\hline Manufacturing Share in overall economy & 0.034 & 2,222 \\
Log Output per Worker & $0.081^{*}$ & 2,366 \\
Log Gross Value Added & 0.010 & 2,348 \\
Average Establishment Size & 0.036 & 2,357 \\
Log Public Expenditure & 0.015 & 2,113 \\
Log Distance to the US & $-0.341^{*}$ & 2,367 \\
Socio-economic characteristics & & \\
\% of Economically Active Population (age 20-49) & -0.038 & 2,367 \\
\% of Households with Own Car & $0.330^{*}$ & 2,367 \\
\% of Professionals among Employed & -0.007 & 2,367 \\
\hline
\end{tabular}

Note: Each cell shows the pairwise correlation coefficient of the municipality characteristics given in the respective row at first column and the average homicide rate over 2008-2012 (PostWar period) * indicates statistical significance at the $5 \%$ level or better. The socio-economic characteristics are from the 2000 Census, Log output per worker, log gross value-added, and the average establishment size are from the 2004 census, the manufacturing share in overall economy (measured in employment) is obtained from the IMSS (Social Security) 2005, Public expenditure data is from year 2005 and the distance to the US border is the author's own calculation. 


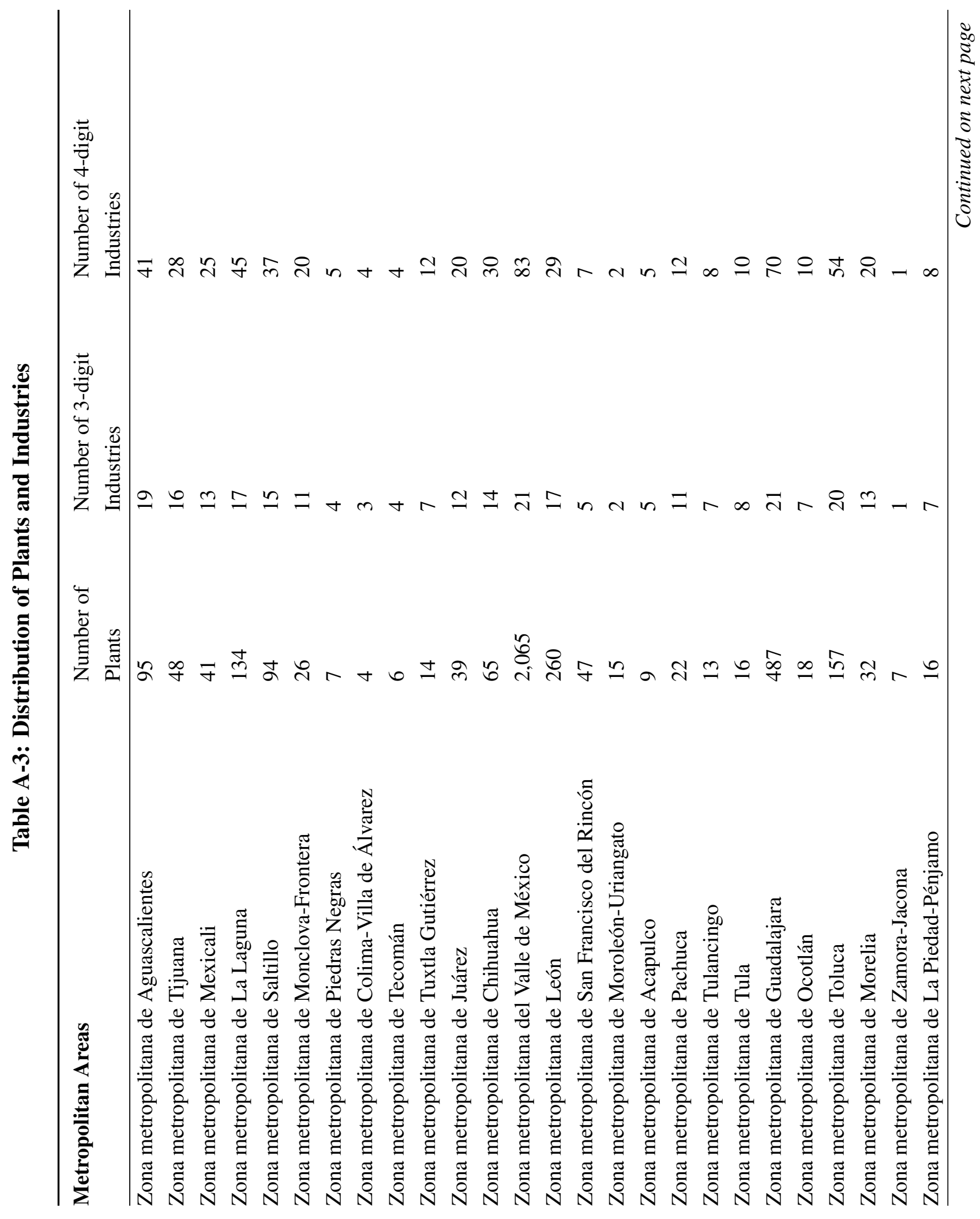




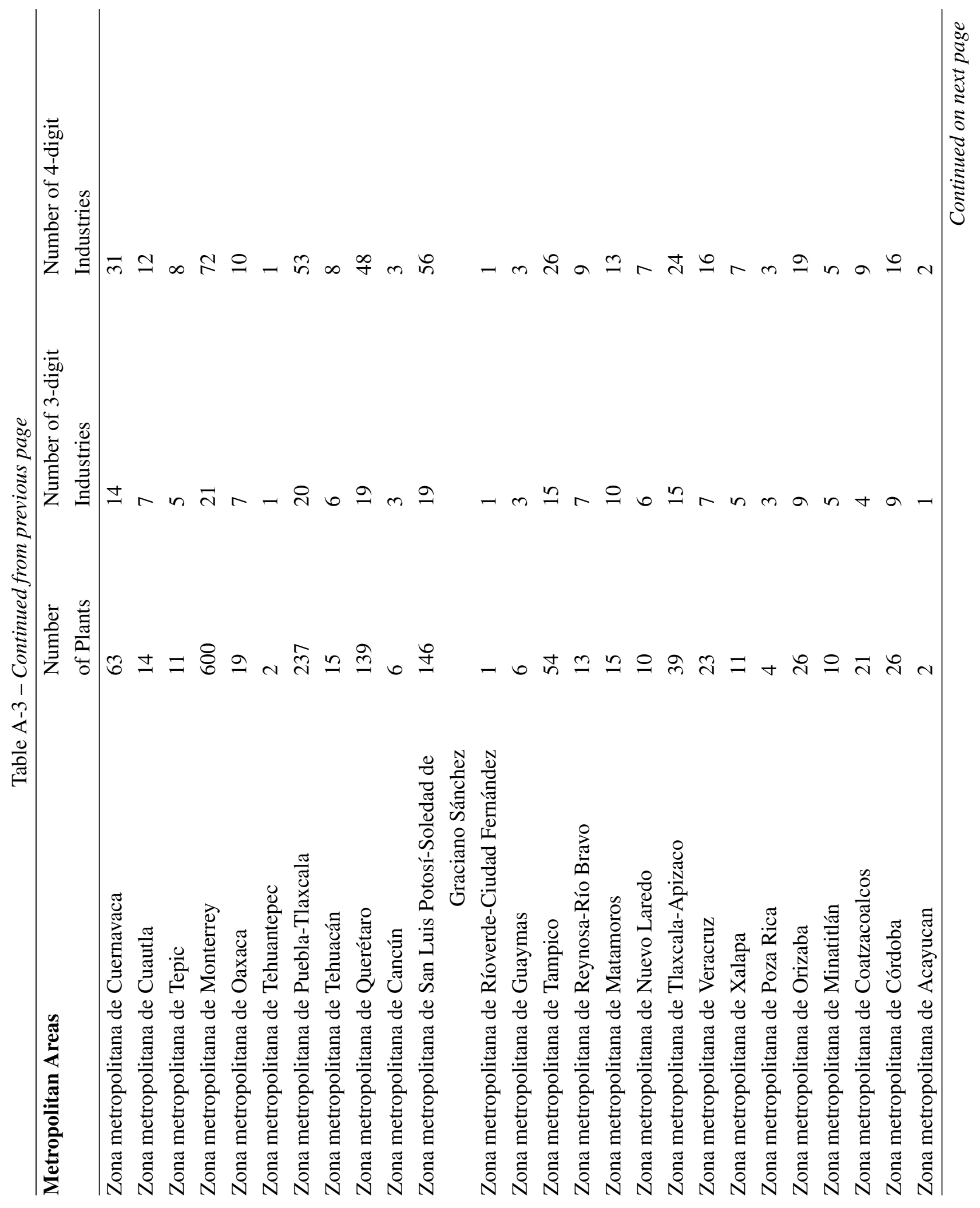




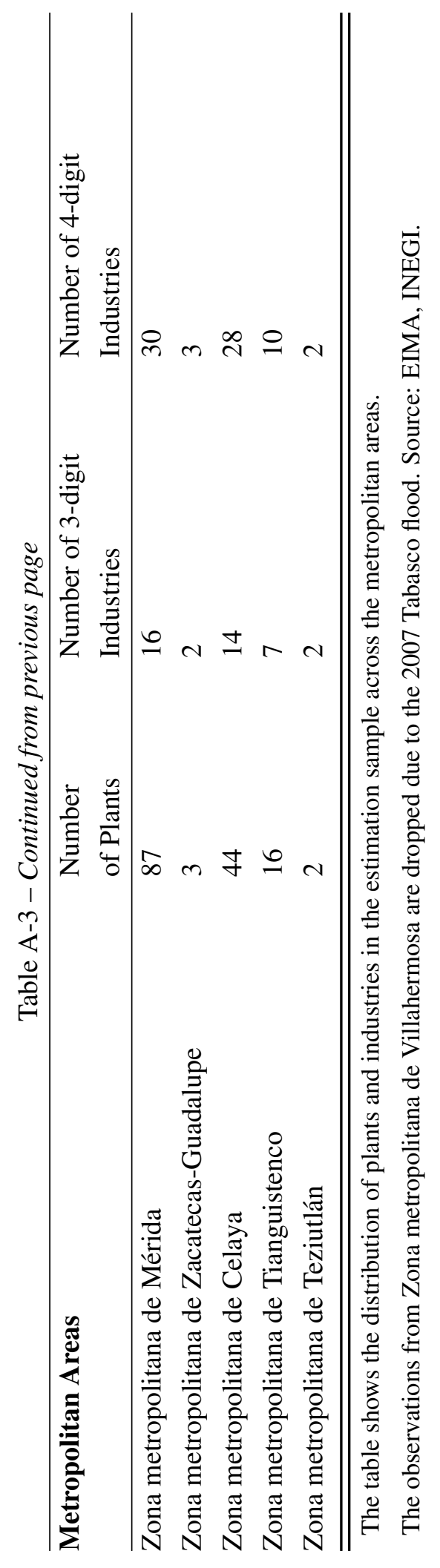




\section{A.2 The Drug War in Mexico}

Table A-4 shows the evolution in the number of major cartels in Mexico over the period of 2006-2010. In about four years the number of major cartels increased more than $70 \%$ (from 7 to 12).

Table A-4: Fragmentation of Major Drug Cartels in Mexico

\begin{tabular}{lll}
2006 & $2007-2009$ & 2010 \\
\hline Pacifico cartel (Sinaloa) & $\begin{array}{l}\text { Pacifico cartel } \\
\text { Beltrán-Levya cartel }\end{array}$ & $\begin{array}{l}\text { Pacifico cartel } \\
\text { Pacifico Sur cartel } \\
\text { Acapulco Independent cartel } \\
\text { "La Barbie" cartel }\end{array}$ \\
$\begin{array}{l}\text { Juárez cartel } \\
\text { Tijuana cartel }\end{array}$ & $\begin{array}{l}\text { Juárez cartel } \\
\text { Tijuana cartel } \\
\text { "El Teo" faction }\end{array}$ & $\begin{array}{l}\text { Juárez cartel } \\
\text { Tijuana cartel } \\
\text { "El Teo" faction }\end{array}$ \\
Golfo cartel & Golfo-Zetas cartel & $\begin{array}{l}\text { Golfo cartel } \\
\text { Zetas cartel }\end{array}$ \\
$\begin{array}{l}\text { La Familia } \\
\text { Michoacana }\end{array}$ & La Familia Michoacana & $\begin{array}{l}\text { La Familia Michoacana } \\
\text { La Resistencia }\end{array}$ \\
Milenio cartel & Milenio cartel & Jalisco cartel-Nueva Generación \\
\hline
\end{tabular}

Source: Bagley and Rosen (2015). 
Figure A-3 shows the evolution of homicide rate in metropolitan areas in Mexico since 2007.

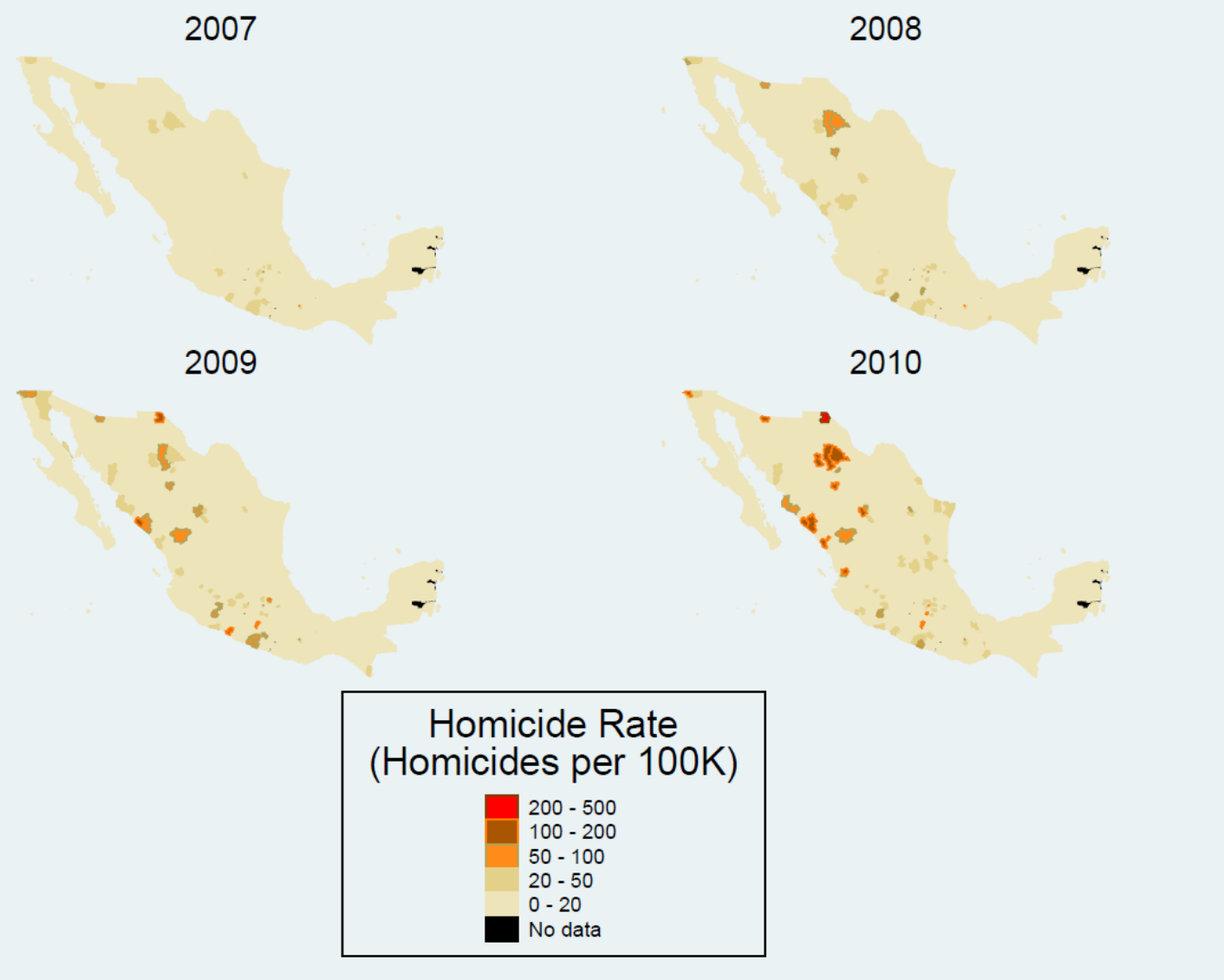

Figure A-3: Expansion of Urban Violence in Mexico

The number of homicides per 100,000 inhabitants across municipalities with at least 100,000 inhabitants or otherwise belonging to a metropolitan area.

\section{A.3 Military Interventions}

At the end of December 2006 the federal government, in agreement with some states started the joint military operations (Operativos Conjuntos Militares). Figures A-4 show the states that join the federal government's policy intervention. The location of states that joined the military interventions mostly coincide with the major drug trafficking routes. Merino (2011) shows a causal link between the military interventions and the surge in violence and using a regression discontinuity design, Dell (2015) establishes the causal link between the change in the government's policy and the increased violence in Mexico. 


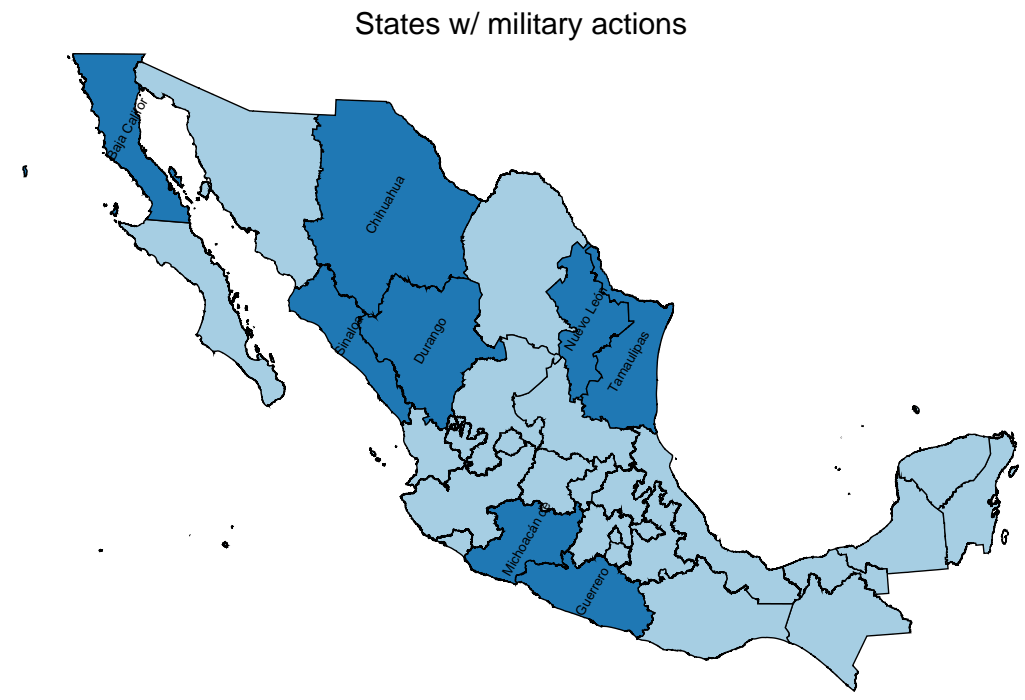

Figure A-4: States that conduct military operations against drug cartels with the federal army.

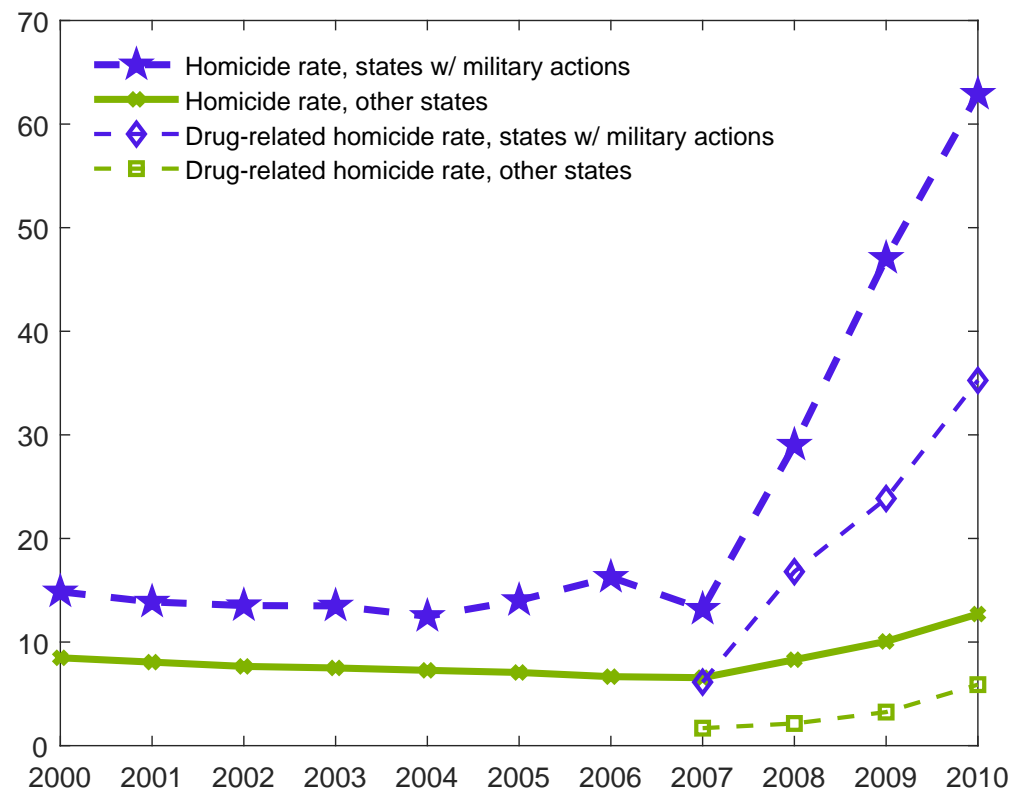

Figure A-5: Violence across States and the Kingpin strategy 


\section{A.4 Migration patterns}

Using the estimated state-level migration flows provided by Consejo Nacional de Población (CONAPO), Table A-5 presents the change in the pattern of migration in exposed versus not exposed states. For the purpose of this descriptive analysis, the state-level organized crime rate is used to describe exposed versus non-exposed states. Exposed states are states with an average organized crime rate during 2008-2010 above the 75th percentile. These are: Baja California, Chihuahua, Durango, Guerrero, Michoacán, Nayarit, Sinaloa, Sonara. Non-exposed states are states with an average organized crime rate during 2008-2010 below the 25th percentile. These are: Baja California Sur, Campeche, Chiapas, Puebla, Querétaro, Tlaxcala, Veracruz, and Yucatán. Table A-5 shows a significant drop in the inflow of domestic immigrants into the exposed states between 2005 and 2010. Exposed states also have significantly less inflow of international immigrants in comparison to nonexposed states. Although there is an overall strong declining trend in international emigrants during the sample period, exposed states have a significantly smaller decrease in the number of people moving out of the country in comparison to non-exposed states.

\section{Table A-5: Migration Pattern and Drug War}

\begin{tabular}{|c|c|c|c|c|}
\hline 2005-2010 Growth & $\begin{array}{c}\text { Exposed States } \\
\text { Post-drug war org. crime }(>=\text { p75) } \\
\text { Mean }\end{array}$ & $\begin{array}{c}\text { Not exposed States } \\
\text { Post-drug war org. crime }(>=\text { p25) } \\
\text { Mean }\end{array}$ & Difference & t-stat \\
\hline Inter State Emigrants & $0.6 \%$ & $-1.5 \%$ & $2.1 \%$ & -0.37 \\
\hline International Emigrants & $-42.1 \%$ & $-45.5 \%$ & $3.4 \%$ & -4.70 \\
\hline Inter State Immigrants & $-6.5 \%$ & $7.4 \%$ & $-13.9 \%$ & 1.97 \\
\hline International Immigrants & $13.6 \%$ & $27.2 \%$ & $-13.6 \%$ & 2.34 \\
\hline
\end{tabular}

Table shows the 2005-2010 change in the state level migration patterns across exposed versus non-exposed states. States with average organized crime rate during 2008-2010 above the 75the percentile are defined as exposed states. These are: Baja California, Chihuahua, Durango, Guerrero, Michoacán, Nayarit, Sinaloa, Sonara. States with average organized crime rate during 2008-2010 below the 25the percentile are defined as non-exposed states. These are: Baja California Sur, Campeche, Chiapas, Puebla, Querétaro, Tlaxcala, Veracruz, and Yucatán. Source for the migration data: Consejo Nacional de Población (CONAPO) 

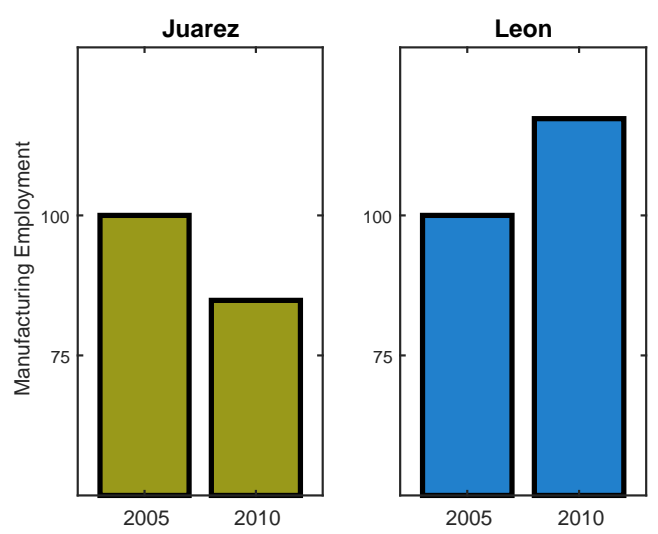

(a) Juarez versus Leon
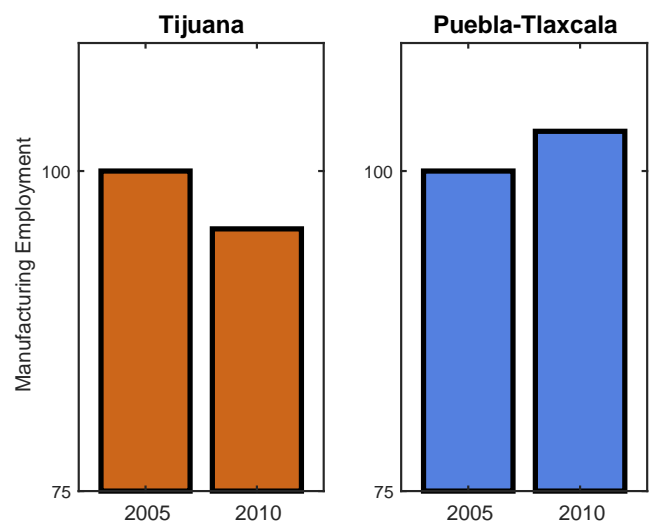

(c) Tijuana versus Puebla-Tlaxcala

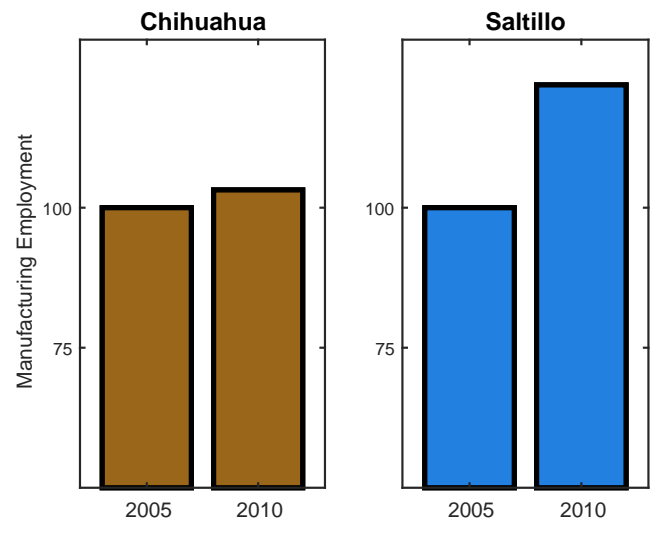

(b) Chihuahua versus Saltillo
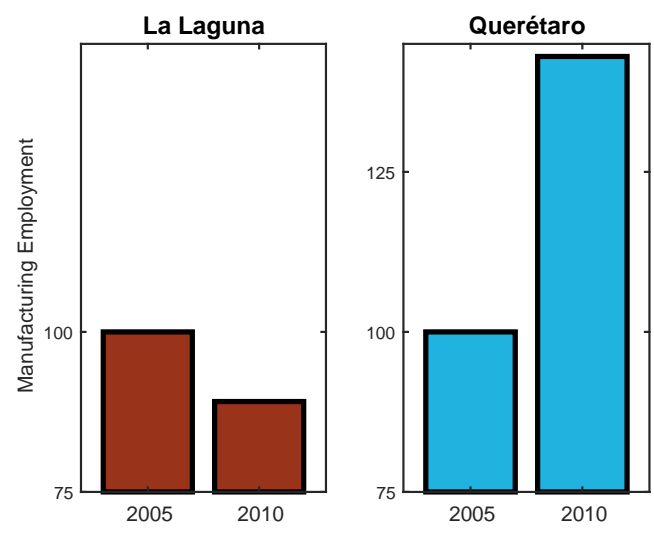

(d) La Laguna versus Queretaro

Figure A-6: Manufacturing employment across selected metropolitan areas

Manufacturing employment in 2005 at each metropolitan area is normalized to 100. Data from the Mexican Institute of Social Security (IMSS).

\section{A.5 Manufacturing employment across selected metropolitan areas}




\section{B Robustness and Additional Analysis}

\section{B.1 Additional Results}

\section{B.1.1 Export}

Table B-1 reports the estimation results on plant-level exporting in detail. The dependent variable in column (1) is the export dummy, in column (2) is the share of foreign sales in total sales, in column (3) is the total number of exported products as a share of total number of products sold, in column (4) is the logarithm of the foreign sales, and in column (5) is the logarithm of the number of exported products. Table B-1 confirms the results presented in the main text that exporting activities are not disproportionately affected by the Drug War.

Table B-1: Export and the Drug War Violence

$$
\text { Specification: } 2 \text { SLS }
$$

\begin{tabular}{lccccc} 
Dep. Var. & $\begin{array}{c}\text { Export } \\
\text { Indicator }\end{array}$ & $\begin{array}{c}\text { Share of } \\
\text { Foreign Sales }\end{array}$ & $\begin{array}{c}\text { Share of } \\
\text { Exported Products }\end{array}$ & $\begin{array}{c}\text { Log Export } \\
\text { Revenue }\end{array}$ & $\begin{array}{c}\text { Log Number of } \\
\text { Exported Products }\end{array}$ \\
\hline Log Homicide Rate & -0.018 & -0.009 & -0.020 & -0.195 & -0.015 \\
& $(0.023)$ & $(0.010)$ & $(0.019)$ & $(0.137)$ & $(0.023)$ \\
Plant FEs & $\checkmark$ & $\checkmark$ & $\checkmark$ & $\checkmark$ & $\checkmark$ \\
Pre-Trends & $\checkmark$ & $\checkmark$ & $\checkmark$ & $\checkmark$ & $\checkmark$ \\
5-dig. Industry x Year FEs & $\checkmark$ & $\checkmark$ & $\checkmark$ & $\checkmark$ & $\checkmark$ \\
F-test of excluding statistics & 21.15 & 21.15 & 21.15 & 29.32 & 29.32 \\
N & 30,605 & 30,605 & 30,605 & 10,812 & 10,812 \\
\hline \hline
\end{tabular}

Note: Estimation by two stage least squares. All regressions include plant fixed effects, five-digit industry by years fixed effects, and pre-trends in the homicide rate (2002 Homicide Rate x Year FEs). Robust standard errors, reported in parentheses, are two-way clustered by metropolitan area (57) and by four-digit industry level (84). ${ }^{*},{ }^{* *}$ and ${ }^{* * *}$ indicate significance at the $10 \%, 5 \%$ and $1 \%$ levels respectively. 


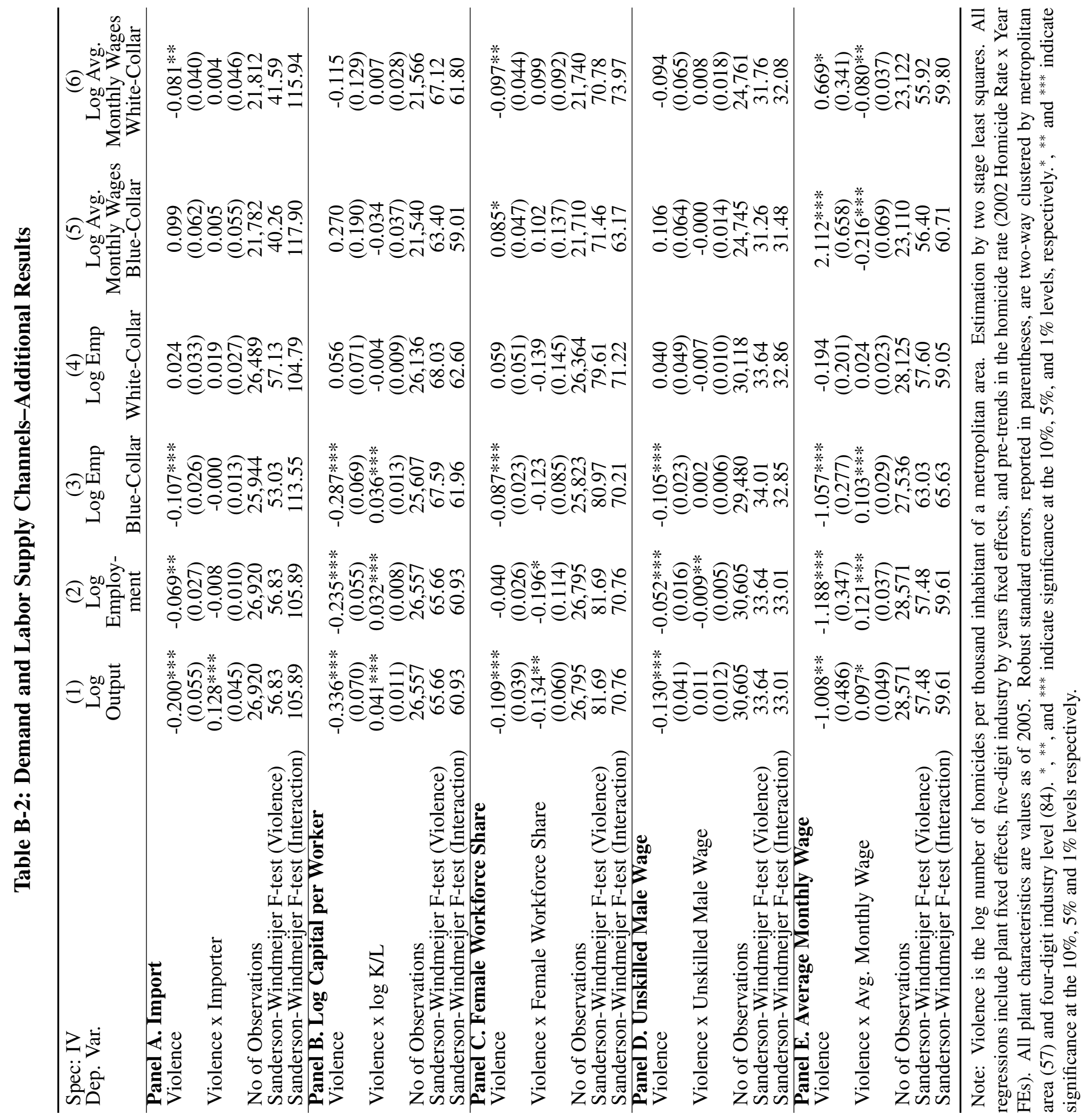




\section{B.1.2 Heterogeneity across Firms}

\section{B.1.3 Plant Exit}

To focus on heterogeneity in exit probabilities, I estimate a version of equation 1 where I interact the various plant-level characteristics with the metropolitan area level violence as measured by the logarithm of the homicide rate. As exit is a relatively rare event, instead of controlling for five-digit, I control for three-digit industry by year fixed effects. The 2SLS estimation results are presented in Table B-3. While this approach ignores the binary nature of the exit variable, it is useful to see how the exit probabilities vary depending on initial plant characteristics. The results show that exit due to the Mexican Drug War is more likely the smaller the plant size. Exit due to violence is also more likely if the plants have a higher share of female employees (column 6) and have lower wages (column 7). These results show that violence-induced labor supply changes also operate at the extensive margin. The reduction in local market size due to violence is also important in deriving exit as I find that exporters and importers are less likely to exit due to the Mexican Drug War (columns 2-3), and plant are less likely to exit the more diversified they are in output and input markets (columns 4-5).

\section{B.2 Differential Time Trends for Exporters}

Table B-4 shows the results when differential time trends for exporters are additionally controlled for. Here I allow for differential time trends for each exporter by interacting plants' exporting status in 2005 with year fixed effects. The results are robust.

\section{B.3 Analysis with only data from 2005 and 2010}

Table B-5 presents the 2SLS estimation of equation 1 using only data from years 2005 and 2010.

\section{B.4 Violence Outbreak and Trade Shocks}

In this section I address the concern that other local market shocks may be confounding the results. In particular, Utar and Ruiz (2013) show that rising import competition in the US has a substantial impact in Mexico via maquiladoras, export processing plants in Mexico that are tied to the US market. Recently Dell, Feigenberg, and Teshima (2018) find that areas that encounter decline in employment due to the Chinese import competition shock in the US market also suffer from heightened 


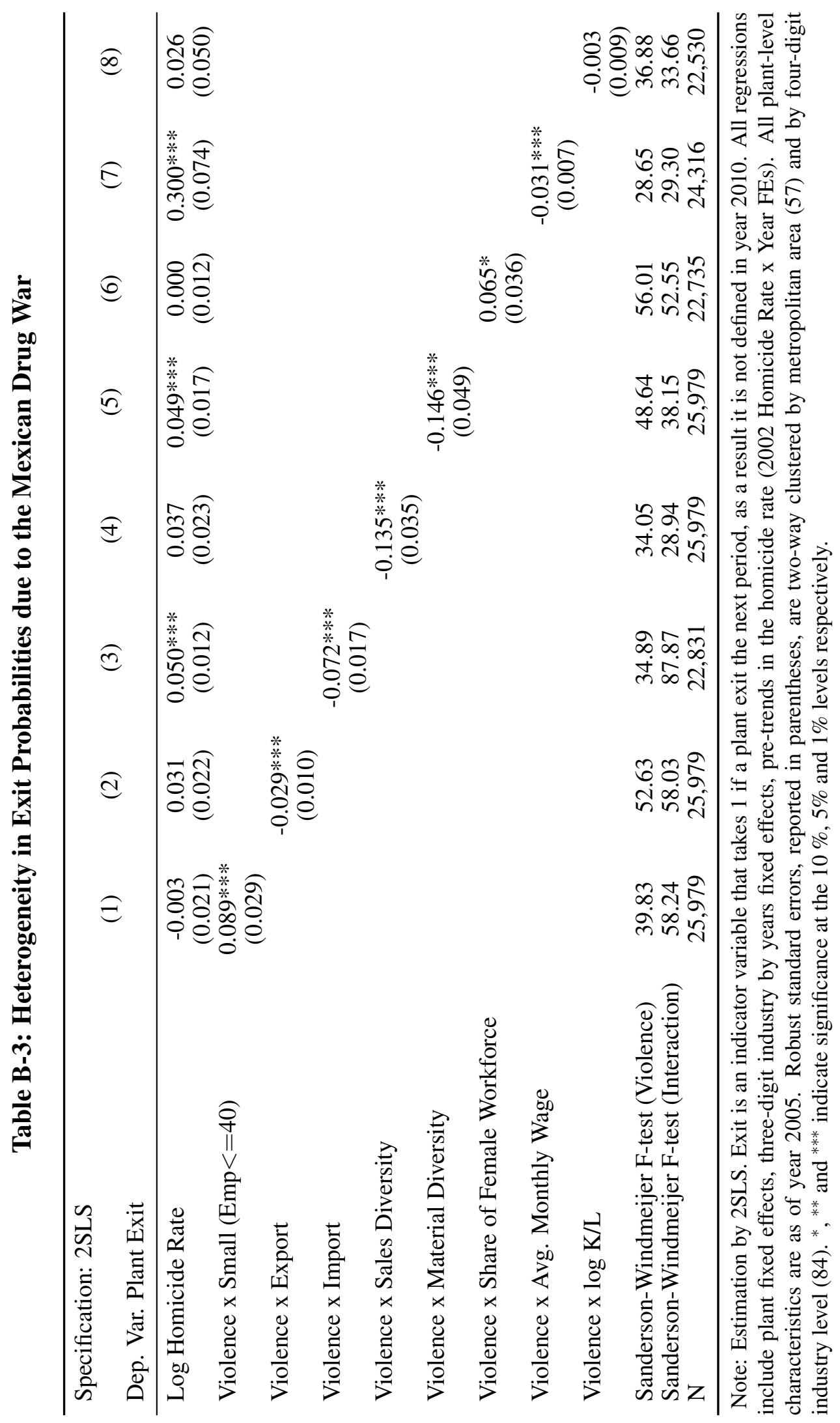




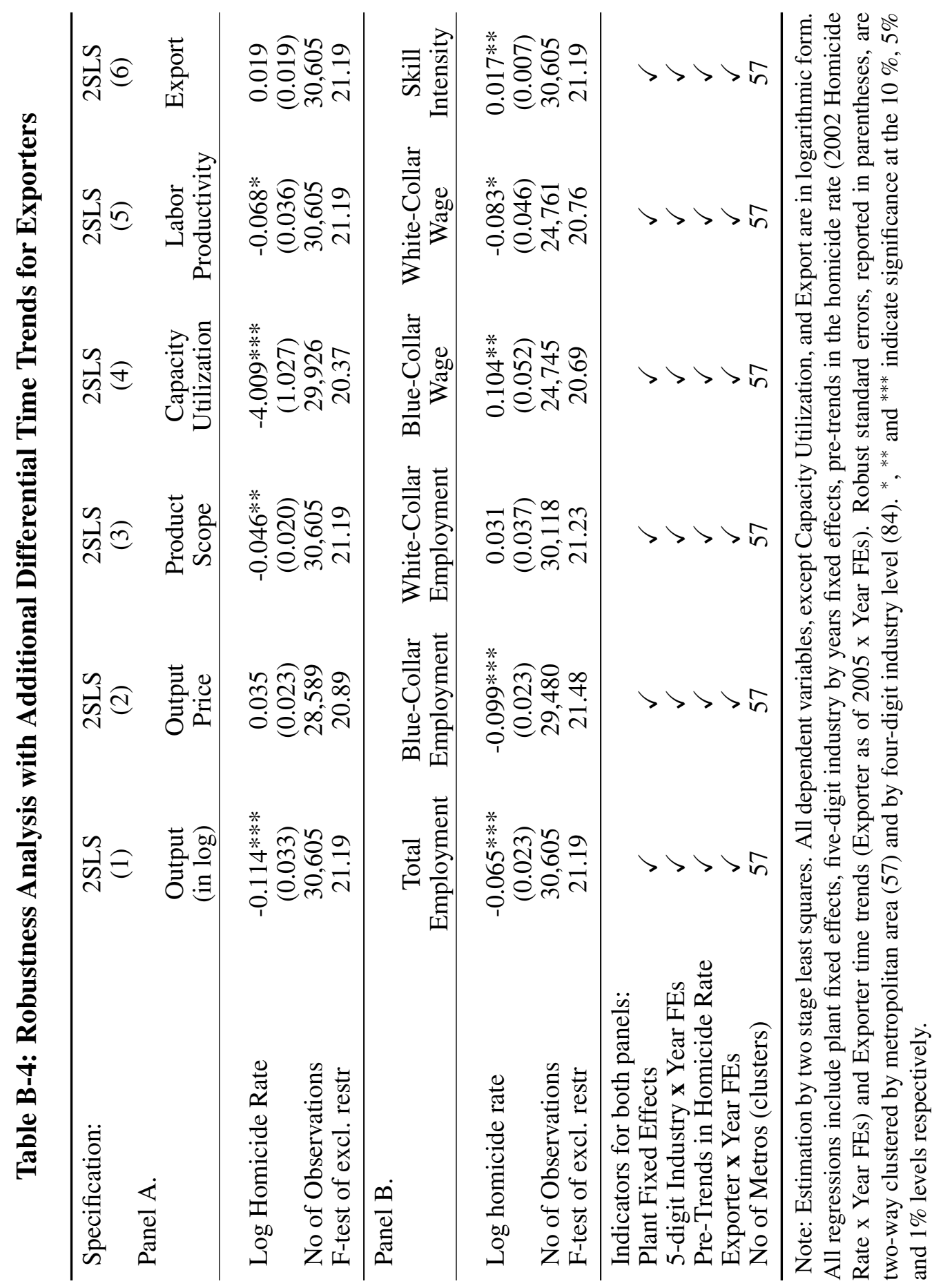




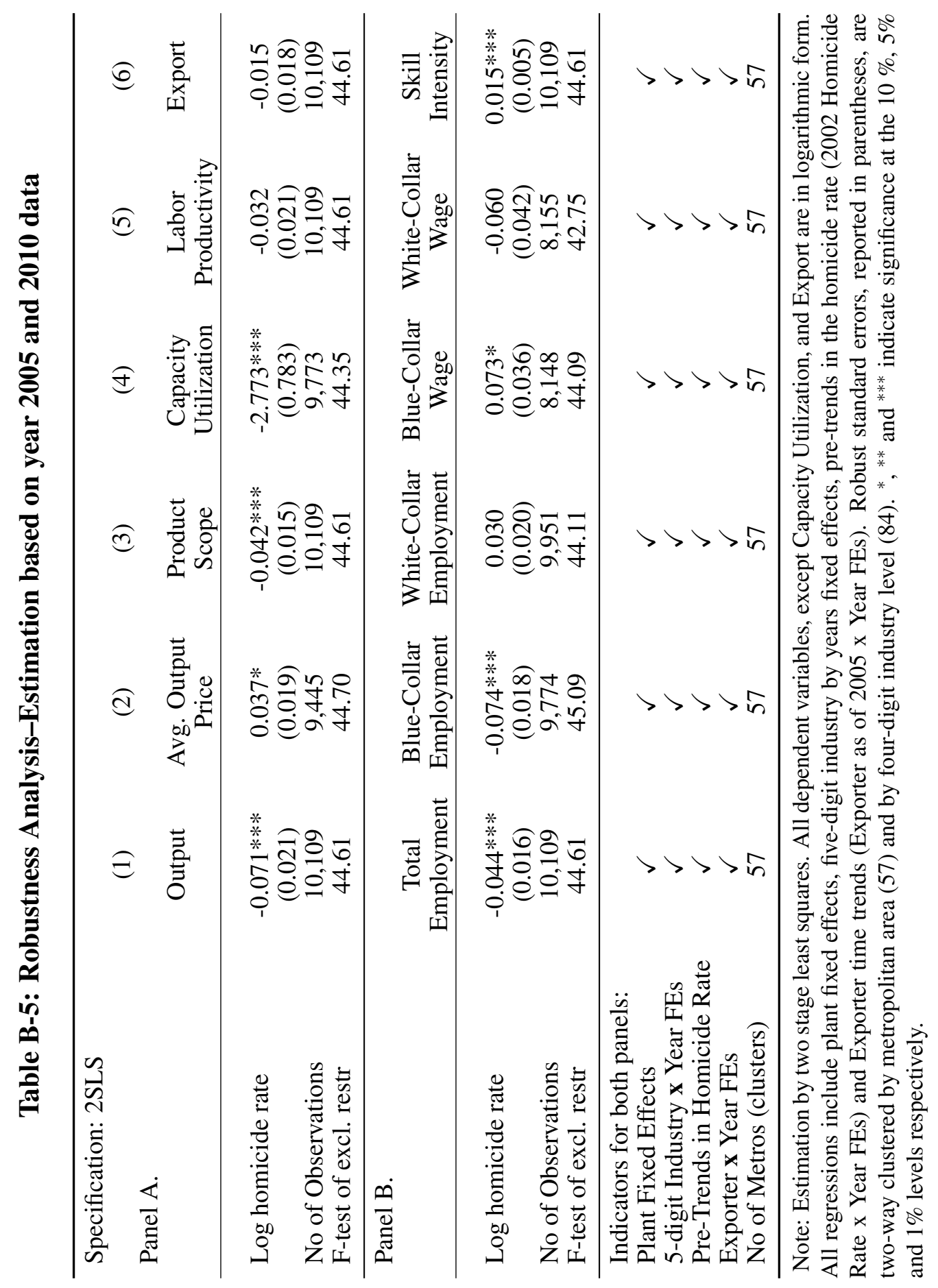


drug violence. Since the results here are robust to eliminating all potential changes happening at the product by year level it is very unlikely that such effects play a role. Regardless, I conduct a further robustness check by constructing a metropolitan area level import competition shock due to China's rise in the US market.

Let $\Delta$ TradeComp $_{j}$ be the per worker measure of change in trade competition between 2005 and 2010. Following Utar and Ruiz (2013) and Dell, Feigenberg, and Teshima (2018), I use the following measure of trade competition:

$$
\begin{gathered}
\Delta \text { TradeComp }_{j}=\sum_{k} \frac{L_{j k, i n i}}{L_{k, i n i}} \frac{\Delta^{05-10} M C H^{U S}}{L_{j, i n i}} \\
\Delta^{05-10} M C H^{U S}=\frac{M C H_{j, 2005}}{\operatorname{TotMCH}_{2005}} *\left[\text { TotMCH }_{2010}-\text { TotMCH }_{2005}\right]
\end{gathered}
$$

where $L_{j k, i n i}$ is the employment of industry $k$ in metropolitan area $j$ at the initial year, $L_{k, i n i}$ is total initial employment of industry $k$ in Mexico and $L_{j, i n i}$ is total non-agricultural employment in metropolitan area $j . \Delta^{05-10} M C H^{U S}$ is the predicted change in Chinese imports in the US in industry $k$ between 2005 and 2010. ${ }^{55}$ A higher value of $\Delta$ TradeComp $_{j}$ means that a metropolitan area has a larger initial share of employment in industries where Chinese imports in the US are predicted to grow.

I then interact $\Delta$ TradeComp $_{j}$ with year fixed effects and include this in equation 1 and reestimate the impact of violence shock as proxied by the logarithm of the homicide rate. The logarithm of the homicide rate is instrumented as described in Section 3. Estimates that are presented in B-6 re-confirm that the results are robust.

\section{B.5 Alternative Specifications}

\section{B.5.1 Alternative Instruments}

Table B-7 presents the results where the logarithm of the homicide rate is instrumented with three alternative instruments.

1. In columns (1)-(2) the instrument is $M O_{s t} * \widehat{\ln P_{t}^{\text {coke }}}$ where $\widehat{\ln P_{t}^{\text {coke }}}$ is the predicted cocaine prices

\footnotetext{
${ }^{55}$ Industry $k$ denotes four-digit NAICS industry. Initial employment shares are calculated using Census 2004.
} 


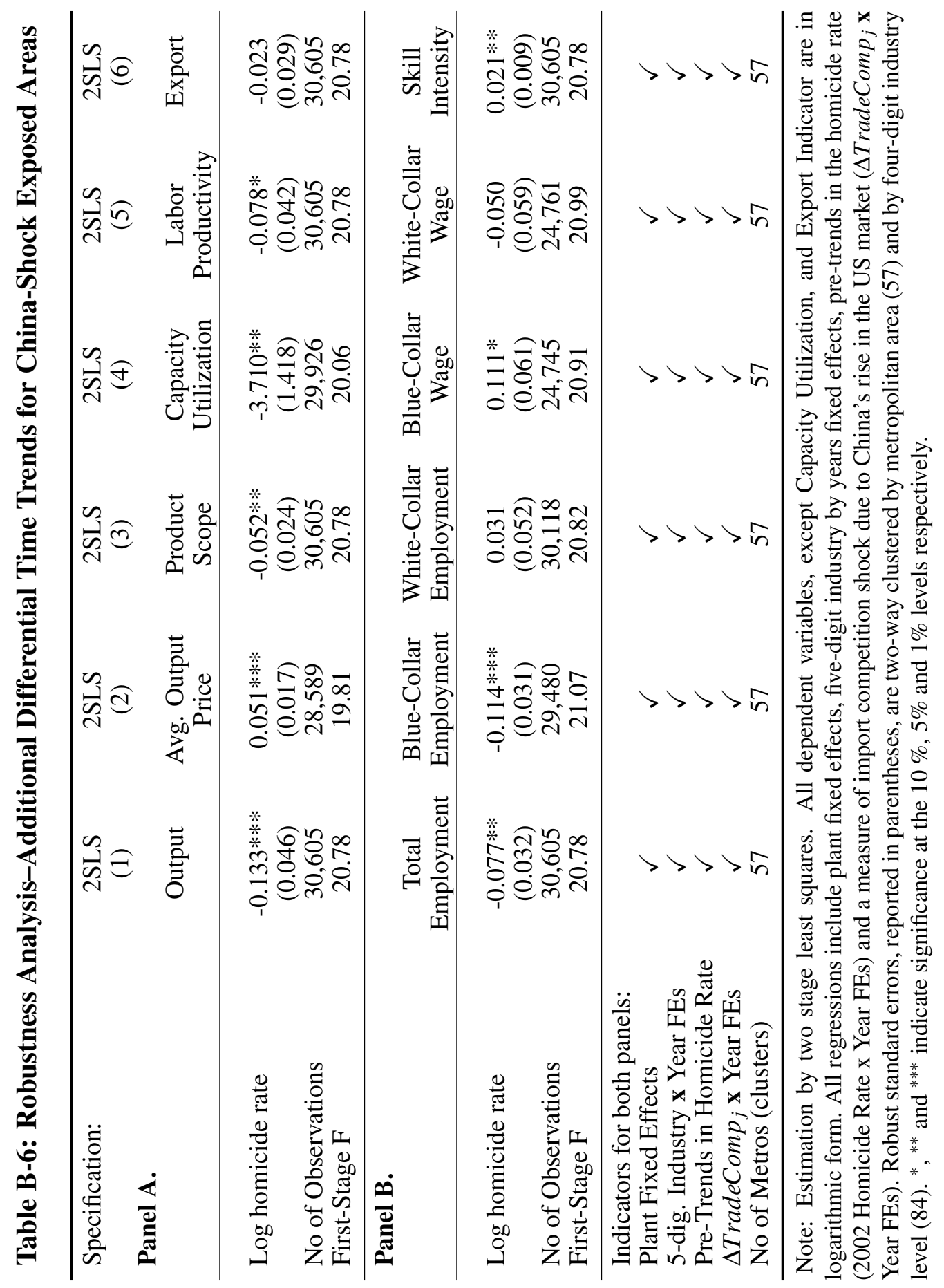


obtained from regressing the cocaine prices in the US on lagged cocaine ships seizures and cocaine cultivated lands in Colombia.

To construct this instrument, I regress the logarithm of cocaine prices in the US over the log of coca-cultivated land (in hectar) in Columbia (lnHectar ${ }^{C C}$ ) with a three-year lag and the annual $\log$ number of DTO ships $\left(\right.$ lnShips $^{C C}$ ) seized by the Colombian government with a one-year lag (Equation B-1):

$$
\ln P_{t}^{\text {coke }}=\beta_{0}+\beta_{1} \ln H e c t a r r_{t-3}^{C C}+\beta_{2} \operatorname{lnShips} s_{t-1}^{C C}+\varepsilon_{t} .
$$

Although the number of observations is limited, the estimation of Equation B-1 results in statistically significant $\beta_{1}$ and $\beta_{2}$ coefficients with expected signs: namely, $\widehat{\beta_{1}}=-0.847$ with $t$-value -3.15 and $\widehat{\beta_{2}}=0.347$ with $t$-value 11.43 . I then use the cocaine prices over the sample period predicted by the Colombian supply developments, $\widehat{\ln P_{t}^{c o k e}}$ and interact it with the locations susceptible to the policy intervention. Thus, I only use the time variation in cocaine prices that is associated with the plausibly exogenous changes in Colombia. ${ }^{56}$ Therefore,

$$
I 2_{j t} \equiv M O_{s t} * \widehat{\ln P_{t}^{c o k e}}
$$

where $\widehat{\ln P_{t}^{c o k e}}$ denotes the predicted values of inflation and purity adjusted cocaine prices in the US (in logarithm).

2. In columns (3)-(4) the instrument is $M O_{s t} * T_{w o G a n g} * D E C_{t-1 / 2}^{c o k e}$ where $T w o G a n g$ is an indicator for metropolitan areas with at least two drug gang presence over 2000-2006. The data on drug gangs' location of operations are from Coscia and Rios (2012) (see section C).

3. In columns (5)-(6) the instrument is DistanceU $S_{j} *$ CokeErad $_{t-1 / 2}^{\text {colombia }}$ where DistanceU $S_{j}$ is the

\footnotetext{
${ }^{56}$ Beginning in 2000, Colombia implemented policies aimed at reducing the cultivation of coca together with policies that aimed at preventing drug shipments out of the country (Mejia and Restrepo, 2016a). The efforts were especially effective in decreasing the cocaine supply during the second half of 2000s. Consequently, the dealer-level price of cocaine per pure gram increased between 2005 and 2010 by $46 \%$ in the US (author's calculation from the National Drug Control Strategy data).
} 
distance of a metropolitan area to the US border and CokeErad ${ }_{t-1 / 2}^{C O L}$ is the amount of cocaine eradication in Colombia between June $t-1$ and June $t$. 


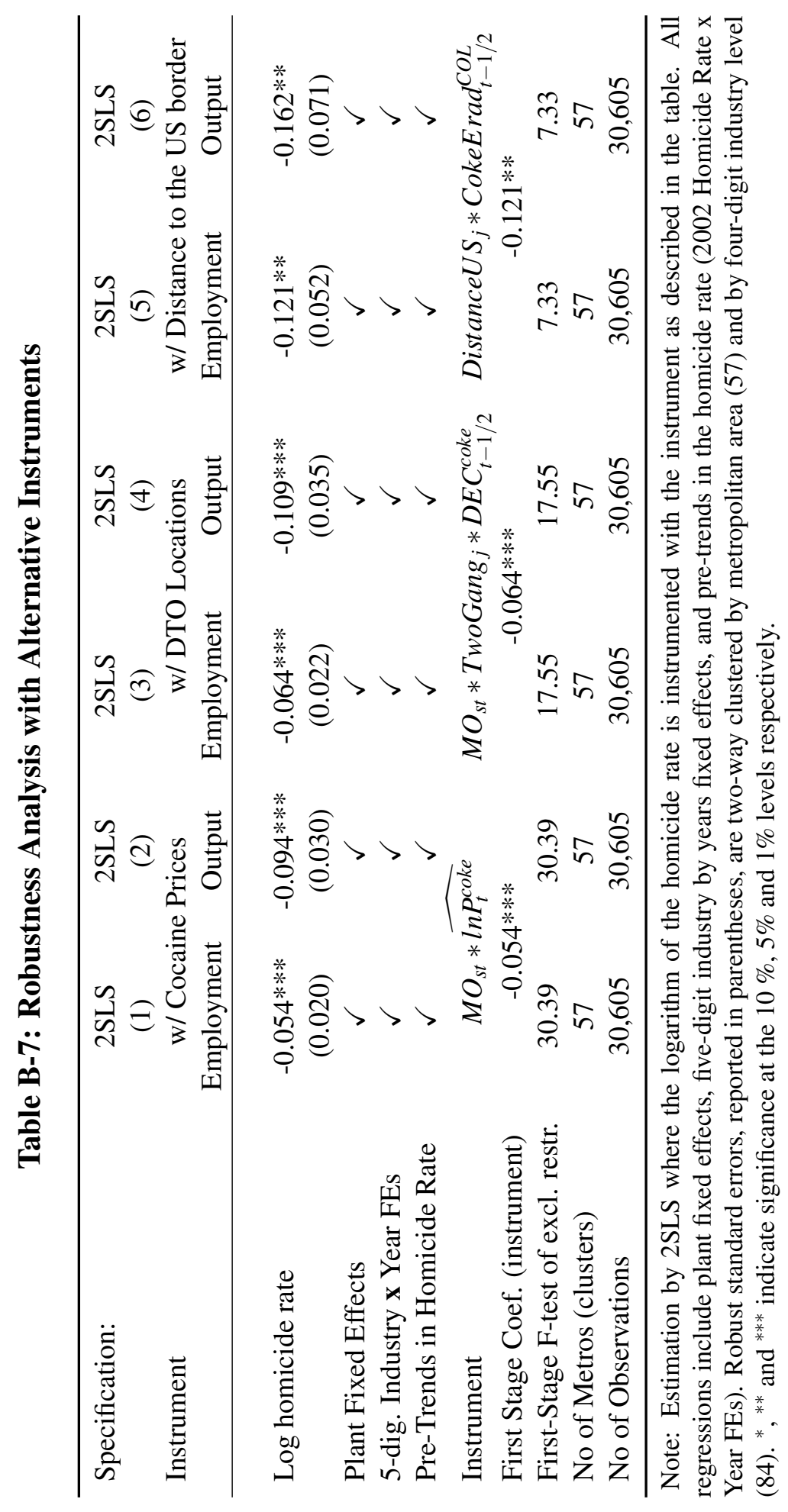




\section{B.5.2 A Difference-in-Differences Specification}

In Section 2.4 I define high-intensity drug war areas based on the change in the number and the rate of homicide. Using this definition, I also conduct a difference-in-difference specification and estimate the following:

$$
\ln Y_{i k j t}=\alpha_{0}+\alpha_{1} D W Z_{j} * D 2007_{t}+X_{t j}+\tau_{k t}+\eta_{i}+\varepsilon_{i k j t} .
$$

As before, $Y_{i k j t}$ is plant $i$ 's outcome in industry $k$ located in metropolitan area $j$ and time period $t . X_{t j}$ is a vector of time-varying metropolitan area characteristics and includes pre-trends in the homicide rate; employment shares of crop production; metal mining including gold, silver, copper, and uranium; and the metropolitan area-level employment share of oil and natural gas extraction. $\tau_{k t}$ denotes three-digit industry by time fixed effects, and $\eta_{i}$ denotes plant fixed effects that can be correlated with plant or metropolitan area characteristics. $D W Z_{j}$ is an indicator variable that takes 1 if the metropolitan area is defined as a high-intensity drug war zone. The definition of "High-intensity drug war zones" follows the text (Section 2.4), and D2007 $t$ is an indicator variable that takes 1 during president Calderón's term.

Results presented in Table B-8 show qualitatively similar results: plants located in metropolitan areas that are highly exposed to drug violence experience a $4.9 \%$ disproportionate decline in output and experience a $4 \%$ disproportionate decline in the total number of employees. 
Specification: OLS
Drug War Violence $\equiv D W Z_{j} * D 2007_{t}$

(2)

(3)

(4)

(5)

(6)

Panel A.

Output Avg. Output Product Capacity Labor Export

Price Scope Utilization Productivity

\begin{tabular}{lcccccc}
\hline & & & & & & \\
Drug War Violence & $-0.051^{* * *}$ & 0.018 & $-0.036^{* * *}$ & $-1.528^{* * *}$ & $-0.030^{* *}$ & -0.007 \\
& $(0.012)$ & $(0.016)$ & $(0.009)$ & $(0.454)$ & $(0.014)$ & $(0.011)$ \\
$\mathrm{N}$ & 30,605 & 28,589 & 30,605 & 29,926 & 30,605 & 30,605 \\
\hline Panel B. & & & & & & \\
& Total & Blue-Collar & White-Collar & Blue-Collar & White-Collar & Skill \\
& Employment & Employment & Employment & Wage & Wage & Intensity \\
\hline & & & & & & \\
Drug War Violence & $-0.033^{* *}$ & $-0.047 * * *$ & 0.021 & 0.040 & $-0.049 *$ & $0.008^{* *}$ \\
& $(0.014)$ & $(0.013)$ & $(0.021)$ & $(0.025)$ & $(0.025)$ & $(0.004)$ \\
N & 30,605 & 29,480 & 30,118 & 24,745 & 24,761 & 30,605 \\
\hline For both panels: & & & & & $\checkmark$ & $\checkmark$ \\
Plant FEs & $\checkmark$ & $\checkmark$ & $\checkmark$ & $\checkmark$ & $\checkmark$ & $\checkmark$ \\
5-dig. Industry $\mathbf{x}$ Year FEs & $\checkmark$ & $\checkmark$ & $\checkmark$ & $\checkmark$ & $\checkmark$ & $\checkmark$ \\
Time-varying Metro Controls & $\checkmark$ & $\checkmark$ & $\checkmark$ & $\checkmark$ & $\checkmark$ & $\checkmark$ \\
Pre-trends in homicide rate & $\checkmark$ & $\checkmark$ & $\checkmark$ & $\checkmark$ & 57 & 57 \\
No. of LMs (clusters) & 57 & 57 & 57 & 57 & 57 \\
\hline
\end{tabular}

Note: Estimation by ordinary least squares. "Drug War Violence" is measured as the interaction variable of the Drug War zones as defined in the text and the dummy variable that takes 1 on and after 2007. All dependent variables, except "Export indicator" are in logarithmic form. "Time-varying Metro Controls" include employment shares of crop production; metal mining including gold, silver, copper, and uranium; and the metropolitan area-level employment share of oil and natural gas extraction. Robust standard errors, reported in parentheses, are two-way clustered by metropolitan area (57) and by four-digit industry level (84). ${ }^{*},{ }^{* *}$, and ${ }^{* * *}$ indicate significance at the $10 \%, 5 \%$, and $1 \%$ levels, respectively.

\section{B.6 Analysis with the Monthly Data}

For the monthly analysis, I use the EIMA collected at the monthly frequency and monthly data on homicides across Mexican municipalities to construct the monthly homicide rate at the metropolitan area level. I then utilize the monthly data on cocaine seizures from the Colombian Defense Ministry to construct the instrument as in 2. Table B-9 presents a summary of estimation results when the analysis is conducted at the monthly frequency. In these results the log of monthly homicide rate at 
metropolitan area $j$ is instrumented with the same instrument as in the main text, $M O_{s t} * D E C_{t-1 / 2}^{c o k e}$, except that now I use the cocaine seizures data at the monthly frequency. Here, too, both the homicide rate and the cocaine seizures are lagged in six months. Elasticity estimates shown in Table B-9 are similar to the ones found in the main analysis.

Table B-9: Main Results with the Monthly Data

Specification: 2SLS

Panel A.

Output Avg. Output Product Capacity Labor

Price Scope Utilization Productivity

\begin{tabular}{|c|c|c|c|c|c|c|}
\hline \multirow[t]{2}{*}{ Violence } & $-0.127 * * *$ & 0.026 & -0.027 & $-4.322 * * *$ & $-0.070 *$ & -0.019 \\
\hline & $(0.048)$ & $(0.027)$ & $(0.024)$ & $(1.395)$ & $(0.040)$ & $(0.018)$ \\
\hline $\mathrm{N}$ & 334,306 & 311,484 & 334,306 & 330,591 & 333,596 & 338,737 \\
\hline F-test of excl rest & 11.41 & 11.40 & 11.41 & 10.83 & 11.40 & 11.41 \\
\hline \multicolumn{7}{|l|}{ Panel B. } \\
\hline & $\begin{array}{c}\text { Total } \\
\text { Employment }\end{array}$ & $\begin{array}{l}\text { Blue-Collar } \\
\text { Employment }\end{array}$ & $\begin{array}{l}\text { White-Collar } \\
\text { Employment }\end{array}$ & $\begin{array}{c}\text { Blue-Collar } \\
\text { Wage }\end{array}$ & $\begin{array}{c}\text { White-Collar } \\
\text { Wage }\end{array}$ & $\begin{array}{c}\text { Skill } \\
\text { Intensity }\end{array}$ \\
\hline Violence & $\begin{array}{c}-0.077 * * \\
(0.031)\end{array}$ & $\begin{array}{c}-0.122 * * * \\
(0.041)\end{array}$ & $\begin{array}{c}0.029 \\
(0.049)\end{array}$ & $\begin{array}{l}0.118^{*} \\
(0.060)\end{array}$ & $\begin{array}{l}-0.105 * \\
(0.060)\end{array}$ & $\begin{array}{l}0.018 * \\
(0.009)\end{array}$ \\
\hline $\mathrm{N}$ & 337,604 & 324,665 & 331,053 & 269,725 & 269,884 & 337,604 \\
\hline F-test of excl rest & 11.38 & 11.62 & 11.43 & 10.22 & 10.22 & 11.38 \\
\hline \multicolumn{7}{|l|}{ For both panels: } \\
\hline Plant FEs & $\checkmark$ & $\checkmark$ & $\checkmark$ & $\checkmark$ & $\checkmark$ & $\checkmark$ \\
\hline 5-dig. Industry $\mathbf{x}$ Year FEs & $\checkmark$ & $\checkmark$ & $\checkmark$ & $\checkmark$ & $\checkmark$ & $\checkmark$ \\
\hline Monthly Time FE & $\checkmark$ & $\checkmark$ & $\checkmark$ & $\checkmark$ & $\checkmark$ & $\checkmark$ \\
\hline Pre-trends in homicide rate & $\checkmark$ & $\checkmark$ & $\checkmark$ & $\checkmark$ & $\checkmark$ & $\checkmark$ \\
\hline No. of LMs (clusters) & 57 & 57 & 57 & 57 & 57 & 57 \\
\hline
\end{tabular}

Note: Estimation by two stage least squares. All regressions include plant fixed effects, five-digit industry by years fixed effects, pre-trends in the homicide rate (2002 Homicide Rate x Year FEs), and monthly time fixed effects. Robust standard errors, reported in parentheses, are two-way clustered by metropolitan area (57) and by four-digit industry level (84). ${ }^{*},{ }^{* *}$, and ${ }^{* * *}$ indicate significance at the $10 \%, 5 \%$, and $1 \%$ levels, respectively. 


\section{B.7 Metropolitan Area Level Security Expenses}

Table B-10 presents results when the metropolitan area-level 2005-2010 growth in security expenses are controlled for. To do that, the growth rate for each metropolitan area is interacted with year dummies. The results show that including the security expenses do not change the results, indicating that the exclusion restrictions are not violated.

\section{Table B-10: Main Results with the Metro-level Control of Security Expenses}

Specification: 2SLS

(4)

Panel A.

\begin{tabular}{|c|c|c|c|c|c|}
\hline Output & $\begin{array}{l}\text { Avg. Output } \\
\text { Price }\end{array}$ & $\begin{array}{l}\text { Product } \\
\text { Scope }\end{array}$ & $\begin{array}{l}\text { Capacity } \\
\text { Utilization }\end{array}$ & $\begin{array}{c}\text { Labor } \\
\text { Productivity }\end{array}$ & Export \\
\hline
\end{tabular}

\begin{tabular}{lcccccc}
\hline & & & & & \\
Violence & $-0.109 * * *$ & 0.038 & $-0.046^{* *}$ & $-4.318^{* * *}$ & $-0.061 *$ & -0.019 \\
& $(0.033)$ & $(0.023)$ & $(0.020)$ & $(1.084)$ & $(0.034)$ & $(0.023)$ \\
$\mathrm{N}$ & 30,605 & 28,589 & 30,605 & 29,926 & 30,605 & 30,605 \\
F-test of excl rest & 20.89 & 20.59 & 20.89 & 20.07 & 20.89 & 20.89 \\
\hline
\end{tabular}

\section{Panel B.}

\begin{tabular}{cccccc} 
Total & Blue-Collar & White-Collar & Blue-Collar & White-Collar & Skill \\
Employment & Employment & Employment & Wage & Wage & Intensity \\
\hline
\end{tabular}

\begin{tabular}{lcccccc} 
Violence & $-0.068^{* * *}$ & $-0.103 * * *$ & 0.027 & $0.115^{* *}$ & $-0.084^{*}$ & $0.018^{* *}$ \\
& $(0.022)$ & $(0.023)$ & $(0.037)$ & $(0.054)$ & $(0.048)$ & $(0.008)$ \\
N & 30,605 & 29,480 & 30,118 & 24,745 & 24,761 & 30,605 \\
F-test of excl rest & 20.89 & 21.19 & 20.94 & 20.65 & 20.55 & 20.89 \\
\hline For both panels: & & & & & & $\checkmark$ \\
Plant FEs & $\checkmark$ & $\checkmark$ & $\checkmark$ & $\checkmark$ & $\checkmark$ & $\checkmark$ \\
5-dig. Industry x Year FEs & $\checkmark$ & $\checkmark$ & $\checkmark$ & $\checkmark$ & $\checkmark$ & $\checkmark$ \\
Pre-trends in homicide rate & $\checkmark$ & $\checkmark$ & $\checkmark$ & $\checkmark$ & $\checkmark$ & $\checkmark$ \\
Security Expenses & $\checkmark$ & $\checkmark$ & $\checkmark$ & $\checkmark$ & $\checkmark$ & $\checkmark$ \\
\hline
\end{tabular}

Note: Estimation by two stage least squares. All regressions include plant fixed effects, five-digit industry by years fixed effects, pre-trends in the homicide rate (2002 Homicide Rate x Year FEs) and the metropolitan area-level 2005-2010 growth in security expenses interacted with year fixed effects. Robust standard errors, reported in parentheses, are two-way clustered by metropolitan area (57) and by four-digit industry level (84). ${ }^{*}, *$, and ${ }^{* *}$ indicate significance at the $10 \%, 5 \%$, and $1 \%$ levels, respectively. 


\section{B.8 Plant Exit and the Impact at the Intensive Margin}

I show that plants that are exposed to the violence shock are more likely to exit, and that the likelihood of exit is stronger if the plants are more female-intensive, oriented towards the domestic market rather than exporting and importing and smaller. I also show that such plants disproportionately downsize conditional on staying in the market. These results may imply that selection may be leading to underestimation of the true effect at the intensive margin. To gauge this, I use the "identification-at infinity" idea (Chamberlain (1986) and Mulligan and Rubinstein (2008)) that the selection bias must be lower for plants with higher survival probability and restrict the estimation sample to plants with higher survival probability and observe how the estimates change as one drops step by step the plants that most likely exit. Table B-11 presents the results when plants are allocated in sub-samples depending on their average probability of exit across the sample years. The results suggest that to some extent the endogenous exit is likely to lead to understating the true impact at the intensive margin as the coefficient estimates get larger for employment and output impact of violence. As such, one can interpret the findings in the paper as the lower bound of the real impact. 
Table B-11: Exit Likelihood and the Impact at the Intensive Margin

Specification:2SLS

(1) (2) (3)

(4)

(5)

All except top 1\% except top 5\% except top 10\% except top 15\%

$\begin{array}{lcr}\text { Exit Prob } & \text { All } & \text { except top 1\% }\end{array}$

Log Homicide Rate $-0.112 * * * \quad-0.128 * * *$

$\begin{array}{ccc}-0.121^{* * *} & -0.130 * * * & -0.129 * * * \\ (0.040) & (0.037) & (0.039)\end{array}$

(0.033)

$(0.037)$

21.77

22.45

23.00

First-Stage F

21.15

21.44

25,230

23,901

22,573

Panel B. Dep. Var. Employment

Log Homicide Rate $-0.069 * * * \quad-0.075 * * *$ $-0.074 * * * \quad-0.066 * * * \quad-0.067 * * *$

(0.022)

(0.025)

(0.025)

(0.023)

(0.024)

First-Stage F

$21.15 \quad 21.44$

21.77

22.45

23.00

$\mathrm{N}$

30,605

26,293

25,230

23,901

22,573

Panel C.

Dep. Var. Blue-Collar Employment

Log Homicide Rate

$-0.101 * * * \quad-0.110 * * *$

$-0.108 * * *$

$-0.101 * * *$

$-0.104 * * *$

(0.023)

(0.028)

(0.029)

(0.029)

(0.029)

First-Stage F

21.45

21.95

22.26

23.04

23.63

$\mathrm{N}$

29,480

25,348

24,302

23,000

21,694

Panel D.

Dep. Var. Blue-Collar Wages (on payroll)

Log Homicide Rate

$0.106 * * \quad 0.105^{* *} \quad 0.100 * *$

(0.048)

0.093*

$0.089 *$

(0.052)

(0.047)

21.13

(0.052)

(0.048)

First-Stage F

20.66

20.76

20,377

21.72

22.34

N

24,745

21,340

19,188

18,046

Panel E.

Dep. Var. White Collar Employment

Log Homicide Rate

$0.028-0.037$

(0.036)

(0.038)

0.033

0.043

0.041

21.20

21.65

(0.038)

(0.041)

$(0.042)$

First-Stage F

30,118

25,916

22.02

22.47

23.00

Panel F.

Dep. Var. White Collar Wages (on payroll)

Log Homicide Rate

$-0.080^{*}$

$-0.083 *$

-0.080 *

23,604

22,325

(0.047)

(0.044)

$(0.042)$

$-0.079 *$

$-0.070$

First-Stage F

20.74

21.09

21.48

(0.047)

(0.048)

$\mathrm{N}$

24,761

21,362

20,400

22.16

22.73

19,206

18,059

Note: Estimation by two stage least squares. All regressions include plant fixed effects, five-digit industry by years fixed effects, and pre-trends in the homicide rate (2002 Homicide Rate x Year FEs). All dependent variables are in logarithmic form. Robust standard errors, reported in parentheses, are two-way clustered by metropolitan area and by four-digit industry level (84). ${ }^{*},{ }^{* *}$ and ${ }^{* * *}$ indicate significance at the $10 \%, 5 \%$ and $1 \%$ levels respectively. 


\section{Data Appendix}

\section{C.1 Plant-level Data}

EIMA 2005-2010: La Encuesta Industrial Mensual Ampliada (EIMA) is a monthly survey of manufacturing plants carried out by INEGI. It constitutes the basis of Gross Domestic Product and Economic Indicators on employment, production, and productivity among others. It includes 230 economic classes of activity (clases de actividad) and covers 7,328 establishments that produce $86 \%$ of the nationwide manufacturing value-added. Industries in the data are classified based on the North American Industry Classification System, SCIAN 2002. ${ }^{57}$ It was developed jointly by the U.S. Economic Classification Policy Committee (ECPC), Statistics Canada and Mexico's Instituto Nacional de Estadistica y Geografia (INEGI) to allow for a high level of comparability in business statistics among the North American countries.

Each of 230 economic classes within the manufacturing sector has a unique six-digit number. For example, 311320 refers to 'Preparation of chocolate and chocolate products from cacao' and 311330 refers to 'Preparation of chocolate products from chocolate'. For each detailed manufacturing activity, clase, plants are ranked according to their production capacity as of Economic Census 2004 and they are included to the survey from the top until at least $80 \%$ of all production within each detailed product category is covered. If a plant employs 300 or more employees, they are always included in the survey.

EIMA provides information on the number of white collar and blue collar workers, wages, hours and days worked, and plant capacity utilization. Importantly, EIMA reports quantity and value of production, sales, and export for each product that a plant produces separately. For example, within economic activity 311330 'Preparation of chocolate products from purchased chocolate' there are more than 30 products specified, e.g. chocolate covered almonds (311330023), or chocolate covered raisins (311330025). Using this information, it is possible to construct plant-level prices for each product.

In recent years there have been important changes in the way companies are organized. One of

\footnotetext{
${ }^{57}$ Sistema de Clasificación Industrial de América del Norte.
} 
the most important is related to outsourcing of personnel. The EIMA captures information both of the personnel dependent on the corporate name, as well as that provided by a personnel service provider, so that both of these two components of the personnel employed in the manufacturing sector are in the data-set.

Plant-level wages, salaries and benefits are deflated using the consumer price index and expressed in thousand 2010 peso. Plant-level sales and production values are deflated using the industry-level producer price deflators and expressed in thousand 2010 peso. The consumer and producer price indices are from Banco de Mexico.

EIA 2005: La Encuesta Industrial Anual (EIA) is an annual survey of manufacturing plants carried out by INEGI. It provides detailed balance sheet information of the manufacturing plants including information on employment, fixed assets, wages, itemized expenses, itemized income, value of production, and inventories. The industry classification of plants is based on the North American Industry Classification System (NAICS), 2002. This survey runs on the same sample rules over 20032007 with the EIMA, used in this study, hence EIA and EIMA can be matched at the plant-level using the unique plant identification system. I enrich the initial plant characteristics with the data from EIA 2005. These data include gender composition of workforce, capital items, detailed account of expenditures. When the EIA data used in the analysis the analysis is conducted in the matched EIAEIM sample, which is somewhat smaller than the main sample but with very similar characteristics overall. Table $\mathrm{C}-1$ presents the summary statistics from the EIMA-EIA matched sample. 
Table C-1: Comparison of EIMA and the EIA-EIM matched sample

\begin{tabular}{lccc|ccc}
\hline & \multicolumn{3}{c}{ EIMA Sample } & \multicolumn{3}{c}{ EIMA-EIA Matched Sample } \\
& \multicolumn{3}{c}{ N=30,605 } & \multicolumn{3}{c}{ N=26,920 } \\
& Mean & Median & StDev & Mean & Median & StDev \\
& & & & & & \\
\hline Number of Employees & 238.36 & 99.83 & 491.39 & 240.88 & 101 & 481.69 \\
Number of Blue-Collar Employees & 159.56 & 64.67 & 322.90 & 161.70 & 65.33 & 330.54 \\
Number of White-Collar Employees & 71.92 & 22.92 & 229.18 & 72.37 & 23.08 & 207.89 \\
Number of Days Worked & 280.48 & 295 & 55.58 & 280.97 & 295.00 & 55.24 \\
Capacity Utilization Rate & 70.20 & 75 & 21.11 & 70.02 & 75.00 & 21.23 \\
Number of Varieties & 3.13 & 2 & 3.02 & 3.13 & 2.00 & 3.03 \\
Log Value of Output & 11.25 & 11.27 & 2.05 & 11.27 & 11.29 & 2.05 \\
\hline
\end{tabular}

Note: All values are expressed in 2010 thousand Mexican peso. Table shows the summary statistics of main variables in the estimation sample (metropolitan areas). Source: EIMA, EIA, INEGI.

Encuesta Nacional de Empleo, Salarios, Tecnología y Capacitación en el Sector Manufacturero (ENESTyC) 2005:

The ENESTyC is a representative establishment-level survey of manufacturing firms conducted in 1995, 1999, 2001, and 2005. This study employs ENESTyC 2005 which is representative based on 2004 Economic census information and covers 9,920 manufacturing establishments and 685 maquiladoras. This survey is used to derive the sales and material entropy measures as it reports the geographic distribution of sales and material purchases (see below for details). The survey also reports wages across detailed occupation-gender categories within plants, as well as unionization rates across different type of employees within plants. Using this data I calculate the average wages paid among unskilled female and male workers and the unionization rates among the production workers. Table C-2 presents the unionization rate among production workers across selected industries. The plantlevel match between EIMA and ENESTyC is possible for a subset of ENESTyC establishments. Since in this match there is a systematic bias toward bigger firms, rather than using the plant-level match I incorporate the ENESTyC characteristics with the main data-set via the establishments' four-digit industry of operation. 


\section{Table C-2: Unionization Rates Across Selected Industries}

\begin{tabular}{lc}
\hline Industry & $\begin{array}{c}\text { Unionization Rate } \\
\text { (production workers) }\end{array}$ \\
Sawmills and Wood Preservation & 0.06 \\
Seafood Product Preparation and Packaging & 0.06 \\
Leather and Hide Tanning and Finishing & 0.17 \\
Architectural and Structural Metals Manufacturing & 0.17 \\
Other Nonmetallic Mineral Product Manufacturing & 0.22 \\
Pesticide, Fertilizer, and Other Agricultural Chemical Manufacturing & 0.23 \\
Agriculture, Construction, and Mining Machinery Manufacturing & 0.28 \\
Pharmaceutical and Medicine Manufacturing & 0.28 \\
Textile Furnishings Mills & 0.38 \\
Lime and Gypsum Product Manufacturing & 0.38 \\
Iron and Steel Mills and Ferroalloy Manufacturing & 0.42 \\
Converted Paper Product Manufacturing & 0.46 \\
Fiber, Yarn, and Thread Mills & 0.47 \\
Pulp, Paper, and Paperboard Mills & 0.51 \\
Fabric Mills & 0.51 \\
\hline
\end{tabular}

Source: ENETyC 2005. Unionization rate is the number of union member production workers over the total number of production workers. Author's calculation.

\section{C.2 Spatial and Regional Data}

Distance to the US border: I select more than 130 points along the US border with latitude and longitude information and obtain the position of each locality (village) in Mexico (degrees/minutes/seconds (DMS) ) from INEGI. After converting the DMS measure to decimal degrees, I use the Haversine formula to calculate the great circle distance from each urban Mexican village (locality) to around 130 US border points. ${ }^{58}$ I then take the distance between each municipality's position and the closest border point.

Homicide Rates: Information on the number of homicides by municipality and month is obtained from INEGI. Homicide rates used in the descriptive analysis throughout the paper are calculated as the number of homicides in 100,000 people. Homicide rates used in the regressions are

\footnotetext{
${ }^{58} \mathrm{I}$ also use the Pythagorean theorem to calculate the $\mathrm{km}$ distance, obtaining very similar results.
} 
re-scaled and they are the number of homicides in 1,000 people. Municipality-level annual population numbers are calculated using the census data for years 1990, 1995, 2000, 2005, and the annual state-level population estimates of INEGI. INEGI also provides the number of intentional homicides by occupation of victims at the nation-wide. This data is used in preparing the data underlying the figures in section 2.3.

The two newspapers, Reforma and Milenia also provide the state-wide number of organized crime related homicides since the start of the Drug War (see Figure C-1). Since the data on the organized crime related homicides do not cover the pre-Drug War time period and do not have detailed geography information, it is not suitable in this analysis. Also note that my IV strategy aims at capturing the variation in the homicide rate that is related with the organized crime as it focuses on the Mexican Drug War.

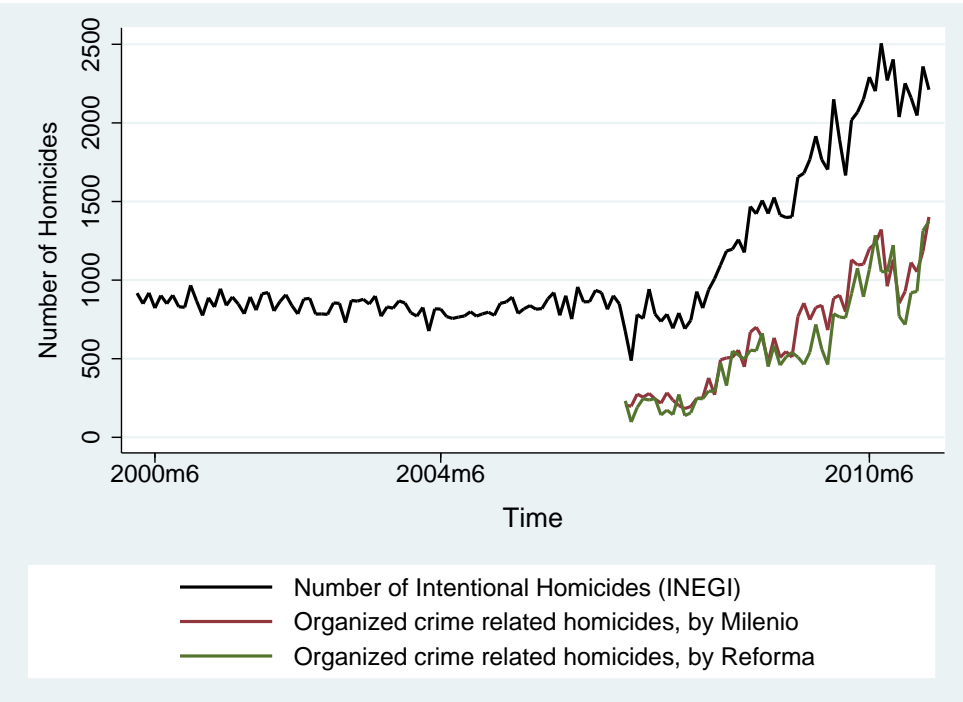

\section{Figure C-1: Organized Crime Related Violence in Mexico}

Drug Trafficking Organizations: Yearly information on the municipalities in which Mexico's drug trafficking organizations operate comes from 'Knowing Where and How Criminal Organizations Operate Using Web Content' by Michele Coscia and Viridiana Rios published at the Association for Computing Machinery (ACM)'s International Conference on Information and Knowledge Management (CIKM) in 2012. Using computer science and big data techniques Coscia and Rios develop a 
framework that uses Web content to identify the areas of operation and modus operandi of Mexican drug trafficking organizations over 1990-2010.

Metropolitan area-level data: The analysis makes use of a set of time varying metropolitan area-level variables. These are the annual information on the metropolitan area level employment shares of crop production, metal mining including gold, silver, copper, and uranium as well as oil and natural gas extraction. The sources of annual data on municipality level employment across industries are the records of contributions to the Mexican Institute of Social Security (IMSS). The industry classification used in this data is the Mexican version of the North American Industrial Classification System (SCIAN) in its 2007 revision. INEGI is the source of the additional municipality-level variables, which include the number of strikes, the number of registered vehicles, the number of traffic accidents, the number of traffic accidents due to bad road conditions, and high-school success rate. Whenever used in the plant-level analysis these data are aggregated at the metropolitan level using the key provided by INEGI matching municipalities with metropolitan areas.

Per-capita security and public expenditure data come from Ted Enamorado, Luis F. López-Calva, Carlos Rodríguez-Castelán, and Hernán Winkler's study, titled “Income inequality and violent crime: Evidence from Mexico's drug war", published in 2016 at the Journal of Development Economics. The data are reported at a five-year frequency between 1990 and 2010 in real terms as of August 2010. I use the data between 2005 and 2010. Using the metropolitan area and municipality level population information, I converted the data into per capita values for each metropolitan areas.

\section{C.3 Time-Series data}

Cocaine Data: Cocaine prices are purity-adjusted prices of a gram of cocaine in the US. The quarterly data is obtained from the annual reports of the National Drug Intelligence Center. The annual data source is the US Office of National Drug Control Policy, the data obtained from the United Nations Office on Drugs and Crime (UNODC, 2014).

Cocaine seizures data are from Castillo, Mejia and Restrepo (2020). The source of data is the Colombian Ministry of Defense, Acción Social, Comando General de las Fuerzas Militares, Fuerza 
Aérea Colombiana, Armada Nacional y Naciones Unidas. The seizure data are reported at the monthly frequency between 1999-2012. This data also reports annual data on cocaine cultivated land in Colombia. I also obtain information on the net coca cultivated land between 1986-2012 in the Andean region from the 2015 Data Supplement of National Drug Control Strategy, an annual report prepared by the Office of National Drug Control Policy.

Occupation Data: The data on the total number of employees per occupation is obtained from INEGI. The occupation information is used to calculate the risk to life per occupation presented in section 2.3. The underlying source of this data is the National Survey of Occupation and Employment (Encuesta Nacional de Ocupación y Empleo, ENOE).

\section{C.4 Construction of Variables}

Construction of Entropy Measures of Diversification: The nation-wide representative survey ENESTyC 2005 reports for each plant the percentage of sales as well as material use for each geographic region in the world. These regions are 1) domestic, 2) US, 3) Canada, 4) Caribbean and Central America, 5) South America, 6) Europe, 7) Middle East and Asia and 8) Africa, Australia, New Zealand. The entropy measure of diversification DivSales is defined as follows. Let $P_{i}$ be the

share of the $i$ th geographic segment in the total sales of the firm. Then $\operatorname{DivSales}_{i}=\sum_{1}^{N} P_{i} \operatorname{In}\left(\frac{1}{P_{i}}\right)$ This is a weighted average of the shares of the segments, the weight for each segment being the logarithm of the inverse of its share. The measure, which is used in the IO literature (Palepu (1985), Rumelt (1982)), gets larger the more segments a firm operates in, and the less the relative importance of each of the segments in the total sales. It takes zero for non-diversified firms. Similarly, a diversification measure of materials, DivMats , is calculated for each firm $i$. I then map these information with the plants in my sample using the four-digit industry classification.

\section{The top four industries with the highest sales diversity measure, DivSales, are the following:}

1. Motor Vehicle Parts Manufacturing

2. Resin, Synthetic Rubber, and Artificial Synthetic Fibers and Filaments Manufacturing

3. Basic Chemical Manufacturing 
4. Nonferrous Metal (except Aluminum) Production and Processing

The bottom four industries with the lowest sales diversity measure, DivSales, are the following:

1. Other Furniture Related Product Manufacturing (mattresses, and box springs)

2. Other Food Manufacturing (corn snacks, tortilla chips, peanuts, French fries, ..)

3. Cement and Concrete Product Manufacturing

4. Animal Slaughtering and Processing

The top four industries with the highest material diversity measure, DivMats, are the following:

1. Motor Vehicle Manufacturing

2. Electrical Equipment Manufacturing

3. Motor Vehicle Parts Manufacturing

4. Semiconductor and Other Electronic Component Manufacturing

The bottom four industries with the lowest material diversity measure, DivMats, are the following:

1. Cement and Concrete Product Manufacturing

2. Lime and Gypsum Product Manufacturing

3. Sawmills and Wood Preservation

4. Bakeries and Tortilla Manufacturing

Construction of Trade Exposure Variable: In constructing trade exposure variables at the metropolitan level I use employment information from the Mexican Census 2004 (Censos Economi$\cos 2004$ ) and international trade data from the US. Censos Economicos 2004 provides employment information at municipality and industry level. Industry classification in 2004 Census is the Mexican version of NAICS (SCIAN). US and Mexican versions of NAICS are identical at the first four digits. Import information for the US is obtained from the US Census (usatrade). The data includes all goods that physically arrive into the United States, whether they are consumed domestically or are used further in production. The import value excludes transportation, insurance, freight and other related 
charges incurred above the price paid. The data employ the North American Industry Classification System (NAICS) definitions for industries. To calculate the trade competition exposure variable for each metropolitan area I first calculate the predicted change in Chinese imports in the US in industry $k$ between year 2005 and year 2010 for each four-digit NAICS industry. I divide this measure with the total non-agricultural number of employees in metropolitan area $j$ to obtain the per-worker measure of the predicted change in Chinese imports in the US. A la Bartik 1991, I then use the ratio of employment of industry $k$ in metropolitan area $j$ in the census year 2004, $E_{k j 0}$ to the total initial Mexican employment for industry $j, E_{j o}=\sum_{k} E_{k j 0}$ to map the change in the Chinese imports in the US with the Mexican metropolitan areas. 